Linköping Studies in Science and Technology

Dissertation No. 1978

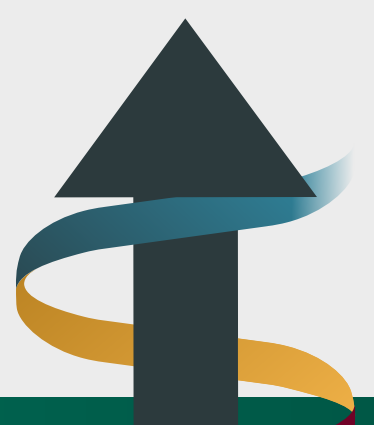

Effective and Efficient Design and Provision of Product-Service Systems challenges, Opportunities, and Solutions

Johannes Matschewsky
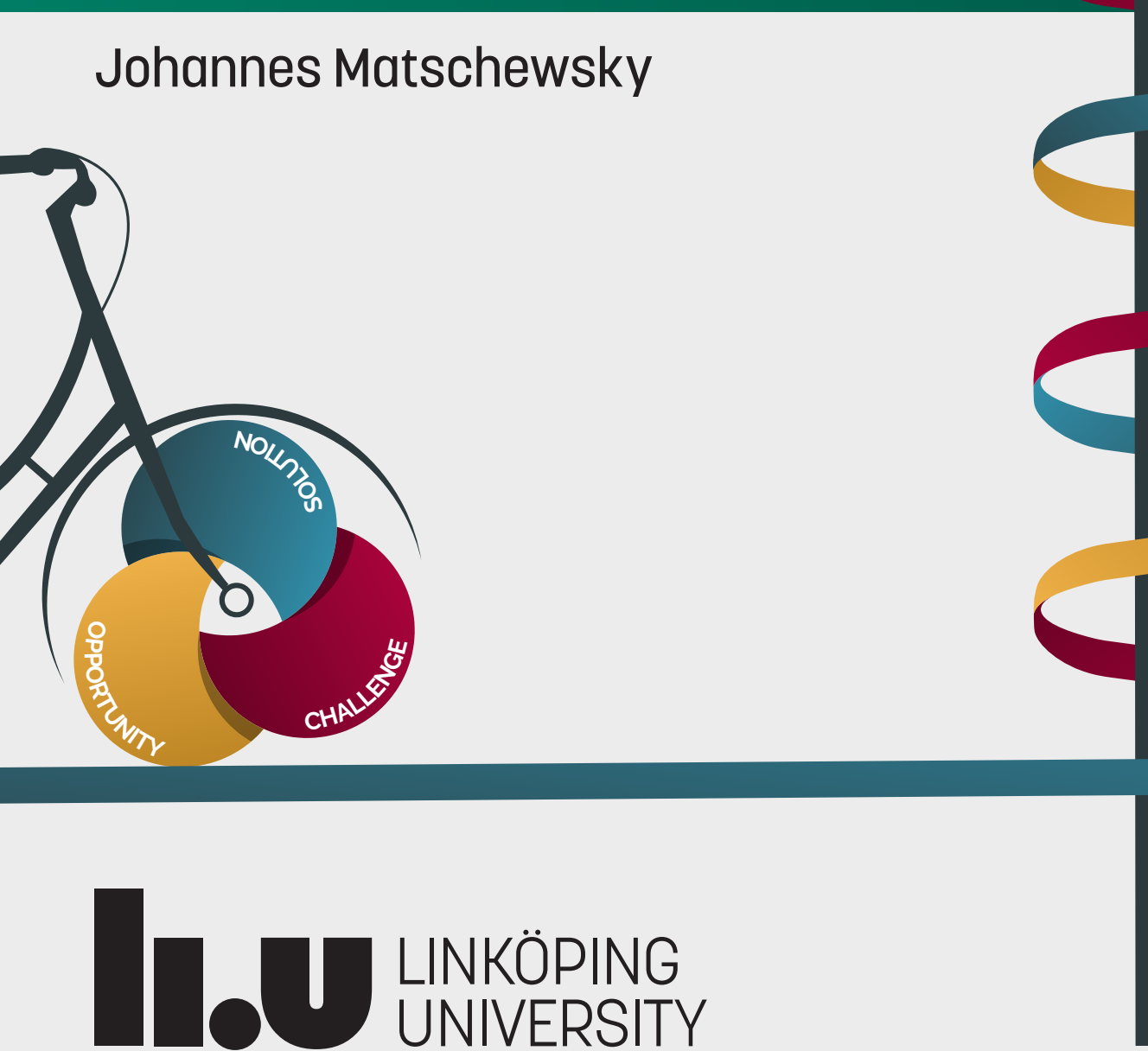

LINKÖPING
UNIVERSITY 
Johannes Matschewsky

\section{EFFECTIVE AND EFFICIENT DESIGN AND PROVISION OF PRODUCT-SERVICE SYSTEMS \\ - Challenges, Opportunities, and Solutions}


The cover was designed by the author. The bicycle was created by Felix Brönnimann from the Noun project, www.thenounproject.com, and modified by the author. All figures and illustrations have been created by the author using Inkscape, www.inkscape.org. Where vector illustrations under the Creative Commons license have been used as a basis, this is marked by an asterisk* in the figure caption and credits for these elements can be found in an endnote on page 120.

The main text of this thesis is set in the Carrara font family by Hoftype, while graphical illustrations and the title page utilize the open-source font Raleway by Matt McInerney, with modifications by Pablo Impallari and Igino Marini.

Dymaxion Map Wireframe used with permission. The Fuller Projection Map design is a trademark of the Buckminster Fuller Institute. (C) 1938, 1967 \& 1992. All rights reserved.

Appended publications reprinted with permission.

Johannes Matschewsky, 2019

"Effective and Efficient Design and Provision of Product-Service Systems Challenges, Opportunities, and Solutions"

Linköping Studies in Science and Technology

Dissertation No. 1978

ISBN: 978-91-7685-091-6

ISSN: $0345-7524$

Printed in Sweden by LiU-Tryck, Linköping, 2019

Distributed by:

Linköping University

Department of Management and Engineering

SE-581 83 Linköping, Sweden

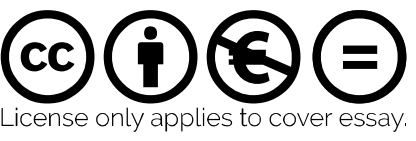


We are not going to be able to operate our Spaceship Earth successfully nor for much longer, unless we see it as a whole spaceship, and our fate as common.

It has to be everybody or nobody. R. Buckminster Fuller 



\section{Abstract}

The world manufacturing companies operate in is changing. In the past, these companies relied on the design and sale of products. Today, this linear model of business is becoming increasingly insufficient. As customers are more and more focused on their core business, buying and operating machinery and other goods becomes unattractive to them. In response to this, manufacturing companies are expanding their value capture into additional stages of the product lifecycle by providing integrated offerings of products and services - Product-Service Systems (PSSs).

Designing and providing PSSs is fundamentally different from traditional product sales. Expanding to become a PSS provider is, therefore, challenging for companies with a history of designing and selling products. Departing from this, it is the aim of this thesis to support manufacturing companies in their expansion to effective and efficient design and provision of PSSs. The research reported has both descriptive and prescriptive properties, reflecting the goals of understanding the status quo in manufacturing companies' practice and providing support based on this.

To establish a point of departure, the current design and provision of two manufacturing companies expanding their business towards PSSs was investigated. From this, an in-depth understanding of the status quo and a number of challenges emerged.

Based on this, the research had the goal to contribute to identifying and developing solutions to these challenges, with an initial focus on methods supporting PSS design and provision. However, although methods fitting to the challenges identified exist, they appear to receive limited uptake in manufacturing companies' practice. In order to improve their practical utility, a structured method is proposed to assist users in both academia and practice in developing methods in a requirements-oriented fashion. The utility of methods in improving the efficiency and effectiveness of PSS design and provision is thereby to be enhanced.

A particular challenge for manufacturing companies expanding to become PSS providers is the change in how value is captured: Resulting from the extensive involvement throughout the lifecycle, a need for a broader, multidimensional understanding of value capture was identified. However, the manufacturing companies investigated have been found to experience challenges in grasping this change, with a focus on a product sales-centric understanding of value capture remaining prevalent. To support companies towards reaping the benefits of the expansion to PSS design and provision, methods to explore how value is currently created and captured in the use phase and how to enhance the future value capture based on that information in the design phase have been developed and applied. As a result, broadly relevant value dimensions were attained, aiming to facilitate a lifecycle-focused, effective, and efficient design and provision of PSSs. 
Eventually, to broaden the understanding of effective and efficient design and provision of PSSs in practice today, the potential contributions of real-world PSSs to a circular economy were investigated based on an existing framework. The result was ambiguous, indicating both advancements compared to traditional sales and substantial room for improvement, particularly with a focus on the absolute decoupling of economic activity and resource use.

Based on the synthesis of the research results, manufacturing companies are supported in their expansion to effective and efficient design and provision of PSSs - and towards a promising future. 


\section{Populärvetenskaplig sammanfattning}

Hur privatpersoner konsumerar håller på att förändras. Ett exempel på detta är att hyra istället för att äga, något som kan vara bättre både för miljön och för plånboken. Trots fördelarna är dock många konsumenter motvilliga till att förändra sin konsumtion. Detta då själva ägandet av mo(bilen) ses som allt för viktigt i sig och innebär såväl status som självförverkligande.

Även handeln mellan företag genomgår en liknande förändring då fler och fler företag köper eller säljer en funktion (så som belysning) istället för en produkt (t.ex. lampor). Denna så kallade funktionsförsäljning utgörs oftast av en kombination av såväl produkter och tjänster och benämns som PSS (Product-Service System). I näringslivet är motståndet till förändring svagare, vilket kan förklaras med att företag inte baserar sin konsumtion lika mycket på känslor och status. PSS blir därför allt vanligare då fler och fler ser fördelarna med att köpa funktion istället för produkt.

Funktionsförsäljning innebär att PSS-leverantören (den som säljer funktionen) behåller kontrollen över ingående produkter och tjänster och när kunden inte behöver funktionen längre kan leverantören ta tillbaka och använda produkterna till andra kunder. Detta ger PSS-leverantörer möjligheter att t ex utifrån ett livscykelperspektiv skapa kundvärden och minska sina kostnader samtidigt som de kan reducera sin resursförbrukning. Ekonomiska drivkrafter skapas inom företagen för att sänka resursförbrukningen, öka resurseffektiviteten och att förlänga produkternas livstid, genom t.ex. återtillverkning.

Övergången till PSS förändrar nästan allt $i$ hur ett företag går tillväga för att designa, konstruera, sälja, erbjuda, återanvända och återtillverka. I denna avhandling studerades förändringsprocesserna inom två stora tillverkande företag $\mathrm{i}$ Sverige, som har utvecklats från att sälja produkter till att erbjuda PSS, och ett antal utmaningar kopplade till design- och användningsfasen identifierades.

En framgångsfaktor visade sig vara hur leverantörerna uppfattar att deras PSS skapar värde och för vem. Värde skapas för PSS-leverantören över hela livscykeln och utgörs ofta av andra former än direkt monetärt värde, t.ex. information. För företag som övergår till PSS är det svårt att fullt förstå konsekvenser av det förändrade arbetssättet, och därav anpassas inte de ingående processerna till de förändrade förhållandena. Vilket $i$ sin tur leder till att ineffektiva, produktfokuserade processer kvarstår. Forskningen i den här avhandlingen har således resulterat i två metoder: Den ena stödjer PSS-leverantörers förmåga att undersöka sitt aktuella värdeskapande. Den andra stödjer dem i hur de kan utöka värdeskapandet genom att göra förändringar i sin design och leverans av PSS.

Det räcker dock inte med att enbart förstå det förändrade värdet för att effektivt möjliggöra en övergång från att producera och sälja produkter till att erbjuda PSS. Det utvecklas och publiceras därför allt fler metoder, främst inom akademin, vars syfte är att stödja utveckling och försäljning av PSS. Det är dock få av dem som 
används av industrin. I syfte att understödja utvecklandet av effektivare och mer använda PSS-metoder, föreslås därför i denna avhandling ett nytt strukturerat arbetssätt som hjälper användare i båda akademin och industrin att ta fram metoder med fokus på deras slutliga användare. På så sätt förbättras nyttan som metoder kan ge för att utöka effekten och effektiviteten på PSS-design och -leverans.

Slutligen, för att bidra till en bredare förståelse kring den praktiska betydelsen av PSS i industrin undersöktes det potentiella bidraget av PSS till en cirkulär ekonomi. Resultatet blev tvetydigt och indikerade både förbättringar jämfört med klassisk försäljning men också stora utvecklingsmöjligheter, särskilt när det gäller att frikoppla resursförbrukning och ekonomisk tillväxt. 


\section{Acknowledgments}

Unbelievable as it is - five years are over. In the beginning, everyone tells you that this is a marathon - which is definitely true! Inevitably, though, it appears to turn into a sprint at the end, regardless of how much of the road already lies behind you. The finish line is near, and now more than ever, it is clear that I would have never gotten here alone.

First of all, I want to thank my main supervisor Mattias Lindahl and my secondary supervisor Tomohiko Sakao. Mattias, without you answering my random email some seven-and-a-half years ago, my life would have taken a completely different path. Talk about a butterfly effect! As I look back on this time, I am grateful for your guidance and motivation, and especially for your positive look on all the minor or major challenges that I encountered throughout this process. When I felt like the mountain before me was just too steep to climb, and that I had no clue about mountaineering, you told me that mountain is just a big pile of dirt and that, if all else fails, we would just get a bulldozer and plow right through it. I am certain you will continue to inspire and motivate future (Ph.D.) students to turn challenges into opportunities. Tom, thank you for your dedication and support for me and my work. I have profited tremendously from your knowledge and leadership throughout writing and research projects - as I have from your clearheaded, result-focused take on even (in my mind) the most difficult issues. There is no challenge big enough that you could not propose a coherent solution to it. I am deeply grateful for having had both of you as my supervisors, and although I am supposed to be independent now, I do look forward to continuing to work with you.

I want to thank the case companies Levor and Navitas for their support throughout the years, in terms of funding, but even more so, through the tremendous insight the practitioners at these companies shared, forming the basis of this work. I am further grateful to Mistra REES, funded by Mistra (The Swedish Foundation for Strategic Environmental Research) for supporting my research.

I want to express my sincere gratitude to Daniela Pigosso (DTU) for giving me very detailed and supportive feedback on an earlier thesis draft during my $90 \%$ seminar. I also want to thank Mica Comstock for his diligent checking of all my strange German capitalization habits and my excessive use of compound-nouns.

A big thank you to everyone at the division - for everything! Having been in the writing bubble for the past months, and mostly working at home, has made me miss the great and unique workplace we have. I look forward to contributing to making it even better! I am particularly grateful to Jonas Ammenberg, Stefan Anderberg, Roozbeh Feiz, and Wisdom Kanda for commenting in detail on an earlier thesis draft, and to Don Huisingh for a helpful discussion in the pre-writing phase. I thank Olof Hjelm for his support in writing the Swedish popular science abstract for this thesis, and Sara Gustafsson for her very helpful, in-depth pre- 
submission review of one of the appended papers. I am grateful to the Ph.D. Group for the support and discussions throughout the years and to Maria Eriksson for being able to answer every imaginable question. Thanks to the Friday Burgers group for fun breaks and great talks!

I want to thank my friend Wisdom for the insightful, interesting and fun discussions throughout these years, and for all the help you have provided me along this process. I don't think you ever answered "I don't know" to any of my questions throughout these years. When I left the division after my diploma in 2012, you were one of the people I was most looking forward to seeing again, and I am glad and honored to now work alongside someone as driven, humble and kind as you are. Roozbeh, I look forward to more great and deep discussions - I have so much to learn from you (did you see that was an em dash?). Sergio, we really have to step it up with the cappuching! I look forward to continuing working with you, but most of all, I look forward to you continuing to be my friend. Marianna, thank you for being a great officemate and thank you so much for being a wonderful friend. Work would just not be the same without you. I am so grateful for your hard work in our common research project that, for a substantial part, you made a success.

I also want to thank my dear family back in Germany. Danke für Alles! Thank you for your support through all these years and for trusting that everything would be fine through my slightly erratic first years as a university student. Although I ended up farther from home than you would like, I am so grateful that we can see each other often and then, it does not feel like we are so far apart at all.

Brini, mein Traum, what can I even say? Five years ago, when I moved to Sweden, we had no idea where this road would take us. In the licentiate thesis, I wrote that "you have taken this new life that only one year ago, was just mine, and you have made it ours." Now again, over two years have passed. We are now a family of three, and as if being the most wonderful partner anyone could imagine, being my best friend and a terrific doctor was not enough, it turns out, that you even are the most wonderful mom our little Theodor could ever wish for. And yet again, with every passing day, you amaze me with your kindness, your energy and determination, and with your laughter - which now is one of my two favorite sounds in the world. Not only would this book be empty if it was not for you, even if it was full of the most intelligent words ever put onto paper, without you, it would mean nothing.

Teddy, if you can read this, then congratulations on learning to read, and additionally, on learning English. Wow, three languages! At the time of writing, your Mama and I are amazed that you are rolling yourself from your back to your belly, so you really have come a long way. Now, put this book away, because it is probably outdated, and honestly, it is not that entertaining to read. If you want, come to me, I can recommend a lot of books that I think you will enjoy much more. 


\section{Who is this Book for?}

Until the day of the defense, this work is a doctoral thesis, written to gain a degree. After that day, what remains is a book - but who is that book for?

The effort to write a thesis like the one in your hands, even if it is a compilation thesis, is substantial. However, particularly in the nature of a compilation thesis lies a challenge: From experience, it appears that these theses are seldom read, and rarely cited. Of course, a researcher will always cite a peer-reviewed article in a journal rather than a thesis. So, is the entire effort concentrated on the day of the defense and are colleagues, supervisors, examiners, and the opponent the only ones who will ever take a closer look?

A circumstance I feel particularly lucky about is that through this journey, I was not only given the chance to become a researcher; I could also become a teacher. I am responsible for the master-level course Integrated Product-Service Engineering at Linköping University and have led and administrated this course for two years. Parts of the research background of my licentiate thesis have been assigned reading in the past, and the feedback with respect to ease of understanding compared to other assigned reading in the form of journal papers was positive.

As a result, this focus became a strong motivation for me in the writing process. Even if the academic world may not take notice of this book in any significant way, some 50 future product-service engineers every year will have no choice but to. It is with them in mind that this book is written.

For that reason, I have tried to keep the language approachable; to, when in doubt, overexplain when it comes to content and flow; to allow for some reflexiveness in the background-chapter; and to keep the use of acronyms and jargon to the necessary minimum. I hope that this effort will extend both the shelf-life and the impact of this work.

If you are a (future) student of the course reading this now, you know that I heartily welcome your feedback. Nothing is set in stone, and the information in this book will need to be revised sooner rather than later - so please share your reflections, they are much appreciated. As in every session, I will leave you with some words of R. Buckminster Fuller: "Every time you make a new experiment, you learn more. You cannot learn less.” 



\section{List of Appended Publications}

\section{Publication 1}

Matschewsky, J., 2017. PSS without PSS Design - Possible Causes, Effects and Solutions, in: Sustainability through Innovation in Product Life Cycle Design. Springer Japan, 233-248.

\section{Publication 2}

Matschewsky, J., Kambanou, M.L., Sakao, T., 2018. Designing and providing integrated product-service systems - challenges, opportunities and solutions resulting from prescriptive approaches in two industrial companies. International Journal of Production Research 56, 2150-2168.

\section{Publication 3}

Matschewsky, J., Brambila-Macias, S.A., Neramballi, A., Sakao, T. A method for the development and selection of design methods - Investigating the design of resource-efficient offerings. Research in Engineering Design, Under Review.

\section{Publication 4}

Matschewsky, J., Lindahl, M., Sakao, T., (2018). Capturing and enhancing provider value in product-service systems throughout the lifecycle: A systematic approach. CIRP Journal of Manufacturing Science and Technology.

\section{Publication 5}

Matschewsky, J., Inadvertent Circularity? - Assessing a Product-Service System for its Potential Contribution to a Circular Economy. Sustainability, Submitted. 



\section{Related Publications}

Kanda, W., Matschewsky, J., 2018. An exploratory expansion of the concept of product-service systems beyond products and services. Procedia CIRP 73, 185-190.

Rondini, A., Matschewsky, J., Pezzotta, G., Bertoni, M., 2018. A simplified approach towards customer and provider value in PSS for small and medium-sized enterprises. Procedia CIRP 73, 61-66.

Matschewsky, J., 2018. Värdet i att samtidigt utveckla produkter och tjänster. Handbook. Production2030.

Sakao, T., Song, W., Matschewsky, J., 2017. Creating service modules for customising product/service systems by extending DSM. CIRP Annals Manufacturing Technology 66, 21-24.

Matschewsky, J., 2016. What's in it for the Provider? A Lifecycle-Focused Approach towards Designing for Value in Product-Service Systems. Licentiate Thesis. Linköping University.

Matschewsky, J., Sakao, T., Khanagha, S., Elfving, S.W., 2016. What's in it for the Provider? The Case of a Telecom Vendor's Value Capturing from the Transition to Product-Service Systems. Procedia CIRP 47, 6-11.

Matschewsky, J., Lindahl, M., Sakao, T., 2015. Facilitating Industrial Adoption of Design Methods for Product-Service Systems, in: ICED15: 2oth International Conference on Engineering Design. Milan, pp. 301-310.

Matschewsky, J., Sakao, T., Lindahl, M., 2015. ProVa - Provider Value Evaluation for Integrated Product Service Offerings. Procedia CIRP 30, 305-310. 



\section{Glossary}

This glossary provides an overview of central concepts and terms as they should be understood in the context of this thesis. Page numbers are given where more exhaustive descriptions can be found in the main text.

Business model - The "design or architecture of the $\rightarrow$ value creation, delivery and capture mechanisms" of a business (Reim et al., 2015). (13)

Business models, product-service systems - The reliance of $\rightarrow$ customer value creation on product- or service components and the level of integration between them. (13ff.)

Circular economy, $C E-A n$ "economy that is restorative and regenerative by design and aims to keep products, components, and materials at their highest utility and $\rightarrow$ value at all times" (EMF, 2015a, pg. 5). (3, 16f.)

Customer - A business procuring $\rightarrow$ product-service systems.

Customer value - A customer's assessment of the utility of a product-service system based on the perception of what is received for what is given (adjusted from Zeithaml, 1988). Extensive elaborations are found in Woodruff (1997). (22ff.)

Effectiveness - The degree to which a product-service system fulfills a $\rightarrow$ customer's expectations and creates $\rightarrow$ customer value.

Effectiveness, resource - The degree to which resources retain their $\rightarrow$ value over time, as facilitated by intentional $\rightarrow$ design focusing on all activities throughout the $\rightarrow$ lifecycle of a $\rightarrow$ product-service system. (16)

Efficiency - The amount of resources required throughout the $\rightarrow$ lifecycle to create a given $\rightarrow$ customer value. This can be, e.g., time, monetary, human or material resources. (16f.)

Lifecycle, product-service systems - The stages of $\rightarrow$ design, production, deployment, use ( $\rightarrow$ provision), and end of life (reuse, remanufacturing) of a $\rightarrow$ product-service system including loops and iterations.

Manufacturing company - A company with a background in designing and selling products. All case companies described are manufacturing companies expanding to also become $\rightarrow$ providers of $\rightarrow$ product-service systems. Only if a company should cease selling products, it stops being a manufacturing company and is exclusively a $\rightarrow$ product-service system provider.

Method - A predefined and systematic description which facilitates the user's work towards the desired outcome (based on Lindahl, 2005). (18ff.) 
Product-service systems, PSSs - An integrated offering of products and services, $\rightarrow$ designed jointly with a $\rightarrow$ lifecycle focus to create $\rightarrow$ customer value. (13ff.)

Product-service systems, design of - The integrated design of product and service components with a lifecycle focus based on, e.g., mechanical engineering, software engineering, and service engineering. (18ff.)

Product-service systems, highly integrated $-\mathrm{A} \rightarrow$ product-service system in which the $\rightarrow$ provider remains in ownership and control of the physical components throughout the entire $\rightarrow$ lifecycle, encompassing use- and result-oriented product-service system $\rightarrow$ business models. $(2-3,10,13)$

Product-service systems, provision of - Commences with the deployment of physical components at the start of the use phase on site for the $\rightarrow$ customer to use or for the $\rightarrow$ provider to operate; ends when the physical components return to the $\rightarrow$ provider permanently. Through the lifecycle of $\rightarrow$ highly integrated product-service systems, several loops of use phase and end of life efforts (reuse, remanufacturing) occur in succession.

Provider, product-service systems provider - A $\rightarrow$ manufacturing company that is $\rightarrow$ designing or $\rightarrow$ providing $\rightarrow$ product-service systems. (13f.)

Provider value - The accumulative intangible and tangible $\rightarrow$ value captured by a $\rightarrow$ product-service systems $\rightarrow$ provider throughout the $\rightarrow$ lifecycle. (21ff., 82 ff.)

Servitization - Process a $\rightarrow$ manufacturing company undergoes as it expands from designing and selling products to becoming a product-service system $\rightarrow$ provider. (13f.)

Value - The worth of a $\rightarrow$ product-service system as a relation between what is received (e.g., need fulfillment, quality, satisfaction, utility) and what is given (e.g., price, sacrifices) (see Woodruff, 1997). (21ff.) 


\section{Contents}

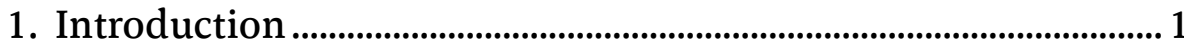

1.1 Background - A Critical Shift ....................................................................

1.2 Problematization of the Research .............................................................. 4

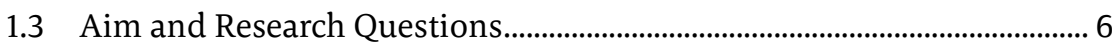

1.4 Interrelations Between the Research Questions.............................................7

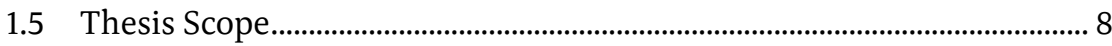

1.5.1 Two Manufacturing Companies Expanding Towards PSSs......... 8

1.5.2 Methods to Support the Design and Provision of PSSs ................ 9

1.5.3 Value as a Concept in PSS Design and Provision ............................. 9

1.5.4 Effective and Efficient PSSs Towards a Circular Economy......... 10

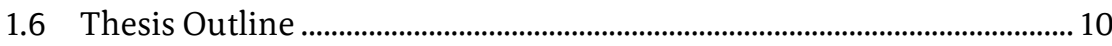

2. Research Background .........................................................................13

2.1 Product-Service Systems .......................................................................................13

2.1.1 The Facets of Product-Service Systems ............................................13

2.1.2 PSS Business Models in Focus........................................................... 14

2.1.3 Effective and Efficient PSSs Towards a Circular Economy......... 16

2.1.4 Challenges for Effective and Efficient PSSs.................................... 18

2.2 Designing Product-Service Systems and the Role of Methods .............. 18

2.2.1 Particularities of PSSs and the Need for a Distinct Approach .. 18

2.2.2 PSS Design, the Value of Methods and Challenges in Practice..19

2.3 Value as a Concept in the Context of Product-Service Systems...............21

2.3.1 Value in Other Fields Relevant to PSS Design and Provision.....21

2.3.2 Value-Centric Research in PSSs ......................................................21

2.3.3 Value Assessments for PSSs .............................................................22

2.3.4 Insight into Particularities of Provider Value for PSSs................ 23

2.4 Challenges for Companies in a Changing World ...................................... 23

2.5 Reflecting upon the Research Background .................................................... 25

2.5.1 The Focus of this Research with Respect to PSSs and a CE........ 25

2.5.2 Synthesis of the Research Background.............................................26

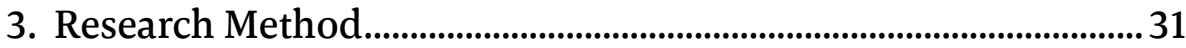

3.1 Challenges, Opportunities, and Solutions - A Research Journey..........31

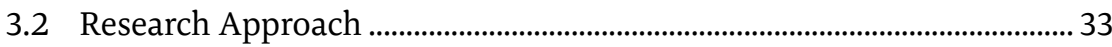


3.3 Overview of the Research Methods Employed .............................................. 36

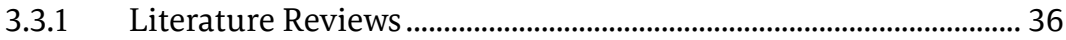

3.3.2 Interviews and Focus Groups......................................................... 38

3.3.3 Approaches Supporting Interviews ................................................. 39

3.3.4 Questionnaire and Survey .............................................................. 40

3.4 Methodologies to Answer Research Questions .............................................41

3.5 Quality of the Research .................................................................................. 45

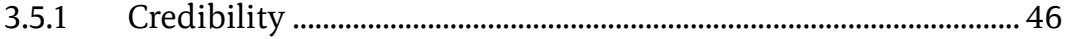

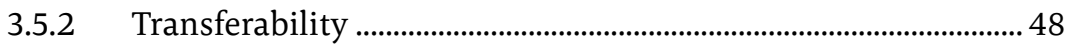

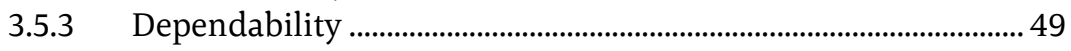

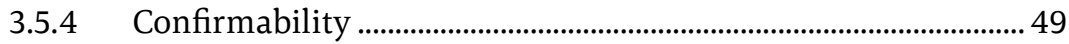

3.6 Reflexivity and Problematization................................................................... 50

3.6.1 The Impact of Research Design and Methods ................................ 50

3.6.2 Reflecting on Underlying Assumptions and Concepts................. 51

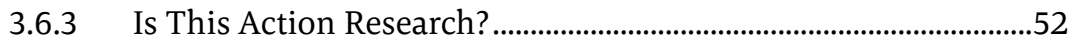

4. The Appended Publications ................................................................ 55

4.1 Publication 1 - PSSs Without PSS Design ......................................................55

4.2 Publication 2-Designing and Providing PSSs - Challenges, Opportunities, and Solutions.......................................................................57

4.3 Publication 3 - Development and Selection of Design Methods........ 60

4.4 Publication 4 - Capturing and Enhancing Provider Value in PSSs.....65

4.5 Publication 5 - Inadvertent Circularity? PSSs Towards a CE...................70

\section{Discussion - Supporting Design and Provision of PSSs.}

5.1 PSS Design and Provision - Challenges, Effects, Intended Solutions.75

5.1.1 Persisting Product-Centered Mindset ....................................................76

5.1.2 Separation of Product and Service Design .........................................77

5.1.3 Alignment with Changing Incentive Structures ..............................78

5.1.4 Product-Focused Information and Costing Structures..................79

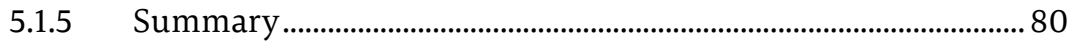

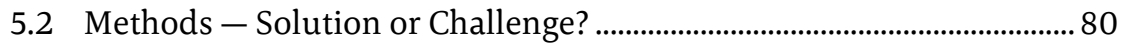

5.3 Provider Value in PSSs - Turning Challenges into Opportunities...... 82

5.3.1 The Provider Value Concept.................................................................. 83

5.3.2 Supporting Analysis and Enhancement of Provider Value....... 84

5.3.3 The Impact of Provider Value in a Manufacturing Industry

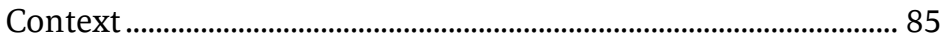

5.3.4 Improvement of the Provider Value Evaluation Method.............87 
5.4 Efficient and Effective PSSs Towards a Circular Economy 90

5.4.1 PSSs Towards a CE Without the Help of Methods .........................90

5.4.2 PSSs Towards Per-Unit Efficiency and Effectiveness.....................90

5.4.3 Enhancing PSSs' Prospects of Contributing to Absolute Decoupling

6. Supporting the Expansion to Effective and Efficient PSS Design and Provision 95

7. Conclusions and Outlook.................................................................... 99

7.1 Challenges in Adjusting to the Design and Provision of PSSs ................99

7.2 Developing and Applying Methods for PSS Design and Provision .......99

7.3 Supporting Value Capture Throughout the Lifecycle. 100

7.4 PSSs Towards a CE Without Methods - Contributions and Shortcomings 100

7.5 Future Research and Outlook 101

References 103 



\section{List of Figures}

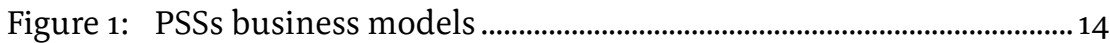

Figure 2: Focus of this research with respect to a CE and PSSs.......................26

Figure 3: Theory and its relevance for RQs and goals of the research ..........28

Figure 4: Research approach and connection between research foci...........34

Figure 5: Data-gathering document for provider value analysis.................... 40

Figure 6: Methodology towards answering RQ1 .................................................. 41

Figure 7: Methodology towards answering RQ2 2............................................. 42

Figure 8: Methodology towards answering RQ3 ..................................................43

Figure 9: Methodology towards answering RQ4 ….............................................45

Figure 10: Method for the development of design methods...............................62

Figure 11: Process of the provider value evaluation method .............................67

Figure 12: Challenges in servitization identified ................................................76

Figure 13: Value capture in product sales and PSSs ............................................... 83

Figure 14: Analyzing and enhancing the capture of provider value ...............85

Figure 15: Adjustment of provider value evaluation over time........................89

Figure 16: Synthesis - Supporting effective and efficient PSSs.......................97

\section{List of Tables}

Table 1: Challenges for companies in servitization...........................................24

Table 2: Research questions, related publications, and methods used.....36

Table 3: User requirements on design methods with average rating .........63

Table 4: Design method characteristics and qualifiers....................................64

Table 5: Clustered value dimensions identified ....................................................68

Table 6: Evaluation of value dimensions by practitioners ............................69

Table 7: Results of per-unit assessment of the CE contribution of PSS.....72

Table 8: Adjustments of the provider value evaluation method...................88

Table 9: Abridged version of practical implications........................................98 



\section{Chapter 1}

\section{Introduction}

This chapter introduces the key issues at the center of the research conducted, its aim and the research questions operationalizing and structuring the presentation of the results.

\subsection{Background - A Critical Shift}

The world manufacturing companies operate in is changing at a rapid pace. In the past, the overall mode of business of such companies can be described along the following lines: Products are designed, manufactured and lastly sold to customers, at which point income is generated, and the manufacturing company captures value in exchange (Grönroos and Voima, 2013). Typically, their involvement used to end there, although providing services is an important source of revenue for many manufacturing companies.

This linear mode of business is becoming insufficient for many manufacturing companies. Their customers ${ }^{1}$ are increasingly focused on their own core business and therefore less interested in buying products and performing tasks that are not central to this (Vandermerwe and Rada, 1988; Goedkoop et al., 1999; BrambilaMacias et al., 2018). In addition, the manufacturing companies themselves are seeking to go beyond producing and selling physical goods. Instead, they are expanding their value capture to additional stages of the lifecycle. This means that instead of selling the physical goods produced, they remain in the ownership and control of the manufacturing company (Lindahl and Ölundh, 2001). These can then provide the availability of these goods for customers to use; or, companies may operate an offering entirely, and based on that, sell the result of its use (Tukker, 2004; Meier et al., 2010). Resulting from this, the main focus for manufacturing companies shifts from producing and selling artifacts as the primary way of creating and capturing value to providing services relying on these artifacts (Vargo and Lusch, 2004; Grönroos, 2008). In turn, the customers' focus on

\footnotetext{
${ }^{1}$ The research in this thesis focuses on business-to-business (B2B) relationships. In the context of the research presented, substantial differences emerge when business-to-consumer (B2C) or B2B markets are considered. As summarized by Tukker (2015), these can stem from end consumers' focus on ownership and control of products (Halme et al., 2006), possessing new or fashionable products (Intlekofer et al., 2010) and ease and immediacy of access (Williams, 2007).
} 
the physical goods progressively fades away, and they will start to perceive the offering as a service.

The process manufacturing companies undergo when expanding ${ }^{2}$ from an exclusive focus on producing and selling goods to providing services based on these goods has been termed servitization (Vandermerwe and Rada, 1988; Baines et al., 2009a; Martinez et al., 2010) ${ }^{3}$.

A central concept describing the integration of products and services throughout the lifecycle is called the Product-Service System (PSS) , which is defined as "a marketable set of products and services capable of jointly fulfilling a user's needs" (Goedkoop et al., 1999, pg. 3). PSSs, however, go far beyond a mere bundling of products and services. Instead, the two are combined into a mutually dependent whole with a lifecycle perspective and a focus on providing function, service, and performance (Lindahl et al., 2006). The degree of mutual dependency between products and services can differ, and with it, the degree of the involvement of the company providing the PSS throughout the lifecycle. This is illustrated by business model archetypes discussed in PSSs research, ranging from product-oriented, through use- or availability-oriented, all the way to result-oriented offerings (Tukker, 2004; Meier et al., 2010). PSSs in which the provider remains in ownership throughout the lifecycle and has extensive control over the offering are a central focus of the research reported here. With such high levels of productservice integration, these offerings are called highly integrated PSSs ${ }^{5}$ (Miller and Mattes, 2014). The companies designing and providing PSSs are PSS providers.

\footnotetext{
${ }^{2}$ The term transition or service transition is often used when explaining this process, also by the author in previous publications. This terminology has been criticized, as many of the companies undergoing the servitization process also remain producers and sellers of physical products (Kowalkowski et al., 2015). Recently, this situation has been described as organizational ambivalence during servitization (Lenka et al., 2018a). Therefore, the research presented uses the term expansion, which is more in tune with the reality in manufacturing industry practice.

${ }^{3}$ In this context, it must be made clear that servitization is not necessarily a one-way street. Companies can "overextend" their business focus and move away from providing certain services (back) towards a narrower scope of value capture in a process called deservitization (Kowalkowski et al., 2017; Valtakoski, 2017).

${ }^{4}$ A spelling variant using a slash instead of a hyphen exists: Product/Service System. Considering the function of the slash, however, this indicates the possibility to select between two options and even omit one. The hyphen, however, signals connectedness and mutual dependency. For that reason, this spelling variant is used here.

A broad set of terminology is used to describe combined offerings of products and services, e.g. Integrated Product Service Offerings (IPSO, Lindahl et al., 2006) and Functional Sales (Sundin and Bras, 2005).

${ }^{5}$ In order to maintain readability, the term highly integrated PSSs is only used where absolutely necessary to avoid any ambiguity of the arguments made.
} 
Ever since the term was coined in the late 1990s, PSSs have been discussed in relation to improved environmental performance based on increased resource efficiency and effectiveness throughout the lifecycle (Goedkoop et al., 1999; Mont, 2002). The core of this argument lies in the shift of the ownership and control of the physical components of an offering from the customer to the provider in the use and end of life phases of the lifecycle (Lindahl and Ölundh, 2001), which occurs in the case of highly integrated PSSs. As manufacturing companies expand their role from designing and selling to providing availability, maintaining, supporting and ultimately, reusing and remanufacturing, the critical shift at the basis of the expected improvements in resource efficiency and effectiveness becomes manifest (Bocken et al., 2014; Yang and Evans, 2019): Previously, a maker and seller of products was incentivized to produce a growing number of physical artifacts and thus, to consume an ever-increasing amount of resources. Highly integrated PSSs, with providers remaining in ownership and control of the physical components of the offering throughout the lifecycle, can shift that focus to capturing and creating the highest possible value based on the most efficient use of resources. This, in turn, is caused by the customer's payment being independent of the actual effort the provider must invest, making lifecycle-focused efficiency the logical business paradigm. This understanding of a critical shift in incentive structure lies at the basis of the expected environmental benefits of PSSs (Mont, 2002; Ceschin, 2013; Tukker, 2015).

The envisaged benefits in the effectiveness and efficiency of PSSs have recently been discussed in the scope of a more encompassing effort to establish an alternative concept for economic activity: a circular economy (CE). The term, found in use as early as 1928 (Witjes and Lozano, 2016), has been popularized and brought into focus of policymakers, academia and business by the Ellen MacArthur Foundation (EMF). While a concise and agreed-upon definition is still missing (Kirchherr et al., 2017), the EMF describes a CE as "an economy that is restorative and regenerative by design and aims to keep products, components, and materials at their highest utility and value at all times" (EMF, 2015a, pg. 5).

In the broader research on a CE, PSSs are predominantly discussed in the scope of sustainable business models (Boons et al., 2013; Bocken et al., 2014) or circular business models (Geissdoerfer et al., 2017; Nußholz, 2017). There, the focus is to establish modes of successfully conducting business in a way that matches the overall goals of a CE. With a particular focus on PSSs, the discussion quickly centers in on the potential resource efficiency-improvement through highly integrated PSSs (see Yang and Evans, 2019). To achieve this, all phases of the lifecycle are vital. Increased resource efficiency can be realized in many different ways. This can happen, e.g., through using fewer resources in production; through more efficient operation and high utilization of the product components required to create value; and especially through closing loops at the end of the PSS lifecycle, where the product components of a PSS return to the provider to be, ideally, reused or remanufactured (see, e.g., Bocken et al., 2014; Michelini et al., 2017; Kjaer et al., 2019). 


\subsection{Problematization of the Research}

At this point, all seems great: Instead of the linear process of designing, producing and selling more and more objects that eventually end up in recycling or a landfill, manufacturing companies can become providers of PSSs and sell value to customers. This way, their business becomes highly efficient, and the resources that are still needed are circled through reuse and remanufacturing, contributing to a future CE.

Unfortunately, much more is needed for PSSs to actually provide the opportunity to meet the promises related to resource efficiency and broader environmental benefits envisioned decades ago (Goedkoop et al., 1999; Mont, 2002; Tukker, 2004) and to avoid the challenges posed by rebound effects (Binswanger, 2001; Ceschin and Gaziulusoy, 2016) towards resource effectiveness and an absolute decoupling of economic activity and resource use (see, e.g., Kjaer et al., 2019).

For PSSs to be efficient and effective and to constitute an advantage over a product sold to create similar customer value, a number of conditions must be fulfilled - one of them is the ownership and control remaining with the provider. However, many additional challenges and difficulties have emerged in prior research when it comes to becoming a PSS provider and ensuring that the offerings provided are highly efficient throughout the entire lifecycle.

An overarching challenge is the comprehensive shift required for manufacturing companies to successfully expand to become an effective and efficient PSS provider. Moving from a focus on producing and selling with an emphasis on quantity (and quality) towards a whole-lifecycle focus, expanding the scope to the use phase and end of life, is a process that companies often struggle with (Isaksson et al., 2009; Martinez et al., 2010; Zhang and Banerji, 2017). In order to be able to turn this adaptation-challenge into an opportunity, it must first be understood in detail (Martinez et al., 2017).

The area of design is highly impactful to the question of being an effective and efficient PSS provider. Prior research makes it clear that for PSSs to be effective and efficient, they must be designed with a focus on the entire PSS lifecycle and in a profoundly different way than products that are meant to be sold (Morelli, 2006; Sakao, 2011). This means that not only should the PSS as the design object be effective and efficient, but also that effective design is critical (see Abukhader, 2008). Thus, purpose-driven and intentional design centered on the whole PSS lifecycle is needed, utilizing resources efficiently, extending component life, and retaining and re-circling resources at the end of the first life of the physical components, e.g., through remanufacturing or reuse. Although there is a substantial body of research prescribing how PSS design should be carried out (see, e.g., Vasantha et al., 2012; Brambila-Macias et al., 2018), there is little understanding of how manufacturing companies actually go about designing PSS in everyday practice (see Tan et al., 2010). 
An additional challenge for manufacturing companies connected to the expansion to PSSs and adjustment of business models is focused on how value is captured. Whereas in the past, manufacturing companies mainly concentrated on generating income through the sale of products, in PSSs, value capture becomes more complex, as it stretches throughout and beyond the use phase of the offering (see Grönroos and Voima, 2013). However, as in traditional product sales, the opportunities for value capture are predetermined mainly at the design stage of the PSS. In order to be able to do this efficiently and effectively, a manufacturing company expanding towards PSSs must be aware of the need to adapt its understanding of how value is captured and to ensure the implementation of that understanding in its processes focused on the entire PSS lifecycle. Very likely, this is challenging for manufacturing companies (Yang et al., 2016), indicating that assisting them in understanding and enhancing their value capture, e.g., through a support method, may serve the goal of more effective and efficient PSS design and provision.

The challenges of expanding from being a manufacturing company to becoming a PSS provider are manifold, and the solutions proposed by academic research are similar: Gain an understanding of the status quo and develop a support method that manufacturing companies can apply, reaping the benefits of the accrued knowledge instilled into the method ${ }^{6}$. However, beyond individual case studies when a new method for PSS design and provision is presented, the actual use of such methods in industrial practice is subject to discussion (Vezzoli et al., 2014, 2015). This situation begs the question of how well the methods provided are meeting the requirements of manufacturing companies and PSS providers, and what could be done to improve their usefulness in practice.

Yet, even if the expansion of manufacturing companies to becoming PSS providers is well-understood, and departing from that understanding, both their design and value capture are supported by effective, efficient and easy-to-implement and -use methods, then this will still benefit only those companies in awareness of their existence and with the interest and resources to use them. The same is true of all frameworks and methodologies proposed to support companies in implementing circular business models such as PSSs (e.g., Lieder and Rashid, 2016; Heyes et al., 2018; Manninen et al., 2018). However, what about manufacturing companies that are moving to PSSs without the support of methods or frameworks? Insight into the extent to which such an expansion to PSSs corresponds to the current understanding of how PSSs can contribute to a CE is absent in current research concerning both concepts. Further, as sustainability related to a CE and servitization is increasingly seen as a crucial success-factor for companies (Parida and Wincent, 2019), a deeper understanding of the CE contribution through an expansion to PSSs carried out based on a largely economic motivation is timely.

\footnotetext{
${ }^{6}$ With respect to engineering design, this approach is captured well by the Design Research Methodology (Blessing and Chakrabarti, 2009).
} 
By and large, challenges in the expansion to becoming a provider of PSSs abound. Luckily, so do opportunities that reside in a better understanding of this process and methods supporting the design and provision of effective and efficient PSSs towards solving the challenges identified. Understanding that support methods will only reach some companies, investigating the potential extent of a CEcontribution by PSSs that are designed and provided without the backing of a CEcentric framework or methodology serves as a countercheck to this rather prescriptive overall approach.

\subsection{Aim and Research Questions}

Therefore, the overarching aim of this thesis is to support manufacturing companies in the expansion to effective and efficient design and provision of product-service systems.

Through a combination of exploratory and prescriptive research, this thesis focuses on investigating and supporting the effective and efficient design, provision and value capture of manufacturing companies expanding towards PSSs. Further, the research aims to shed light on the potential CE-contributions by PSSs that are designed and provided without the support of CE-focused prescriptive methods and frameworks. The aim is operationalized by four research questions (RQs).

\section{Research Question 1 \\ How have manufacturing companies adjusted their design and provision to product-service systems?}

Manufacturing companies are increasingly expanding their activities towards becoming providers of PSSs. In answering RQ1, the goal is to expand the understanding of how this process occurs in practice. The objective is, therefore, to investigate the challenges these companies are facing during and as a result of the expansion to PSSs. Based on this, the impact of these challenges regarding the effectiveness and efficiency of both the expansion towards PSSs and the resulting PSS design and provision throughout the lifecycle are investigated.

\section{Research Question 2 \\ How can methods facilitating the effective and efficient design and provision of product- service systems be developed and applied?}

In answering RQ2, the research departs from the needs of manufacturing companies expanding their scope of business to PSSs. With these needs in focus, the research presented seeks to identify pathways towards facilitating the development and selection of methods for the design and provision of PSSs that are both 
effective and efficient in use and in the result they deliver. The impact of such methods towards alleviating challenges in PSS design and provision throughout the lifecycle is examined.

\section{Research Question 3 \\ How can the value capture through product- service systems be supported throughout the lifecycle?}

Prior research has indicated that an exclusive focus on value capture in terms of monetary value, as in product sales, may be insufficient when providing PSSs. Towards answering RQ3, the research presented endeavors to achieve an in-depth understanding of the value capture of PSS providers in contrast to product sellers. A method and an approach to be applied in the use and design phase of PSSs are intended to support manufacturing companies in analyzing and enhancing their value-capture with a lifecycle focus as they expand their business to PSSs.

\section{Research Question 4 \\ In what ways can economically-driven, unsupported expansions to product-service systems contribute to a circular economy?}

A growing number of frameworks and methods for the operationalization of the goals and principles of resource efficiency and effectiveness through PSSs in the scope of a CE are presented in the literature. It is likely that many manufacturing companies carry out the expansion to PSSs unaware of and without the support of such frameworks, methods, and other aids. Departing from this, the research responding to RQ4 aims to provide a better understanding of such unsupported expansions and the potential contributions of the resulting PSSs to resource efficiency and effectiveness in the scope of a CE.

\subsection{Interrelations Between the Research Questions}

RQ1 intends to establish the basis for the subsequent questions by compiling the exploratory research carried out with manufacturing companies in the expansion towards PSSs. Based on answering that question, gaps and challenges experienced by these companies are identified.

As methods are a common approach for academia to solve such challenges, these were taken into closer consideration for RQ2. On the one hand, this concerns the possible impact of existing prescriptive methods to facilitate effective and efficient design and provision of PSSs throughout the lifecycle. On the other hand, the research to answer RQ2 considers how such methods are conceived. Based on a prescriptive method, the development and selection of design methods for PSSs 
ought to become more effective, efficient and driven by the requirements of method users in manufacturing companies.

Drawing further on the exploratory RQ1, value is considered a crucial concept for a manufacturing company to embrace in order to become an effective and efficient PSS provider. As customer value is extensively researched in the field of PSSs, the response to RQ3 focuses on understanding the complexity of the provider's value capture when offering PSSs instead of selling products. A method and an approach developed to support PSS providers in analyzing their current value capture in the use phase, and applying lessons learned from this to a future offering in the design phase, are presented. Drawing on lessons learned answering RQ2, improvement efforts were made to enhance the utility of particularly the design-centric method towards more effective and efficient PSS design.

RQ4 draws again on the exploratory research presented in RQ1, approaching it from a different angle: Based on the in-depth understanding attained at a case company, a countercheck to the prescriptive results reported answering RQs 2 and 3, particularly with regards to resource efficiency and effectiveness, is performed. This is achieved by analyzing the potential contribution to resource decoupling towards a CE by a manufacturing company expanding to PSSs without the support of prescriptive, CE-centric methods and frameworks.

\subsection{Thesis Scope}

This subchapter details the central foci of the thesis and lays out the motivation to investigate these aspects in the given context.

\subsubsection{Two Manufacturing Companies Expanding Towards PSSs}

The empirical research conducted is focused on manufacturing companies. This term refers to companies with a background in the design and sale of physical goods that have the opportunity to take control of a larger range of the lifecycle. It is these companies that are often in focus in PSS research (see, e.g., Adrodegari et al., 2017; Tan et al., 2010). A further motivation for focusing on manufacturing companies is that they are highly relevant to the local and Swedish context and therefore, attaining a deeper understanding of the expansion of such companies towards design and provision of PSSs is of great interest.

There are two manufacturing companies at the core of the research conducted: Navitas and Levor ${ }^{7}$. Supplemental insight was gained from Ericsson based on the work of master's students. Navitas and Levor were partners in multi-year collaborations. In order to gain full access to internal documents and for respondents to be able to speak openly during empirical data gathering, confidentiality

${ }^{7}$ The same naming scheme has been used in the licentiate thesis (Matschewsky, 2016). 
agreements were signed in both cases. Thus, data revealed publicly, e.g., in academic publications, had to be redacted to ensure the anonymity of the companies, including their names.

Further, pseudonyms used in the appended publications could not be re-used extensively in order to avoid a comprehensive representation of internal processes and challenges experienced, should a company be identified. This results in a number of pseudonyms being used throughout the appended publications, while some of them refer to the same company. The additional pseudonyms used, Arantius (Publication 4) and Kamiono (Publication 5), describe Navitas and/or Levor as well. To honor the companies' request for anonymity and the great insight they shared, the direct relation between these pseudonyms cannot be disclosed. The additional pseudonyms Arantius and Kamiono are only used when discussing the appended publications 4 and 5 , respectively. ${ }^{8}$ Where the case companies are discussed without reference to a specific publication, e.g., in the research journey in Chapter 3.1, only the pseudonyms Navitas and Levor are used.

\subsubsection{Methods to Support the Design and Provision of PSSs}

Methods are a crucial focus of design research (Reich, 2010) and receive substantial attention in research on PSSs (Sundin et al., 2009; Vasantha et al., 2015; Vezzoli et al., 2015). A considerable number of methods is published with the goal of supporting PSS design and provision - however, as in engineering design, the impact of these methods on practice is unclear (Tomiyama et al., 2009; Vezzoli et al., 2015). As a result, PSS design methods and the enhancement of their practical relevance and usability became one of the foci in the scope of the research. This also served to enhance the reflexiveness of the research (see Reich, 2017) by way of the direct application of lessons learned to an own preexisting method.

\subsubsection{Value as a Concept in PSS Design and Provision}

The concept of value is frequently used in research on PSSs and specifically on PSS design (see, e.g., A. Bertoni et al., 2016; Kuijken et al., 2017; Sakao and Shimomura, 2007). Focusing on this concept to attain and communicate a broader understanding of how extensive the changes for manufacturing companies in expanding towards PSS design and provision actually are with respect to how "income" is generated was an important point of departure of the research conducted and is central to this thesis. As customer value is a term used and understood by practitioners in manufacturing companies (Kimita et al., 2009a; Sakao and Lindahl, 2012), the provider value concept can tie into this pre-existing knowledge to facilitate data gathering and conceptualization and has been adopted as a term in the field of PSS research (Bertoni et al., 2017).

\footnotetext{
${ }^{8}$ Where these pseudonyms are used in a chapter for the first time, a footnote is given to ensure the reason for their use is clear.
} 


\subsubsection{Effective and Efficient PSSs Towards a Circular Economy}

Prior research makes clear that only certain PSS business model archetypes entail the opportunity of increased resource efficiency (Tukker, 2015; Yang and Evans, 2019). For that reason, the research presented here concentrates on highly integrated PSSs (see Miller and Mattes, 2014), which focus only on offerings in which the provider retains ownership and control of the physical components and takes back and reuses or remanufactures these components at the end of the lifecycle. With respect to effectiveness, the research presented considers the successful provision of PSSs at large. In view of this, both successful value creation and value capture are considered as a basis for effective PSS provision to avoid failure and deservitization (Kowalkowski et al., 2017). Considering effectiveness towards improved environmental performance, this is focused on in terms of intentional design and provision of PSSs throughout the lifecycle.

PSSs are currently much discussed in the broader context of a CE (Michelini et al., 2017; Chen, 2018). Of course, this work only covers a small portion of the CE concept. However, the preconditions of the contribution of PSSs to a CE discussed in the literature (Manninen et al., 2018; Kjaer et al., 2019) indicate that reflecting on this in the context of this research is meaningful and may advance the state of the art. Further, by extending the scope of the thesis to a reflection on CE contributions, the possibility is gained to participate in one of the central discussions in academia, politics, and society and to achieve a broader overall research impact.

\subsection{Thesis Outline}

This Ph.D. thesis consists of a cover essay and five appended publications. Here, a brief overview of Chapters 2-7 of the cover essay is given.

In Chapter 2, the research background, central concepts, and theory at the basis of the thesis are laid out. This is based on the respective backgrounds of the appended publications and aims to present a comprehensive overview and synthesis.

In Chapter 3, the research method towards the thesis is laid out. Here, the research journey towards the Ph.D. is elaborated upon. The research approach and methodical interconnectedness of the research questions are illustrated, and the research methods employed are presented. The particular methodologies towards answering each research question are shown in detail. In addition, the research quality is discussed in depth, and the impact of the research design and choice of methods are reflected upon.

In Chapter 4, the appended publications are presented. Particular focus rests on the author's contributions and the results critical to the discussion in the scope of this thesis. 
In Chapter 5, the results presented are discussed with a focus on the research questions. In discussing, reference is made to prior research and cross-references are given where the appended publications influenced one-another.

In Chapter 6, a synthesis of the research results for a central audience of this book is presented: For practitioners in manufacturing companies seeking to expand towards effective and efficient design and provision of PSSs, a simplified graphical overview of the central outcomes of the work is shown, together with a table of possible courses of action during the expansion.

In Chapter 7, concise answers to the research questions are offered, and trajectories of future research are deliberated. 



\section{Chapter 2}

\section{Research Background}

In order to provide a background to the research conducted, this chapter introduces the current state of the research, theory and concepts at the basis of the work. This chapter also clarifies crucial assumptions and delimitations guiding the thesis based on prior research. Further, it provides a synthesis of the background towards a frame of reference.

\subsection{Product-Service Systems}

\subsubsection{The Facets of Product-Service Systems}

In an early definition, PSSs are described as offerings consisting of products (tangible) and services (intangible), which are jointly developed and provided with a focus on creating customer value (see Goedkoop et al., 1999). Besides being considered a type of offering to be brought to market, PSSs are increasingly discussed as an accumulative term for business models ${ }^{9}$ integrating products and services with a lifecycle perspective (see Reim et al., 2015). The business model concept is, in this context, seen as an important facilitator of a successful implementation of PSSs in practice (Barquet et al., 2013; Adrodegari et al., 2017). Since the coining of the term in the late 199os, PSSs have been researched with a focus on or departing from the expectation of reduced environmental impact when compared to traditional product sales (Ceschin, 2013; Bocken et al., 2014; Tukker, 2015). However, doubts were raised and discussed frequently regarding the extent of these aspired advantages realized in manufacturing industry practice (Vezzoli et al., 2012; Manninen et al., 2018; Kjaer et al., 2019).

The academic research on offerings consisting of products and services spans from fields focusing on business through marketing, organizational change, operations management, and design, all the way to an exclusive focus on environmental performance. Due to that broadness, a large number of terms are in use to describe these offerings, with all of these having different connotations and foci related to the respective fields. The term servitization, describing the process a company undergoes when becoming a PSS provider, originates in the areas of marketing and operations management (Baines et al., 2009a, 2017; Zhang and Banerji, 2017), where it emerged as early as 1988 (Vandermerwe and Rada, 1988)

\footnotetext{
${ }^{9}$ In this, the working definition proposed by Reim et al. (2015, pg. 65) is adopted, describing business models in the PSS context as "the design or architecture of the value creation, delivery and capture mechanisms".
} 
and regained traction in connection to the work on service-dominant logic (Vargo and Lusch, 2004). The term has made its way into the field of PSSs (Reim et al., 2015; A. Bertoni et al., 2016) and is frequently used to illustrate the process of becoming a PSS provider (Martinez et al., 2010, 2017). A servitized manufacturing company designing and providing PSSs is, at that time, considered a PSSs provider (based on Lim et al., 2012). However, these companies often also remain product sellers, leading to organizational ambivalence in servitization (Lenka et al., 2018a). Highlighting the focus on environmental aspects, terms such as sustainable PSSs (S.PSSs) have emerged (Vezzoli et al., 2015) and the research field has been extended to include "sustainability-oriented service innovation" (Calabrese et al., 2018). In the face of this abundance of foci, researchers have made efforts to consolidate the fields in order to achieve a higher level of understanding, whether in regard to PSSs at large (Annarelli et al., 2016) or, e.g., in concentrating on joint lessons learned from PSS research focusing on engineering design and marketing (Brambila-Macias et al., 2018).

\subsubsection{PSS Business Models in Focus}

PSSs are not only investigated through a broad set of analytical lenses, but they can also take a variety of forms of implementation and execution in manufacturing industry practice. In order to provide the classification and relatability needed for an academic discussion, prior research has identified different ways of categorizing PSS offerings (see, e.g., Adrodegari et al., 2017; Beuren et al., 2017). However, one characterization system has largely prevailed (Reim et al., 2015) and may currently be considered common knowledge in the field: It is based on the degree to which the customer value creation through a PSS relies on its product or service components as introduced by Tukker (2004) and Meier et al. (2010) and shown in Figure 1.

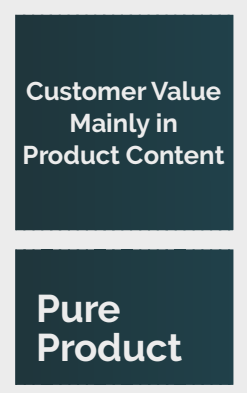

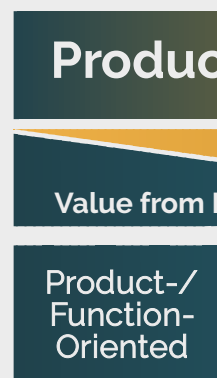

\section{Product-Service System}

Value from Service

Product

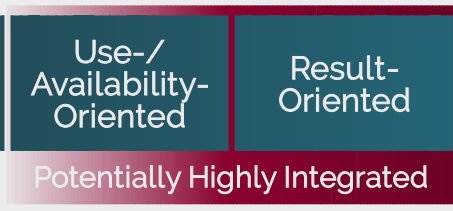

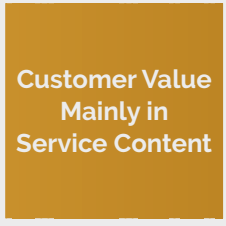

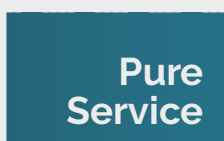

Figure 1: PSSs business models (based on Tukker, 2004; Meier et al., 2010)

Along with the shift in the origin of value generation, critical changes occur with respect to how business is conducted and in turn, how manufacturing companies are incentivized to act when expanding to provide PSSs with a lifecycle focus: 
Function- or product-oriented PSSs leave the majority of the responsibility with the customer, and consequently, providers act very similar to how they would act in a pure product sales scenario (Tukker, 2015). In the case of use-oriented PSSs, the provider ensures that the offering is available for use by the customer as agreed upon, while providers of result-oriented PSSs ${ }^{10}$ retain both ownership of the offering and operate it throughout the use phase of the lifecycle. It is when becoming a provider of use- and result-oriented PSS offerings that companies can undergo a broad set of changes: The organizational structure requires adjustment (Windahl and Lakemond, 2006; Maussang et al., 2009; Cavalieri and Pezzotta, 2012), the internal incentive structure of the business is in need of adaptation (Gebauer et al., 2006; OECD, 2015) and the existing corporate environment must be changed to reflect the new focus of the business (Ceschin, 2013; Tukker, 2015). Adapted from the licentiate thesis (Matschewsky, 2016), the example below is intended to illustrate key aspects of highly integrated PSSs (see Figure 1, summarizing use- and result-oriented PSSs; see also Miller and Mattes, 2014).

\section{Example of Highly Integrated Product-Service Systems}

Assume that, in a product sales scenario, a company was previously the seller of road-cleaning machines, which were sold to municipalities. This company may have gained some revenue by offering services for these machines, but the main source of income would have been the actual sales. Should this company decide to become a provider of highly integrated PSSs, the offering would change substantially: Instead of selling machines, the company now provides clean surfaces. It takes care that the machines are in working order at all times and even supplies the operators for the machines. This means that the municipalities get billed based on the area they would like to have cleaned, and on the cleaning intervals. Both sides can profit from this, e.g. in the form of planning security (long-running contracts). For the provider, there is now a major change in incentive structure: Where previously there was money to be earned in replacing parts, e.g., the sweeping brushes of the machines, now these replacements become costs. There is now an incentive to make parts last longer, if the lifecycle cost of these parts is then lower. That means, e.g., that changed brush design, which costs $30 \%$ more but extends the lifetime by $60 \%$, is economically viable. In addition, as less material is used throughout the lifecycle, environmental benefits are incurred. Further benefits may be improved operational efficiency, since the provider has the best knowledge on how to operate the machine. However, in order to be able to gain these benefits, highly integrated PSSs must be designed from the ground up with a lifecycle focus and through integrating products and services.

\footnotetext{
${ }^{10}$ The existence of such offerings in practice is not undisputed. In a recent publication, for which the author was one of the reviewers, it is argued that result-oriented PSS cannot be achieved based on current remote maintenance technology (Grubic and Jennions, 2018).
} 
It is these highly integrated PSS, in which providers remain in the ownership and control of the physical components of the offering throughout the lifecycle that are in focus in this thesis and particularly when discussing the state of the art on effective and efficient PSSs towards a CE below.

\subsubsection{Effective and Efficient PSSs Towards a Circular Economy}

In research on PSSs, a focus on the goal of improved environmental performance has been present from the very beginning (Goedkoop et al., 1999; Mont, 2002) and researchers have continued to stress this aspect (Vezzoli et al., 2012, 2015). The main reason PSSs are discussed in connection to environmental benefits in comparison with the traditional sale of products is the possibility of improved resource efficiency (see, e.g., Nußholz, 2017; Yang and Evans, 2019). Already simple add-on maintenance may constitute a step forward from a product-centric point of departure. However, the possibility of improved resource efficiency is limited mainly to highly integrated PSSs and stems from the expanding role of the manufacturing company when becoming a PSS provider (Tukker, 2004, pg. 247). Based on this, as illustrated through the example in the box above, the incentives for manufacturing companies becoming PSS providers change fundamentally (ibid.). Efficiency in the use phase moves from being an advantage for the customer to benefitting the provider (see, e.g., Meier et al., 2010; Tan, 2010; Miller and Mattes, 2014). Beyond this, the opportunities to reuse and remanufacture promise substantial resource efficiency improvements, if they are seized.

In recent years, the field of PSS research has matured from theoretical discussions on envisioning environmental benefits towards quantitative accounts, although these are still rare. Lelah et al. (2011) were able to show reductions in indicators such as energy depletion and global warming potential throughout the lifecycle of a result-oriented PSS. Further, Lindahl et al. (2014) reported the environmental and economic benefits of highly integrated PSSs when comparing cases with competing product sales offerings.

However, to move towards and beyond achieving substantial efficiency improvements, a focus on effectiveness is needed (Kjaer et al., 2019). In the context of the manufacturing company becoming a PSS provider, this means an intentional shift towards not just sub-optimization and iterative improvement. Instead, it indicates an improvement by intention and purpose, focusing on all activities throughout the lifecycle towards retaining the value of resources and minimizing waste (Abukhader, 2008; EMF, 2015a). PSS design as introduced in the next subchapter is critical to this. Further, effectiveness in design and provision is closely connected to the CE concept, to which the environmentally-focused research on PSSs has gravitated in recent years.

The term circular economy has gained traction in both the public discourse and in the academic realm. Due to the fast-paced development and broadness of the field, at this point, no commonly agreed definition of a CE is available: In analyzing 114 definitions, Kirchherr et al. (2017) lay out the broadness of the concept and 
point out the different, and partly even lacking, foci. The same analysis finds the 4 Rs of reduction, reuse, recycling and recovery at the center of most definitions (ibid.). The overall goal central to the research presented here is to maintain the value of resources, materials, and products to the highest possible degree and to minimize waste (EMF, 2015b; Kjaer et al., 2019).

PSSs are seen as an important facilitator of maintaining the value of resources in a CE, e.g., through increased efficiency in the use phase, by way of product sharing and the extension of the product lifetime (Tukker, 2015; Bocken et al., 2017; Kjaer et al., 2019). In this context, particularly the image of waste=food as put forth by McDonough and Braungart (2002) in Cradle to Cradle appears highly relevant where technological nutrients are concerned. In traditional product sales, a physical good may be discarded at the end of its first life. However, in the case of highly integrated PSSs, the opportunity to remanufacture or even reuse presents itself, feeding into (an) additional lifecycle/s and maintaining resource value. Of course, again, this requires effectiveness by way of intentional design (Prendeville and Bocken, 2016).

While achieving a $\mathrm{CE}$ is a task requiring changes across all levels of society far beyond production and consumption (see EMF, 2015b), PSSs are seen as critical for the implementation of CE strategies on a company level (Witjes and Lozano, 2016; Murray et al., 2017). In this context, researchers have further pointed out, that no single company can complete the transition to a CE by itself, as entire industrial ecosystems are in need of adaptation (Parida et al., 2019).

Beyond PSSs, different business models relevant to a CE are discussed as sustainable business models (Bocken et al., 2014) and circular business models (Nußholz, 2017; Lahti et al., 2018). An overview of the commonalities and differences between the two concepts is provided by Pieroni et al. (2019). In this context, Bocken et al. (2014, pg. 50) identify "deliver functionality, rather than ownership" as a critical sustainable business model archetype based on the PSSs and servitization literature, by, e.g., pointing out the capability of PSSs to break the link between production volume and profit.

Michelini et al. (2017) point out PSSs as a vital facilitator of the transition from a linear to a circular economy. The authors, however, urge caution with respect to the implementation of the offerings in practice, pointing out the need for highly integrated PSSs to achieve the desired benefits (ibid.). Ritzén and Sandström (2017) point out, that for PSS to contribute to the CE, integration is not only needed between products and services but also within the organization towards a higher level of collaboration.

This need for a high level of integration between products and services for an offering to provide the opportunity for environmental benefits throughout the lifecycle has been pointed out in PSS-centric research predating the popularity of the CE term: In defining the PSS business models introduced above, Tukker 
(2004) points out this need for integration, as do many other researchers in the field (Mont, 2002; Baines et al., 2007; Meier et al., 2010).

\subsubsection{Challenges for Effective and Efficient PSSs}

Even with the focus narrowed to highly integrated PSSs, efficiency and effectiveness throughout the lifecycle are by no means automatic. Particularly as resource efficiency remains in focus for many PSS providers due to its immediate promise of economic advantage, rebound effects loom (Font Vivanco et al., 2015). In PSSs, this is focused on the harmful impact financial resources freed up through increased efficiency may have wherever else they are invested (Binswanger, 2001; Ceschin and Gaziulusoy, 2016). Further, in the case of use-oriented PSSs, negligent customer behavior poses a danger of physical components' premature degradation (Chen, 2018), although approaches to mitigating this challenge are emerging (Reim et al., 2018). Additionally, the common focus on global warming potential may cloud judgments, even when the environmental performance is in direct focus: In a life cycle assessment of PSSs for cleaning ship hulls, an improvement in global warming potential was accompanied by substantially increased eco-toxicity (Kjaer et al., 2018).

Beyond efficiency-related issues, of course, the challenge of effectiveness in PSS design and provision constitutes a high barrier (see Kjaer et al., 2019). A purposedriven expansion to PSSs, and subsequently, design with a focus on closed and expanded loops of resources in a company's PSS provision, is a substantial challenge for a company with a background in the manufacture and sale of goods (Martinez et al., 2010; Bocken et al., 2016). PSS design is vital to meeting this challenge (Vezzoli et al., 2015), and the following subchapter provides detail on this subject and the role of methods supporting it.

\subsection{Designing Product-Service Systems and the Role of Methods}

\subsubsection{Particularities of PSSs and the Need for a Distinct Approach}

PSSs differ so profoundly from traditional product sales offerings and other objects of engineering design that tailor-made methods and tools are needed for their design (Morelli, 2006; Sakao, 2011). A number of researchers have pointed out the need for dedicated methods and approaches based on a variety of reasons: Where Akasaka et al. (2012) point out the broad range of knowledge required to design PSSs successfully as a reason for dedicated design approaches, Vezzoli et al. (2015) mention the need for specific design, development, and delivery of PSSs if high resource efficiency is to be achieved.

Dedicated PSS design is even more vital in order to achieve resource effectiveness in the design and provision of PSSs throughout the lifecycle. To move beyond reducing relative resource use towards ensuring a decoupling of increased customer value creation and resources used, an intentional and purpose-driven 
design that aims to retain the value of resources is crucial (EMF, 2015a; Heyes et al., 2018).

In summarizing a number of critical aspects, Wolfenstetter et al. (2015, pg. 1) point out: "Developing a PSS incorporates the integration of components from multiple engineering disciplines such as mechanical engineering, software engineering, and service engineering. In this regard, it does not make sense to separate the development into domain-specific processes.” Thus, PSS design must provide integrative capabilities to companies moving towards integrated offerings of products and services.

Although particular in many ways, PSS design has emerged from product-oriented engineering design. Blessing and Chakrabarti (2009, pg. 1) define engineering design as "activities that actually generate and develop a product from a need, product idea or technology to the full documentation needed to realize the product and to fulfill the perceived needs of the user and other stakeholders.” In PSS design, the scope of these activities is further extended to the joint design of products and services while focusing on the entire lifecycle of the offering from production, through the use phase all the way to the end of the first life, ideally executed as reuse and remanufacturing (Sakao and Mizuyama, 2014).

\subsubsection{PSS Design, the Value of Methods and Challenges in Practice}

When designing and providing PSSs, a focus on the entire lifecycle is critical to be able to design effectively and efficiently and to capture and create value in a sustainable fashion. Where engineering design is focused on achieving an operational technical solution to be sold (see Ullman, 2002), the design of PSSs must focus on the entire lifecycle and is applied under even greater uncertainty (Erkoyuncu et al., 2011; Herzog et al., 2014), e.g., concerning customer needs. The design object is extended beyond physical components to services (Morelli, 2002; Alonso-Rasgado et al., 2004), and design efforts can even expand to business models or parts thereof (Song et al., 2014; Ceschin and Gaziulusoy, 2016).

A substantial number of overarching (e.g. Sakao et al., 2009; van Halen et al., 2005; Vezzoli et al., 2014) and focused (e.g. Bertoni et al., 2013; Lim et al., 2012; Müller et al., 2009) methods and tools have been presented to support PSS design and provision. However, the degree of practical use of such methods is the subject of continued academic discussion (Tomiyama et al., 2009; Vezzoli et al., 2014, 2015), and some researchers have called for an increased focus on existing design methods instead of the development of new approaches (Stark et al., 2017).

Methods can play an essential role, in particular for companies carrying out the transition to PSSs. They are seen as an important support for companies in their efforts to cope with the ever-accelerating need to adapt to changes (Lindahl, 2005) and provide assistance in reducing errors, shortening lead times and improving the quality of the design outcome (Geis et al., 2008; Geis and Birkhofer, 2009; Eckert, 2013). Further, methods are viewed as an essential instrument to reduce 
complexity and uncertainty in the design process (Montagna, 2011; Fernandes et al., 2014).

Researchers focusing on PSSs in particular and on engineering design in general have identified a number of reasons for the apparent lack of traction academically conceived methods gain outside of direct collaborations between actors in the manufacturing industry and academia (see Araujo et al., 1996; Geis et al., 2008; Jänsch and Birkhofer, 2007). Concentrating on the companies intending to apply such methods, the most obvious reason for this may be a general unawareness of the attainable benefits of using design methods (Araujo et al., 1996) and earlier, unsatisfactory method trials (Geis and Birkhofer, 2009). In focusing on ecodesign, Lindahl (2005) has identified a lack of time, high purchase costs, and the cost of education and knowledge, among others, as key reasons for low levels of design method utilization. Lacking management support for successful method adoption and use is a further reason identified (Lindahl, 2005; Wolf, 2011); as is the deficient availability of the information practitioners need to make informed decisions with respect to methods relevant to the challenges experienced by them (Tromp and Hekkert, 2016). Overly ambitious method implementation efforts have also been found to challenge the absorptive capacity of companies (Birkhofer et al., 2002; Wallace, 2011).

Focusing on the methods as such, Lofthouse (2006) points out the dissatisfaction of many practitioners with workshop-style approaches ill-fit to the users' day-today tasks. The time-consuming nature of many methods and lacking awareness of the possible flexibility in a method's use are a further challenge (Lindahl, 2005; López-Mesa, 2006). It has also been found that fitting methods can be challenging to identify and include in the existing design process (Buchert et al., 2017). Additionally, researchers describe the format many methods are presented in as ill-fit to use in industry practice, as they can be abstract and overly scientific (Jänsch and Birkhofer, 2007; Geis et al., 2008; O'Hare, 2010). Vasantha et al. (2012) point out a need for methods solving individual, delineated tasks in the PSS design process, whereas Tukker (2015) argues against such an approach for fear of overly specific methods only applicable in certain cases. In addition, and particularly relevant in the case of PSS design, methods often lack the ability to handle lowquality and inconsistent data (Lofthouse, 2006), which is typical when a new business model is being implemented, and an initial PSS design process is carried out.

In summary, while PSS design is needed in order to support companies in developing and providing innovative product-service offerings in a fashion that allows value capture and creation and ensures an improved environmental performance, a number of challenges exist (Vezzoli et al., 2014, 2015). Methods intended to support design and provision are made available at a high pace, but evidence of their broad acceptance in practice, as in engineering design in general, is lacking (Jänsch and Birkhofer, 2007; Geis et al., 2008). 


\subsection{Value as a Concept in the Context of Product-Service Systems}

\subsubsection{Value in Other Fields Relevant to PSS Design and Provision}

The concept of value in the context of engineering design has been introduced by Miles (1971). There, value is discussed as a relation of function (or performance) over cost. Today, value is one of the key concepts used in research on PSSs and PSS design (Mont, 2002; Meier et al., 2010), departing from its origins in the fields of marketing and relationship management (Zeithaml, 1988; Ulaga and Chacour, 2001).

In relation to PSS design and provision, research on the service-dominant logic (Vargo and Lusch, 2004) bears particular relevance: Where previously, value was understood as contained in physical artifacts (goods-dominant) a new logic is proposed, focused on the performance of services where value is co-created with the customer. Value creation under this premise has been researched in-depth in the marketing domain (Payne et al., 2007; Grönroos, 2008; Grönroos and Ravald, 2011) while emphasizing the creation of customer value. More recently, Grönroos and Voima (2013) have discussed the concept of value while focusing on both customer and provider: Where previously, value for the provider was generated as value-in-exchange at the point of sale, under a service-dominant logic, value creation encompasses all activities of the customer and provider. The authors further stress the subjectivity of value and its relatedness to customer perception (ibid.). Panarotto (2015) points out that, among some researchers, the concept of value goes beyond monetary value alone (Steiner and Harmon, 2009; Grönroos and Voima, 2013) to encompass, e.g., intangible value such as knowledge, experience, and emotion.

Researchers in the field of PSSs have aimed to assemble and operationalize the knowledge generated on the value concept in various areas (e.g., marketing, operations management, and business) in recent years - in an effort to facilitate its use in manufacturing industry practice towards the effective and efficient design and provision of PSSs (see, e.g., Bertoni et al., 2011; A. Bertoni et al., 2016; Yang et al., 2016). It has been pointed out that understanding value creation and capture throughout the lifecycle is an important prerequisite to designing and providing PSSs with a focus on improved environmental performance (Bertoni et al., 2013). Value-centric research in the field of PSSs will, therefore, be discussed in greater detail in the next subchapter.

\subsubsection{Value-Centric Research in PSSs}

From the outset, PSS research has exhibited a strong focus on the creation of customer value (see Goedkoop et al., 1999; Mont, 2002b). Value co-creation has significant implications on how both customers and providers of service-based offerings interact and perceive their roles (Vargo et al., 2008), which in turn has an impact on how these offerings should be designed. The complexity of the value concept has also been highlighted in the servitization context (Urmetzer et al., 
2018). Until recently, research in the field of PSSs has mainly highlighted the (co)creation of customer value (Kimita et al., 2009a, 2009b). In their work on service engineering, Sakao and Shimomura (2007) define value as a change in the "state" of the receiver of the service from an existing state to a new one which the receiver sees as preferable. This is in line with service-dominant logic as introduced above.

The work on value-driven design by Collopy and Hollingsworth (2012) is highly relevant for research on PSS design research focused on value, as also remarked by Bertoni (2013) and Bertoni et al. (2013). Value-driven design emphasizes system-level optimization in the early stages, making it relevant for research on the design of PSSs with a focus on improved environmental performance (Isaksson et al., 2015) and PSSs' potential contribution to a CE. Again, Bocken et al.'s (2014, p 50) work on sustainable business model archetypes must be remarked as relevant: The PSS-centric archetype "deliver functionality, rather than ownership" lays out both the value and expected environmental benefits of a business model concept.

\subsubsection{Value Assessments for PSSs}

Substantial prior research has been dedicated to value assessment for PSSs in the design stage of the lifecycle. In this context, particularly the publications of M. and A. Bertoni and colleagues have been impactful (see, among others, Bertoni et al., 2017, 2016, 2015). Thus, the work presented here is based partly on the comprehensive account of value assessment metrics for PSSs presented in Bertoni et al. (2017). The examples of value assessment approaches for PSSs presented below are selected for relevance to the central research topics at hand.

As mentioned above, Sakao and Shimomura (2007) focus on customer value creation through service provision. In their design method and software-based support tool, the value as created for a prospective customer is modeled in great detail, allowing for fine-tuning of the design under consideration of a large number of parameters for the state of the customer resulting from interaction with the service. In departing from value analysis (Miles, 1971), Alix et al. (2009) investigate value for PSSs, providing deep insight into value as a function/cost relation from the viewpoints of both customers and the PSS provider. Kimita et al. (2009a) endeavor to establish a relationship between a service offering's quality and the customer value created. This way, an optimal level of quality is to be attained based both on pre-existing requirements and needs arising after the performance of a service. Connected to this, Kimita et al. (2009b) examine the influence of using a PSS on customer satisfaction in an effort to support designers in the conceptual design stage and to evaluate the actual impact of certain features on the state of the customer. Bertoni et al. (2011) reported a method to investigate the value of radical PSS design alternatives early on in the design process. Sakao and Lindahl (2012) provided a step-wise method to assess the expected customer value of different PSS design alternatives through an evaluation against PSS characteristics. Bertoni et al. (2013) provide a tool visualizing customer value in an existing 
computer-aided design environment, thus providing a value indication in the accustomed work setting of design engineers. Kim et al. (2016) approach value assessments for PSSs in a holistic fashion: Key value criteria identified are evaluated from the perspective of sustainability (in this case representing the provider's view) and customer value, supported by an extensive list of categories. After rigorous application of the method, the user achieves a comprehensive overview of the prospective value generation of the offering under development. Rondini et al. (2017) utilize importance-performance analysis to enable PSS designers to assess concepts for the value-added they provide, considering both the customer and provider side. High value-adding concepts are identified, further enhanced and again assessed to ensure a comprehensive understanding of the designer regarding the attainable value.

This only represents a portion of the methods, tools, and approaches available to assess and enhance value creation during the PSS design process. Only recently, researchers have begun to put increasing focus on the complexity of PSS providers' value capture. The following subchapter provides some additional insight into this.

\subsubsection{Insight into Particularities of Provider Value for PSSs}

The multidimensional benefits providers of PSSs can attain are much less researched than their customer-centric counterpart at this point. Some researchers, however, have made an effort to investigate the complexity of the value capture of PSS providers. Yoon et al. (2012) introduced a PSS evaluation approach, taking into account both the customer and the provider side and their interaction. Pezzotta et al. (2014) investigated the benefits for customers and providers during the use phase, focusing on balancing the efficiency of services delivered by the provider and the value experienced by the customer. Yang (2009) introduced performance measurements for PSSs from different points of view, some of which are useful to assess the value capture of PSS providers. Although the focus remains on product-oriented PSSs, Xing et al. (2013) discuss a value model considering both a customer and a supplier perspective. Although Rondini et al. (2016) present a heuristic process focusing on company value as a critical aspect of decision-making at the design stage, the considerations are still mainly driven from a customer perspective. Recently, the term provider value has been adopted by authors to describe the complexity of lifecycle-oriented value capture of PSS providers (Bertoni et al., 2017; Rondini et al., 2017).

\subsection{Challenges for Companies in a Changing World}

The transition of manufacturing companies from solely being makers and sellers of products to becoming providers of integrated offerings of products and services with a lifecycle perspective has been investigated extensively. Departing 
from this, a number of researchers have examined emerging cases of companies struggling with that expansion in prior research.

Martinez et al. (2010) provide an in-depth view into servitization challenges in investigating a UK manufacturing company becoming a PSS provider, and identify several approaches to meet these challenges. Vasantha et al. (2014) also investigated a servitization case in the UK, identifying challenges and opportunities. Isaksson et al. (2009) report generic challenges and opportunities identified in a literature study as well as case studies. Kurak et al. (2013) classify challenges identified in relation to business models. Baines et al. (2009) identified a number of categories of servitization challenges. In presenting a thorough case study, Brax (2005) identified challenges experienced by a particular case of servitization which focused on a service add-on strategy. To provide a condensed overview, Table 1 summarizes challenges of servitization identified in prior research.

Table 1: Challenges for companies in servitization (abridged from Matschewsky et al., 2018a)

\begin{tabular}{|c|c|}
\hline Reference & Challenges Identified \\
\hline Brax (2005) & $\begin{array}{l}\text { - Communication (processes to obtain and utilize feedback) } \\
\text { - Delivery (change in company culture, bad timing) } \\
\text { - Marketing (changes in how case company marketed offering) } \\
\text { - Product-Design (focus on lifecycle vs. short-term uptime and cost) } \\
\text { - Production (acquiring necessary level of knowledge) } \\
\text { - Relationship (perception of staff, opportunism by provider, privacy) }\end{array}$ \\
\hline Baines et al. (2009) & $\begin{array}{l}\text { - Communicating and demonstrating value through services } \\
\text { - Language used with service focus } \\
\text { - PSS delivery, sharing resources \& knowledge amid supply chain \& OEM } \\
\text { - PSS design and having a focus on through-life performance }\end{array}$ \\
\hline $\begin{array}{l}\text { Isaksson et al. } \\
(2009)\end{array}$ & $\begin{array}{l}\text { - Addressing customer needs } \\
\text { - High uncertainty through extensive contract length } \\
\text { - Modelling and simulation } \\
\text { - New competence requirements for PSS design } \\
\text { - True collaboration between service developers and product developers }\end{array}$ \\
\hline $\begin{array}{l}\text { Martinez et al. } \\
(2010)\end{array}$ & $\begin{array}{l}\text { - Delivery of integrated offerings } \\
\text { - Embedded product-service culture } \\
\text { - Internal processes and capabilities } \\
\text { - Strategic alignment } \\
\text { - Supplier relationships }\end{array}$ \\
\hline $\begin{array}{l}\text { Ulaga and Reinartz } \\
\text { (2011) }\end{array}$ & $\begin{array}{l}\text { - Deployment } \\
\text { - Design-to-service } \\
\text { - Execution risk assessment and mitigation } \\
\text { - Sales } \\
\text { - Service-related data processing and interpretation }\end{array}$ \\
\hline Durugbo (2013) & $\begin{array}{l}\text { - Complexity } \\
\text { - Ensuring customer trust } \\
\text { - Sustainability } \\
\text { - Timeliness and service-tie-ins }\end{array}$ \\
\hline Kurak et al. (2013) & $\begin{array}{l}\text { - Human resources } \\
\text { - Market segment and value proposition } \\
\text { - PSS knowledge and ease of use } \\
\end{array}$ \\
\hline $\begin{array}{l}\text { Vasantha et al. } \\
(2014)\end{array}$ & $\begin{array}{l}\text { - Critical factors in moving to higher servitization levels } \\
\text { - Industry-specific challenges to achieve higher levels of servitization }\end{array}$ \\
\hline
\end{tabular}




\subsection{Reflecting upon the Research Background}

\subsubsection{The Focus of this Research with Respect to PSSs and a CE}

The broadness of the CE concept and the ongoing academic discussion on the contribution and role of PSSs in its context requires some reflection. In order to be explicit in outlining the role and contribution of the research presented in this thesis with respect to a $\mathrm{CE}$, this is deliberated hereafter.

Based on the research background, the following central insights were gained:

(1) Achieving increased resource efficiency throughout the lifecycle has been a cornerstone of PSSs research (see, e.g., Manzini and Vezzoli, 2002; Ceschin, 2013; Tukker, 2015).

(2) Resource efficiency, or the narrowing of resource flows, has been discussed as a core trait of circular and sustainable business models, in the scope of which PSSs are frequently discussed (Bocken et al., 2014, 2016; Nußholz, 2017).

(3) Resource effectiveness, and thus resource longevity and slowing the deterioration of resource value, is a critical aspect discussed with respect to PSSs (Kjaer et al., 2019; Pieroni et al., 2019). This concerns closing loops and extending the flow of resources (Bocken et al., 2016), e.g., through reuse, remanufacturing, and PSS sharing (Kjaer et al., 2019). In contrast to this terminology, some authors also refer to closing and slowing resource loops in terms of resource efficiency (Haupt et al., 2017; Linder and Williander, 2017; Mendoza et al., 2017).

(4) With regard to achieving both resource efficiency and effectiveness towards a CE, provider control, ownership of the physical components (Pieroni et al., 2019) and, very importantly, intentional design and a lifecycle focus (Tukker, 2015; Vezzoli et al., 2015) are critical.

Based on this state of the art, when discussing environmental aspects of PSSs in the scope of this thesis, the following aspects are considered: Foremost, there is an exclusive focus on highly integrated PSSs (red and yellow areas of Figure 2). Further, critical points of reflection are the resource efficiency and effectiveness of such highly integrated PSSs throughout the lifecycle. Lastly, it is clear that only a portion of the highly integrated PSSs provided in practice entail resource efficiency and effectiveness towards a potential contribution to a CE (yellow area in Figure 2). Identifying this area and supporting companies in locating their business within this space is a central goal of the research presented. As economic growth is a further value driver identified for such circular business, this indicates a hard-to-achieve sweet-spot for PSS provision (Pieroni et al., 2019).

As Figure 2 further indicates, additional issues are not in the focus of the work presented: Beyond PSSs that are not highly integrated, the largest part of what is considered a CE is not explored here. This concerns aspects of policy (EMF, 2015a), applicable business models other than PSSs (Bocken et al., 2016; Nußholz, 2017) 
and biological cycles within a CE (Bocken et al., 2016; Moreno et al., 2016). Further, the broader field of sustainability and thereby, questions of, e.g., societal well-being and work enrichment (Pieroni et al., 2019) are not researched. In addition, alternative approaches to achieving sustainability, e.g., based on traditional linear business approaches, are not a focus of this work.

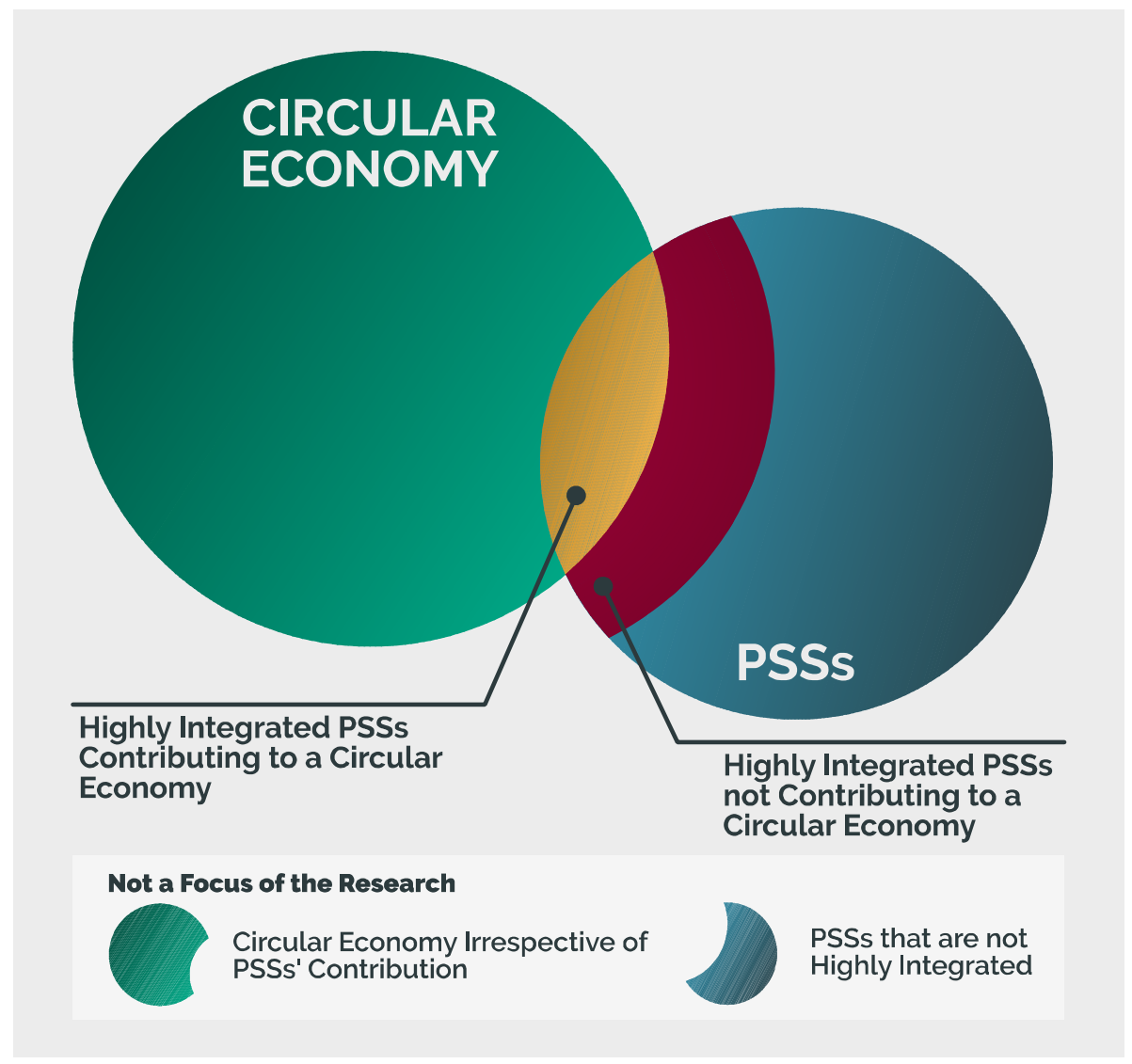

Figure 2: Focus of this research with respect to a CE and PSSs

\subsubsection{Synthesis of the Research Background}

The aim of this thesis is to support manufacturing companies in the expansion to effective and efficient design and provision of product-service systems. As this is unfeasible to do in its entirety, a set of foci must be selected in order to provide meaningful support to companies expanding their business towards PSSs. To avoid repetition, please refer to the subchapters above for references.

The research conducted had its point of departure in the field of PSS design with an explicit focus on design methods originating in the field of engineering design. This background is crucial throughout the research in order to investigate the manufacturing industry practice of designing and providing PSSs. Further, it 
informs the prescriptive portions of the research regarding the development, selection, implementation and use of design methods and methods supporting the expansion of manufacturing companies towards PSSs and PSS provision.

PSS design and methods supporting it, however, are insufficient to fully understand the expansion of manufacturing companies towards becoming PSS providers. This is particularly true as PSS design is a mostly prescriptive concept that endeavors to shape manufacturing industry practice. Theory broadly referred to as servitization literature was used to complement this prescriptive focus with an exploratory approach to gain a deeper understanding of PSSs in manufacturing companies. This allows for an investigation of real-world expansions to PSSs and their impact on the organization and activities of manufacturing companies from a less prescriptive point of view. To have this understanding is critical to the aim of supporting the effective and efficient design and provision of PSSs with a focus on the actual challenges occurring in practice. Together with PSS design and design methods, servitization constitutes the backbone of the research conducted. The other two main research fields are primarily derivatives of either PSS design, servitization, or both.

Although both the PSS design literature and prior research on servitization discuss value with varying foci, the particular importance of understanding and enhancing the value capture of PSS providers required a more in-depth focus on this. Therefore, value and value capture through PSSs are considered as a branch of research in their own right. To a small degree, the value concept supports the understanding of how PSSs are designed and provided in practice in a descriptive sense. However, to a substantial degree, value and particularly the value capture of PSS providers is critical to illustrate the benefits of a lifecycle focus for manufacturing companies becoming PSS providers. Therefore, value capture is highly relevant and highly interconnected with the previously mentioned fields of research. Supporting companies in understanding and enhancing their modes of value capture may be crucial to achieving effective and efficient PSSs in practice.

Lastly, resource efficiency and effectiveness are closely related and much discussed in research on PSSs, PSS design and partly, in servitization. The relation of this to a $C E$ is also present and growing in the PSS design literature. Nevertheless, the motivation for the research and the focus of the fourth research question necessitates a more explicit focus on these issues. Particularly, the expansion of the understanding of how PSSs in practice can contribute to a CE, in accordance with the current understanding of this contribution in the state of the art, clarifies this need. Further, the extensive theoretical understanding of the preconditions for achieving resource efficient and effective PSSs was critical to limiting the focus of the research to highly integrated PSSs.

In summary, the research background based on servitization, design, provision, value (capture) and a focus on resource efficiency and effectiveness throughout the lifecycle is needed to inform the research conducted and to allow for reflection. 
Figure 3 provides an overview of the most relevant areas of research, giving insight or points of reflection towards the respective research question. The progression display of a manufacturing company's expansion towards the provision of highly integrated PSSs ${ }^{11}$ indicates the relevance of the foci of the research in accordance with the progress made by the company.

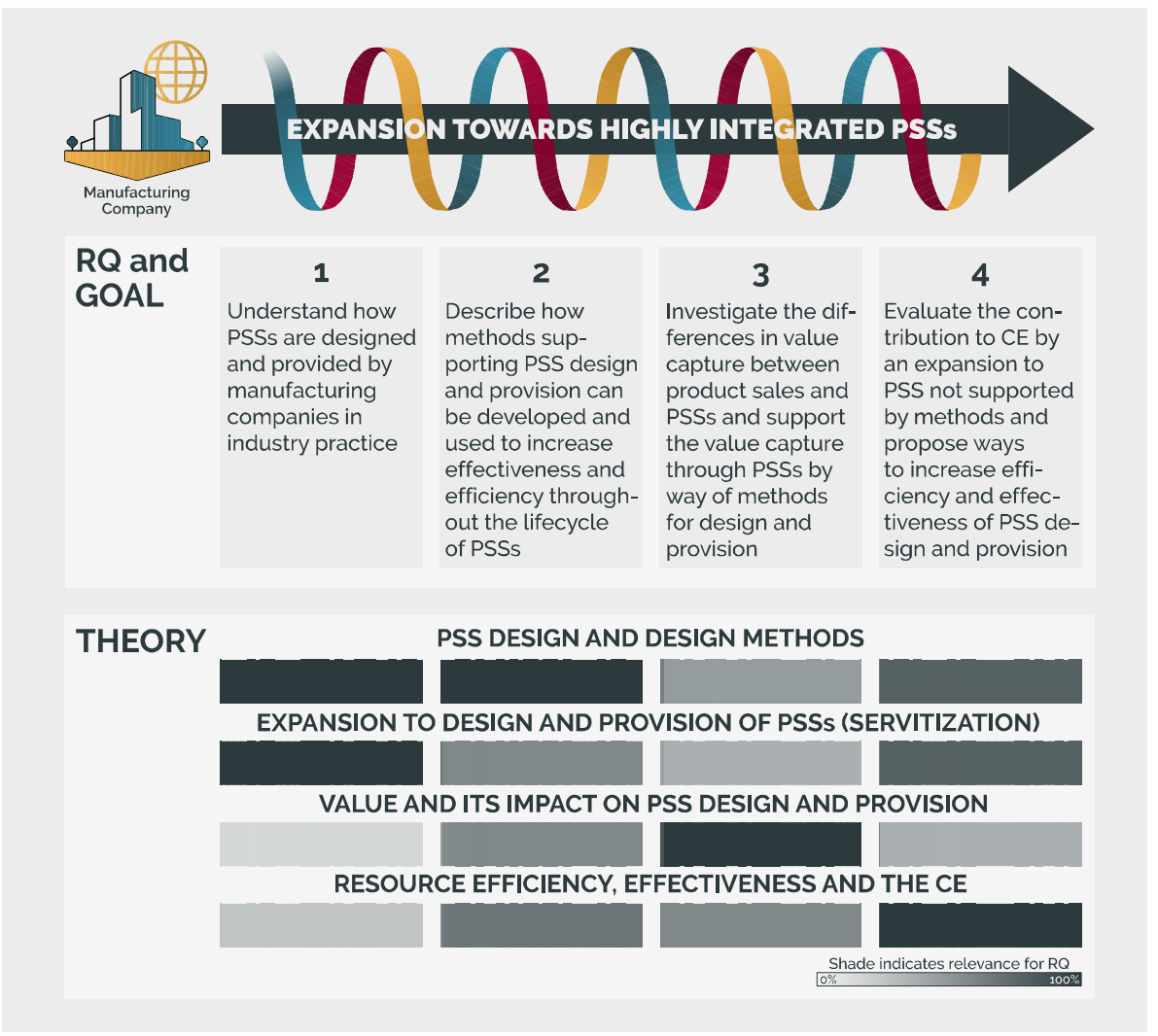

Figure 3: Theory introduced and its relevance for RQs and goals of the research*

For the exploratory research carried out to answer RQ1, mainly extant literature on PSS design and servitization proved to be important. Although generally relevant, the research background on value and resource efficiency and effectiveness was in lesser focus based on the status quo of PSS design and provision in manufacturing industry practice.

For the largely prescriptive research towards RQ2, particularly prior research on PSS design and design methods was an important backdrop. All other fields in the theoretical background are of lesser relevance, while they are still needed to discuss the impact of improved PSS design and design methods on the respective field.

${ }^{11}$ Shown in the form of a hermeneutical spiral (inspired by Paterson and Higgs, 2005). 
Regarding RQ3, value is of central importance as a background towards understanding changes in value capture when moving from product sales to PSSs from a theoretical point of view. However, the remaining fields are of relevance to discuss the expected impact of a more comprehensive value capture through PSS provision.

RQ4 relies mainly on the state of the art in research on PSSs and their possible contribution to a CE through resource efficiency and effectiveness. However, the PSS design and servitization literature provides a much-needed backdrop for the research and is especially important with a focus on identifying ways forward towards increased efficiency and effectiveness of PSS design and provision. 



\section{Chapter 3}

\section{Research Method}

This chapter has a dual focus. On the one hand, it aims to provide the reader with a background and comprehensive understanding of the research journey of over five years of work towards this thesis, clarifying the different research projects and the varying foci throughout the process. To make this accessible and easy to read, Chapter 3.1 is written in the first person. On the other hand, the methods used to collect and analyze data are briefly laid out, and the quality of the research conducted is scrutinized. As there was some overlap in the methods used, this chapter contains text adopted from the licentiate thesis (Matschewsky, 2016).

\subsection{Challenges, Opportunities, and Solutions - A Research Journey}

Pursuing a doctoral degree in the topic of environmental management and environmental engineering in Sweden was beyond imagination when I began my university studies in 2006. After exploring international management and political science, I decided to go for the safe route and to study mechanical engineering design at the University of Applied Sciences for Technology and Economics (HTW) in Dresden, Germany. I knew that, for lack of an in-depth understanding of all things mechanical, it was unlikely that I would amount to an excellent engineering designer. Thus, from the first semester, I started looking for my niche. Research was an appealing field, so I spent my years as a student working in different research institutes in the fields of non-destructive testing, and later, system packaging. This was interesting and educational, but not a career path I wanted to take. A fascination with flight and, despite all its shortcomings, its power to bring people together, led me to spend my mandatory six-month internship at Airbus in Hamburg, focusing on the evaluation of alternative material combinations for oxygen lines in the A380 aircraft, among other tasks. The narrowness of the engineering tasks and a growing awareness of environmental issues, however, eliminated this option for work in the future. When it came to writing my diploma thesis, therefore, I was looking for a topic at the crossroads of engineering and environmental issues in the broadest sense - in a research environment. It was during this time, in late 2011, that I contacted Mattias Lindahl and Tomohiko Sakao at Linköping University (LiU). They first became the supervisors of my diploma thesis, for which I spent seven months researching at LiU in 2012, and subsequently, the supervisors of my doctoral research. In my diploma thesis, I focused on the complexity of the value capture of PSS providers and developed a method to evaluate the potential of different product and service components regarding this (see Matschewsky, 2012). 
I was able to return to Linköping and commenced my Ph.D. studies in February of 2014. As most Ph.D. candidates at Linköping are externally financed, this was also the case for me. For $25 \%$ of my time, I was financed by the research school of the Department of Management and Engineering at LiU, while the remainder was split over a number of projects. This circumstance meant that finding a consistent focus for the research to be conducted was challenging at the start. I came in at the beginning of the last year of a three-year collaboration with Navitas. This collaboration was focused on evaluating the implementation of a PSS design method into the company's existing processes. Within this project, I very soon became the principal researcher, spending time at the case company on an almost weekly basis, conducting interviews and workshops. I was further a member of the VINNOVA-financed research projects KEAP and ÅterProdukt from the start of the research journey. Both projects were focused on remanufacturing and the use of product lifecycle data. In the scope of this, I investigated the status quo of the design processes for both product sales and PSS offerings in different companies. A particular focus lay on information exchange between practitioners in the design stage and in remanufacturing. The work with Navitas was presented in a confidential report. Further, the data gathered at Navitas was published in conference publications and a journal article ${ }^{12}$. Data gathered in KEAP and ÅterProdukt was used in a conference publication and a journal article.

As the end of the collaboration with Navitas was drawing near, a new direct collaboration with Levor was established. Here, my foci were customer and provider value in offering PSSs as compared to traditional product sales offerings. My involvement in the collaboration commenced with a series of interviews in late fall of 2014. The work also involved a study focused on lifecycle costing carried out by other researchers. As this pre-study was considered successful, a more extensive collaboration was agreed upon in 2015, and Levor would remain the primary source of financing for my research as well as my primary study object for the remainder of my Ph.D. journey. In this, my focus remained on customer and provider value. However, based on the extensive collaboration and close connection to a large number of engineers and managers, the expansion of Levor towards PSSs became a central research focus. Several project reports were produced as the project progressed, all of which fell under confidentiality agreements. The data gathered in the course of both project parts was used in conference and journal publications.

Towards the end of the Ph.D. journey, as the collaboration with Levor ended in 2018, I became affiliated with the Mistra REES project. Although I did not participate in data-gathering efforts in this project except on a few occasions, I did coordinate a central publication effort within the project, which resulted in a journal manuscript currently under review.

\footnotetext{
${ }^{12}$ All references in this subchapter regarding Navitas and Levor are redacted to ensure their anonymity. For details, please see Chapter 1.5.1.
} 
My Ph.D. education, however, goes beyond the efforts within the main research projects I worked in. As a result of a master's thesis I supervised, data was gathered and a third case company, Ericsson, came into the picture. Results from these works were utilized in a conference (Matschewsky et al., 2016) and a journal publication (Matschewsky et al., 2018b). I was further able to secure funding to develop a handbook directed towards Swedish businesses detailing the use of the provider value evaluation method developed (Matschewsky et al., 2015b, 2018b; Matschewsky, 2018) - an important step to increase the spread of new knowledge to those actually able to put it to use. I have also endeavored to broaden my research focus and the base of co-authors I work with. This resulted in a journal publication in collaboration with a peer from Beihang University (Sakao et al., 2017), a value-centric conference publication with peers from Bergamo (Rondini et al., 2018) and a conceptual and exploratory publication expanding the PSSs concept beyond products and services developed with a dear colleague (Kanda and Matschewsky, 2018). Lastly, the opportunity to contribute to the discussion on the potential contribution of PSSs as a circular business model within a CE arose. This was based on the extensive understanding gained of the status quo of PSS design and provision at Levor. Comparing these processes with a framework detailing enablers of resource reduction, and ultimately, discussing the prospect of PSSs potentially contributing to absolute decoupling between economic growth and resource consumption, was the goal.

Overall, it is the sum of these experiences that make a Ph.D. journey what it is a winding path with seemingly dead ends, surprising turns, and unexpected roadblocks. Regardless, the goal of a thesis is to present a coherent overview. For that reason, substantial parts of the research journey cannot be represented and reflected upon in this book. Instead, the target was to present a focused account of scientific value and relevance for fellow researchers in the field. The approach and methodology towards this are presented in the following subchapter.

\subsection{Research Approach}

The results discussed within this thesis were attained primarily based on the interplay of an exploratory and a prescriptive research approach. The research approach and connections between the different foci are shown in Figure 4.

The research presented has a prescriptive aim, as it intends to support manufacturing companies in the expansion to the design and provision of PSSs. However, fulfilling this prescriptive aim necessitates prior exploration. In order to meaningfully recommend courses of action to overcome challenges and to make use of extant opportunities, first, these challenges must be known and understood. Therefore, before prescription comes exploration in order to ensure that the solutions provided match the challenges occurring. 


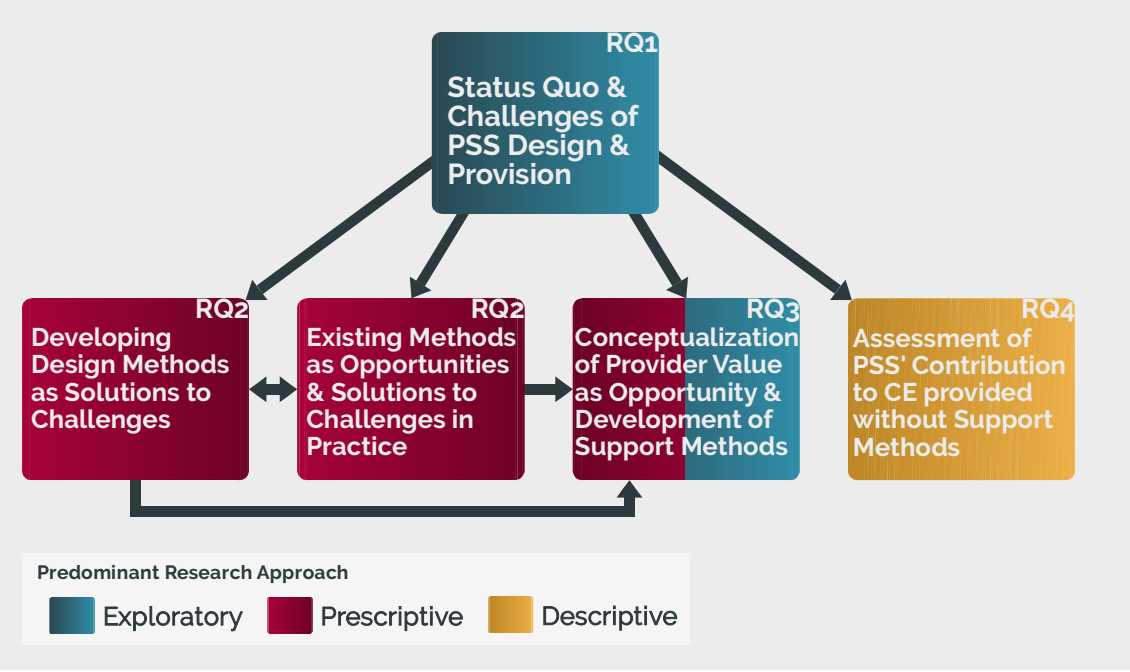

Figure 4: Research approach and connection between research foci

Patton (2002, pg. 193) describes exploratory research as relevant to "[...] new fields of study where little work has been done, few definitive hypotheses exist, and little is known about the nature of the phenomenon [...]"'. Although PSSs are becoming a mature field of study based on over two decades of research, much still lies in the dark. Exploratory work was particularly needed in order to understand the status quo of how PSSs are designed and provided in manufacturing industry practice towards Publications 1 and 2 in response to RQ1. Further, understanding the necessity and possible impact of the changes in value capture when considering PSSs instead of product sales required empirical exploration of that topic. However, in the prescriptive research towards Publication 3 in response to RQ2 also lies some exploration with respect to requirements of method users collected empirically and the method characteristics.

The prescriptive aspects of the research are connected to methods intended to provide solutions to the empirically identified challenges. In the research carried out, this includes the identification and recommendation of existing methods, prescriptive guidance on how design methods should be developed, and the development of methods to support the design and provision of PSSs with respect to a specific challenge.

A third aspect of the research approach adopted is the descriptive work carried out towards answering RQ4 through Publication 5. This research is differentiated from the remaining work, as it is focused on a single topic and evaluates empirical data narrowly based on a preexisting framework.

The exploratory results in Publications 1 and 2 provide insight towards answering RQ1. Herein, Publication 1 reports early findings and observations at the case companies Navitas and Levor. This publication was motivated by results attained early in the research journey: The research on provider value in PSS towards the 
diploma thesis was conducted as desktop research. There was a considerable surprise when commencing empirical research and understanding that neither of the studied companies actually carried out what a researcher would describe as PSS design with a lifecycle perspective. This fueled the more detailed study into both case companies reported in Publication 2. Together, the two studies provide comprehensive insight into the PSS design and provision of the case companies and constitute the exploratory status quo in response to RQ1. In view of this, RQ1 also serves as the point of departure towards fulfilling the aim of the research in supporting the effective and efficient design and provision of PSSs.

The prescriptive results of Publications 1, 2 and 3 serve to answer RQ2. This research question is directly fueled by the challenges and gaps reported as an outcome of RQ1. Directly responding to the challenges found in the manufacturing industry, existing methods and general approaches towards meeting them are pointed out in Publications 1 and 2. However, an overall weakness of these methods emerged: Although many were available, they appeared to be infrequently used in practice. Thus, Publication 3 provides a prescriptive outcome for answering RQ2 through a structured method for the user requirements-oriented development of such methods. Therefore, the gaps and challenges found as a result of RQ1 are filled not only directly, as that may restrict the applicability of the result to the case companies involved. Instead, the overall method proposed allows tackling the challenges of PSS design and provision across the board, with the opportunity to provide solutions to challenges outside the results of RQ1. Thus, a contribution is made to supporting the design and provision of PSSs at large, both by pointing out methods to solve challenges and by endeavoring to improve the development and selection of such methods in a general sense.

The results attained through Publication 4 serve to answer RQ3. These results have both exploratory and prescriptive characteristics. In the exploratory portion, differences between the value capture through product sales and PSSs are elaborated on based on the theoretical background in the field. This again establishes a point of departure for prescriptive support. The understanding of the case companies' value capture considerations in the design and provision of PSSs, resulting from RQ1, indicated a need for support throughout the lifecycle. Thus, two prescriptive methods are proposed to analyze the current PSS-based value capture in the use phase and to act upon lessons learned in the design phase. Towards the overall research aim, both the understanding of provider value and the facilitation of its use in practice serve to support the effective and efficient design and provision of PSSs.

The results of Publication 5 provide a response to RQ4. Driven by the status quo as laid out based on RQ1, this research carried out a countercheck against the results of RQs 2 and 3 by asking: What if frameworks and methods are not used? This question is answered using a descriptive approach by reflecting on the lessons learned based on RQ1 with respect to an existing framework to assess ways PSSs can contribute to a CE. This provides important insight for academics and 
practitioners concerning both the possible impact of PSSs within a CE and the role methods play in this context. Again, progressing to a prescriptive focus, improvement possibilities are pointed out. These are relevant to the case at hand but may serve to support other manufacturing companies as they strive to expand to design and provide PSSs effectively and efficiently.

\subsection{Overview of the Research Methods Employed}

In gathering data, qualitative methods were used almost exclusively. This was due to the extensive amount of interaction with practitioners in different companies, which primarily occurred in the form of interviews and focus group workshops. However, the data gathering was informed by literature reviews of varying extent, and semi-quantitative questionnaires and a survey added depth to the information collected. The account below is restricted to methods central to the results reported and discussed in the following sections. For a detailed account, the reader is referred directly to the appended publications. To provide an overview, Table 2 lays out the research questions, the publications contributing to answering them, and the research methods used to that end.

Table 2: Research questions, related publications, and methods used

\begin{tabular}{|c|c|c|}
\hline Research Question & Main Appended Publication(s) & Methods Used \\
\hline $\begin{array}{l}\text { - How have manufactur- } \\
\text { ing companies adjusted } \\
\text { their design and provision } \\
\text { to product-service systems? }\end{array}$ & $\begin{array}{l}\text { Publication } 1 \text { (PSS without PSS } \\
\text { Design) } \\
\text { Publication } 2 \text { (Designing and } \\
\text { Providing PSS) }\end{array}$ & $\begin{array}{l}\text { - Literature review } \\
\text { - Interviews (Partly sup- } \\
\text { ported by Actor Maps) } \\
\text { - Focus groups }\end{array}$ \\
\hline $\begin{array}{l}2 \text { - How can methods facili- } \\
\text { tating the effective and effi- } \\
\text { cient design and provision } \\
\text { of product-service systems } \\
\text { be developed and applied? }\end{array}$ & $\begin{array}{l}\text { Publication } 1 \text { (PSS without PSS } \\
\text { Design) } \\
\text { Publication } 2 \text { (Designing and } \\
\text { Providing PSS) } \\
\text { Publication } 3 \text { (Development and } \\
\text { Selection of Design Methods) }\end{array}$ & $\begin{array}{l}\text { - Literature review } \\
\text { - Interviews } \\
\text { - Survey } \\
\text { - Focus groups }\end{array}$ \\
\hline $\begin{array}{l}3 \text { - How can the value cap- } \\
\text { ture through product-ser- } \\
\text { vice systems be supported } \\
\text { throughout the lifecycle? }\end{array}$ & $\begin{array}{l}\text { Publication } 4 \text { (Capturing and En- } \\
\text { hancing Provider Value in PSSs) }\end{array}$ & $\begin{array}{l}\text { - Literature review } \\
\text { - Interviews (partly sup- } \\
\text { ported by provider value } \\
\text { analysis) } \\
\end{array}$ \\
\hline $\begin{array}{l}4 \text { - In what ways can eco- } \\
\text { nomically-driven, unsup- } \\
\text { ported expansions to } \\
\text { product-service systems } \\
\text { contribute to a circular } \\
\text { economy? }\end{array}$ & $\begin{array}{l}\text { Publication } 5 \text { (Inadvertent Circu- } \\
\text { larity? PSSs Towards a Circular } \\
\text { Economy) }\end{array}$ & $\begin{array}{l}\text { - Literature review } \\
\text { - Interviews (partly sup- } \\
\text { ported by Actor Maps) } \\
\text { - Focus groups }\end{array}$ \\
\hline
\end{tabular}

\subsubsection{Literature Reviews}

Literature reviews were conducted continuously throughout the research journey, serving as a point of departure for a writing effort, and later, as a point of reflection when discussing the results, their novelty and possible impact. In all 
publications and towards answering all research questions, literature reviews were highly relevant.

\section{Initial review}

An initial review was conducted to arrive at a broad overview of the field of PSSs and other relevant areas (integrated product-service offerings, functional sales, servitization, etc.), engineering design, and engineering design methodology. The review was extended continuously throughout the research process and in accordance with the changing requirements as the work progressed. With respect to Patton's (2002) differentiation, this initial review is considered to be broad. Due to the extensive time frame of this search, a large amount of literature was scanned, diving deeper in case relevant information was discerned (see Yin, 2013). Using categorization options, scientific work deemed interesting was cataloged using the Mendeley reference management software. As the Mendeley software allowed searches directly in the full-text PDFs and based on the set categorization, this approach provided an efficient basis for future searches during the paperwriting process. This is because it rendered repeated extensive searches in webbased engines, including skimming a mass of irrelevant information, almost unnecessary. A disadvantage of this can be that new knowledge can be overlooked by relying on a local database. This challenge was resolved by the in-depth reviews described below. The initial review was mainly used for Publication 1 and provided the basis for the background provided therein.

\section{In-depth reviews}

For each of the appended publications, an in-depth review was conducted. These were narrative reviews (Onwuegbuzie and Frels, 2016) departing from keywordsearches on the relevant topics in the Scopus database as well as, due to its comprehensiveness, Google Scholar. The identified publications were then checked based on their titles and abstracts and, if deemed relevant, added to a designated folder in the author's Mendeley database. Based on the extensive database created by this approach, each publication was reviewed in-depth and critical information added into a table in a separate document. This table was then used as the basis for writing background sections for the respective publications and, as done in Publication 2, partly used to provide a condensed overview of the state of the art of the topic at hand. In the case of Publication 3, parts of the background focused on method characteristics were identified in the initial review and updated accordingly in the writing process, while the background on method user requirements stemmed mainly from a systematic review carried out by the second author of the publication, which was further updated and extended by a narrative review.

In the case of Publication 4, the search focused on the value topic, both immediately tied to PSSs, and on a broader scale. The need for a broadening beyond PSSs alone became apparent after a first, narrow search yielded few results at the beginning of the research journey, a further indication of the novelty of the field and therefore, a basis for the empirical approach taken (Yin, 2013). Thus, as laid out 
above, the scope was broadened to include the business-centric servitization literature, operations management, and literature typically located in the field of marketing. Due to the broadness of the value topic, a keyword-based search was challenging in this regard. As a result, the review departed from seminal papers such as Vargo and Lusch (2004), checking citing articles and snowballing out from there. This approach yielded a wide account of relevant literature. In recent years, the focus on value amongst researchers directly affiliated with the field of PSSs has grown, and in the course of writing the conference papers leading to Publication 4 , the theoretical basis was further expanded in this direction.

\subsubsection{Interviews and Focus Groups}

\section{Semi-Structured Interviews}

Semi-structured interviews (Flick, 2009; Miles et al., 2013) were one of the main data-gathering approaches throughout the course of the research. Interview guides of varying rigidity were used, while at times, sidetracks far outside the intended scope yielded highly interesting results (Flick, 2009, pg. 156). All interviews were digitally recorded.

\section{Focus Groups}

Nearly all focus group sessions carried out in the course of the research journey consisted of 6-10 participants (Patton, 2002, pg. 385). Especially with a focus on cost- and time-effectiveness (Krueger and Casey, 2014, pg. 5), focus groups were a format appreciated by practitioners at the case companies. All focus group sessions commenced with a presentation of the discussion topic by a researcher. A key advantage of focus groups was the presence of a number of participants with different functions and backgrounds in a room to discuss a topic from different points of view (Patton, 2002, pg. 385ff.). This enabled data gathering based on the participants' interaction with one another instead of an exclusive focus on the interaction between respondent and researcher (see Ritchie and Lewis, 2003, pg. 171).

\section{Analysis of Interview and Focus Group Data}

The interviews and focus group sessions of relevance to the results presented in this thesis were carried out with the case companies Navitas and Levor. As the data collected was spread to different publications, there is substantial overlap in the analysis, and largely identical approaches were applied.

The recordings were transcribed either fully or selectively (Flick, 2009, pg. 300), depending on the broadness of the session in focus. Where insight from both case companies was compared, pattern matching with prior knowledge and cross-case synthesis were applied (Miles et al., 2013, pg. 250f.), leading to the emergence of patterns. Where a single case was analyzed, patterns were sought in the comparison of data gathered from different individuals, as done when conducting thematic analysis (Bryman, 2012, pg. 578). The statements relevant to the identified patterns were collected and codes assigned in an effort to establish a 
categorization (Bryman, 2012, pg. 575ff.). This resulted in a table of transcribed and coded quotes. In the case of Publication 2, these were reviewed by the first and second author and clustered further (Miles et al., 2013), providing the basis of the challenges, opportunities, and solutions reported.

\subsubsection{Approaches Supporting Interviews}

Interviews carried out were at times supported and structured through additional approaches, partly explicitly developed for that purpose. In order to facilitate the description of the data gathering and data evaluation, the methods interview and focus group are combined in this subsection, due to their thematic closeness. In the following sections, the supporting approaches used to gather data efficiently and precisely will be introduced.

\section{Actor Maps}

To understand the challenges of becoming a PSS provider and carrying out PSS design, it is vital to gain insight regarding the relationships between different actors (whether individuals, groups or organizations). Getting this understanding directly from practitioners is vital, as the actual processes and connections often deviate substantially from the picture organizational charts aim to convey. Therefore, the approach first introduced in Lindahl et al. (2014a) and further extended and refined in Desai et al. (2017) was applied in some data gathering efforts. Based on their individual work situations, participants were asked to elaborate upon the way they work with integrated offerings, how information is exchanged and shared and how the entire process is organized. Actors and the information exchanged by them was drawn on a whiteboard using different colors, with the emerging map being extended and adjusted throughout the length of the workshop. The results were then digitalized using Microsoft's Visio software. The actor maps generated served to clarify the explanations of the respondents mainly with respect to PSS design.

\section{Provider Value Analysis}

Provider value analysis is a support approach developed to facilitate data gathering on this hard-to-grasp topic and to reduce the inherent challenges of gathering qualitative data through the interview method. To facilitate respondents' understanding, the method takes its departure in customer value, as practitioners are often familiar with the concept (Sakao and Shimomura, 2007), which means that comparative insight on customer value in addition to provider value can also be gathered using this approach.

Through the structured approach, value dimensions for both customer and provider value are identified for later use as evaluation characteristics in the design stage with a focus on designing for value. Figure 5 shows the data-gathering document for provider value analysis. Note that this is a concise description; please see Publication 4 for a more detailed account of the approach's process (Matschewsky et al., 2018b, pg. 5). 


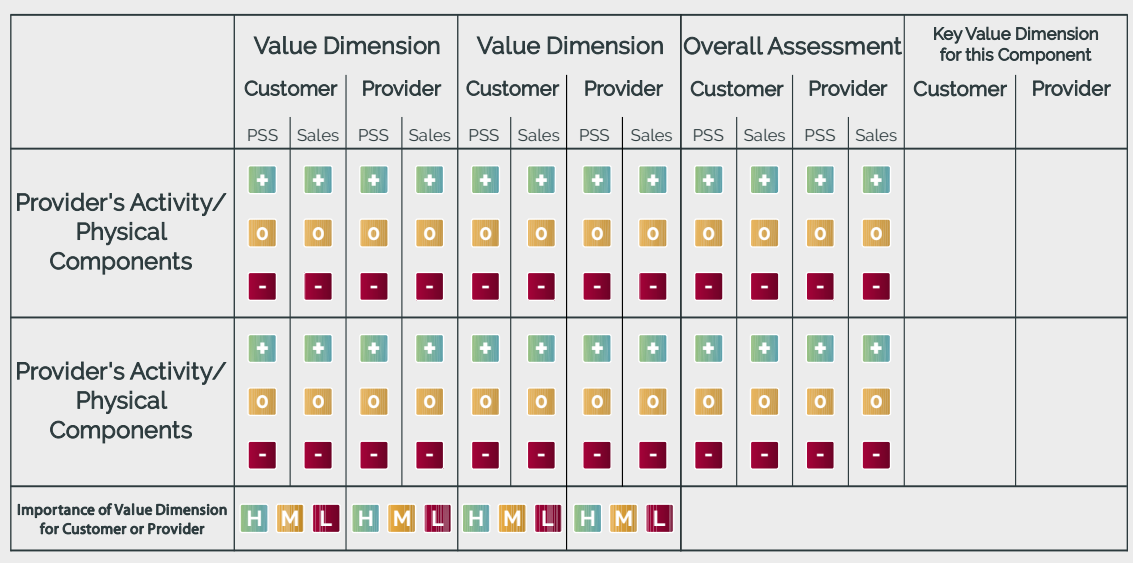

Figure 5: Data-gathering document for provider value analysis (Matschewsky et al., 2018b)

As a result of applying provider value analysis, the following data was collected from all respondents: value dimensions for a provider's value capture for PSS and traditional product sales, the importance of the identified dimensions and the relation between components, services/activities, and the identified dimensions.

As a result of the interviews conducted, provider value analysis yielded a large number of value dimensions. In the empirical work carried out, the value dimensions were clustered through pattern matching (Miles et al., 2013, pg. 250) and thematic analysis (Bryman, 2012, pg. 578). Further, as provider value analysis was used to support semi-structured interviews, the overall data analysis approach used there applies.

\subsubsection{Questionnaire and Survey}

\section{Questionnaire}

A questionnaire was used to gather data in a concise fashion without affecting the actual interview process. As Flick (2009, pg. 164) points out, "[a] questionnaire will allow you to collect data [...], which [is] less relevant than the topics of the interview itself before the actual interview”.

Towards Publication 4, a questionnaire was used to take account of the respondents' understanding of value prior to an interview. Here, this approach was taken to adjust the focus of the actual interview according to the prior knowledge of the respondents, and therefore to ensure an efficient interview process. The questionnaire was sent to each participant three days in advance of the interview and consisted of open-ended questions as well as questions using a five-point Likert scale.

A further paper-based assessment was used during the interview for respondents to rate the relevance of the identified provider value dimensions to the design of PSS on a five-point Likert scale, as reported in Publication 4. 


\section{Analysis of Questionnaire Data}

The data gathered through the paper-based assessment was recorded in a spreadsheet. An average was calculated with respect to each evaluation category to provide an at-a-glance overview to the reader.

\section{Survey}

In the context of qualitative research, surveys are often used to structure data (Given, 2008, pg. 846). Within Publication 3, a web-based survey was used to collect information on the importance of user requirements on design methods. A Likert scale from o to 5 was applied in this case, with an additional option of "I do not know", and the practitioners evaluated the requirements, which were identified based on from a literature review and subsequent interviews, on that scale.

\section{Analysis of Survey Data}

All survey data was collected in a spreadsheet. Based on the raw data, average values and standard deviations were calculated for each user requirement. Based on the averages and standard deviations, the most relevant user requirements on PSS design methods were isolated.

\subsection{Methodologies to Answer Research Questions}

\section{RQ1 - Exploring PSS Design and Provision in Manufacturing Companies}

Figure 6 provides an overview of the methodology for answering RQ1.

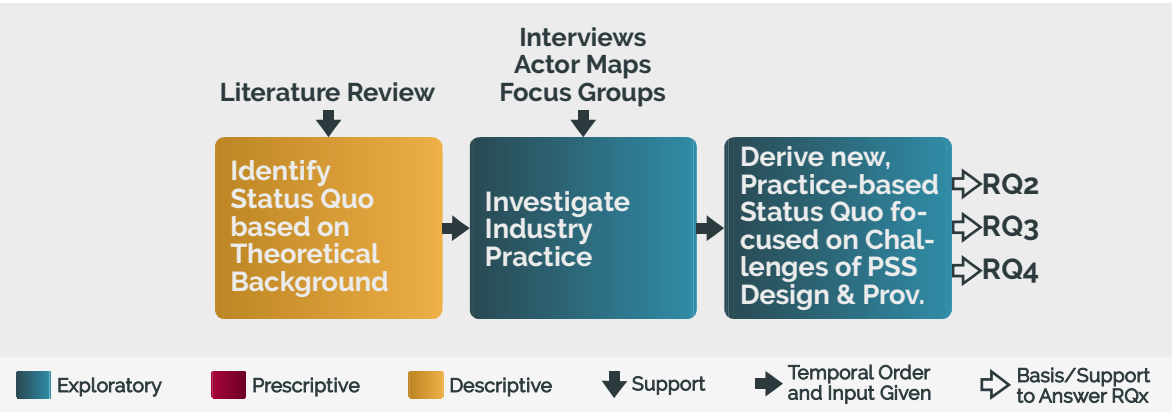

Figure 6: Methodology towards answering RQ1

RQ1 is focused on investigating the expansion of manufacturing companies towards becoming providers of PSSs and the challenges these companies experience during the expansion and through PSS design and provision. The response to this research question is informed by both the initial literature review carried out and focused reviews for Publications 1 and 2. Extensive empirical research was conducted to gain a comprehensive overview of PSS design and provision in practice and challenges therein. This was also presented in Publications 1 and 2. 
Actor maps workshops were carried out with five design-focused participants at case company Levor, delivering insight into the actual processes of design and provision of PSSs. This data-gathering effort also led to an understanding of the interaction of designers with actors throughout the lifecycle. Twenty-two semistructured interviews with staff from design, sales, management, service, etc. provided in-depth insight regarding the design and provision throughout the entire lifecycle of PSSs at the company.

Two semi-structured interviews carried out with case company Navitas provided insight with respect to design processes currently in use. Four focus group sessions at Navitas - only intended to disseminate project results involving practitioners in product design, service design, and management - provided a large amount of data with regards to challenges in Navitas's expansion towards PSSs.

The empirical research conducted was consolidated to provide a comprehensive overview of the challenges of PSS design and provision of the case companies.

The primary analytical frames for the research towards RQ1 are PSSs, PSS Design, and Servitization-literature.

\section{RQ2 - Developing and Applying Methods Supporting the Design and Provision of PSSs}

Figure 7 indicates the methodology applied to answer RQ2.

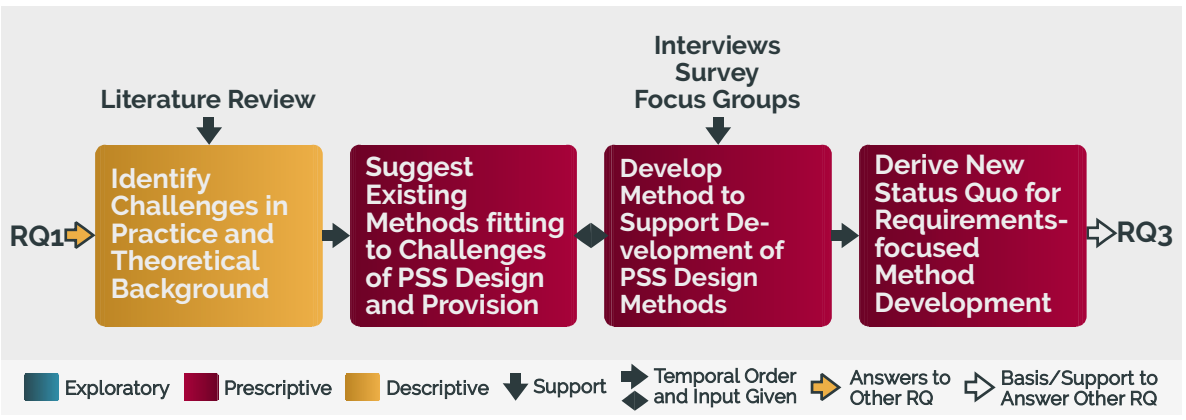

Figure 7: Methodology towards answering RQ2

As the results of answering RQ1 fed into the research towards this RQ, the respective methods applied therein are not reiterated here.

Solutions to the challenges identified towards RQ1 in the form of existing prescriptive methods suggested in Publications 1 and 2 were isolated based on a prior literature review and as a result of the extensive empirical work with the companies Levor and Navitas.

Subsequently, an effort was made to propose a prescriptive method to support the development of methods aiding the design of PSSs as reported in Publication 3. Lessons learned based on the development of own prescriptive methods motivated and fed into this process. To ensure that the method to be developed would 
meet the needs of practitioners (users) and method developers alike, extensive empirical research was undertaken.

Practitioner requirements on design methods were initially identified through an extensive interview study. Based on a literature review, interview questions were formulated focused on requirements for design methods supporting PSS design. Interviewees were selected based on their experience in product or service design. The 24 respondents had various backgrounds and worked in companies ranging from small and medium-sized enterprises all the way to international corporations. An overview of the respondents can be found in Publication 3, Table 1 (pg. 9). Follow-up meetings were then held with representatives from all eight companies to further extend and solidify the requirements.

Two focus group workshops were used to evaluate and expand the method characteristics identified and to attempt establishing correlations between design method characteristics and practitioners' requirements by way of an approach based on quality function deployment (QFD, see Akao, 2004). An overview of the participants can be found in Tables 2 and 3 in Publication 3 (pg. 10-11). The classic focus group format was applied, while the quorum of at least six participants could not be reached in this case. The format was further adjusted from a reliance on an interview guide and a strong moderator role to a nearly entirely discussionbased format centered around the QFD-style document provided to all participants. This structure, however, made way to a broader, more active discussion among the participants of both workshops, albeit with different foci. The interaction shifted towards reasoning and discussion between the participants, particularly regarding the method characteristics.

The primary analytical frame for RQ2 is literature on PSS design, while ecodesign and overall engineering design also play a role. Research focusing on resource efficiency and effectiveness of PSSs is further of relevance.

\section{RQ3 - Conceptualizing and Supporting Provider Value in PSS Design and Provision}

Figure 8 indicates the methodology applied to answer RQ3.

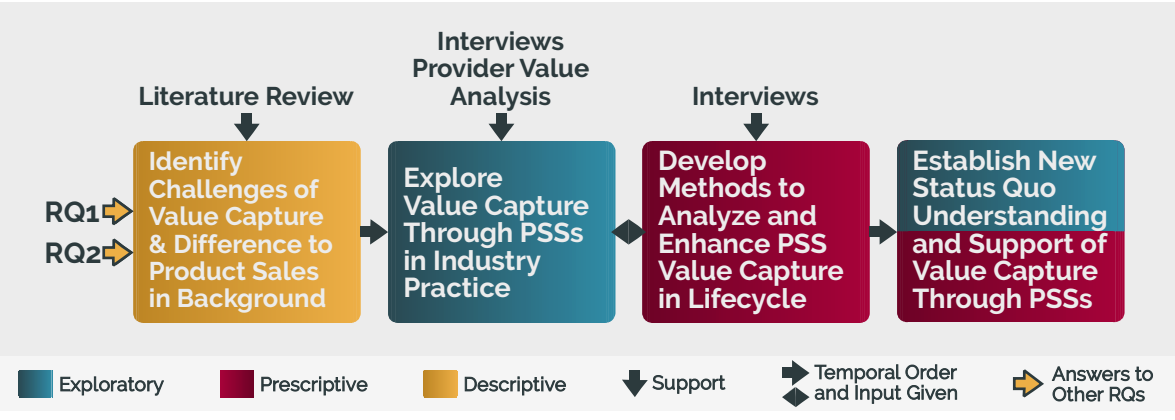

Figure 8: Methodology towards answering $R Q_{3}$ 
A literature review focused on value in the field of PSSs, but also operations management, marketing, and other business-centric fields, informed the research. Further, the understanding attained based on the outcomes of the work in RQs 1 and 2 provided the background and motivation for this research.

The exploratory research towards gaining an understanding of the value capture through PSSs in practice and the prescriptive goal of providing methods to analyze and enhance this method as reported in Publication 4 were closely connected. Provider value analysis, one of the central approaches to gather data, was developed in the course of the descriptive research and improved throughout.

Provider value analysis was applied to support the interviews in an effort to explore the current value capture of case company Arantius ${ }^{13}$ under the involvement of seven practitioners in sales and service. All sessions were held by the author and one of the co-authors of Publication 4. At Ericsson, this data gathering with ten practitioners in service, sales, and research was carried out by master's thesis students. However, the author instructed the students in the use of the approach and supported in reflecting upon the data attained before moving on to additional data gathering sessions.

Subsequently, twelve semi-structured interviews focusing on provider and customer value were held at Arantius. These fed mostly into the conceptualization of PV and its empirical background as indicated in Publication 4. For some of these sessions, the author was the sole researcher present. All interviews were based on an interview guide, which was tested with a peer and discussed with a principal representative from the case company prior to the commencement of the interview study. All of these interviews were preceded by a web-based questionnaire.

Further, an assessment of the relevance of value dimensions identified earlier through provider value analysis was carried out by the respondents, and the applicability of the provider value evaluation method in the scope of PSS design was discussed. All interviews were digitally recorded. The manuscript of Publication 4 was reviewed by a company representative prior to submission.

The primary analytical frames for the results reported towards RQ3 are value-centric literature from the fields of PSSs, servitization, marketing, and operations management.

\footnotetext{
${ }^{13}$ Pseudonym used exclusively in Publication 4, refers to the same case company as Navitas or Levor, while the exact relation cannot be disclosed. For details, please see Chapter 1.5.1.
} 


\section{RQ4 - Potential CE-Contribution by PSSs Without Methods or Frameworks}

Figure 9 indicates the methodology applied to answer RQ4.

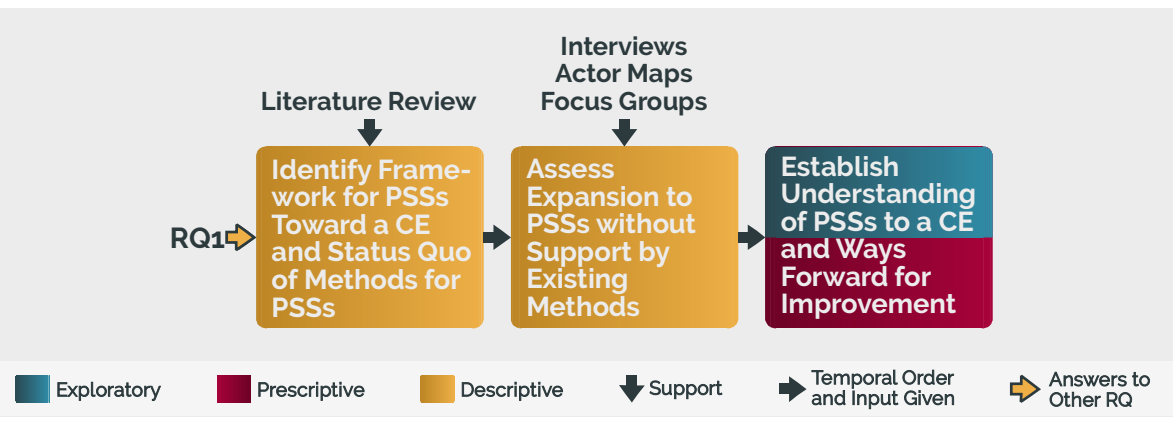

Figure 9: Methodology towards answering RQ4

Publication 5, on which the answer to RQ4 is based, utilized and partly revisits data gathered at case company Kamiono ${ }^{14}$ over the span of over four years.

First, an extensive literature review focusing on the relevance of PSSs as a circular business model was performed in order to achieve an understanding of the theoretical background where the intersection of both fields is concerned.

The comprehensive picture of Kamiono's expansion to the design and provision of PSSs is partly based on empirical data informing RQ1, which was expanded with further data gathered through semi-structured interviews and focus group meetings. However, in order to maintain the anonymity of the case company, please refer to Publication 5 to attain a full understanding of the sources of data and analysis thereof.

The comprehensive understanding of Kamiono's PSS design and provision is analyzed through the structure provided by Kjaer et al.'s (2019) framework to examine the potential contribution of a PSS towards a CE. This is done separately with respect to the relative resource decoupling expected based on PSS strategies towards a $\mathrm{CE}$ and the prospect of a contribution to an absolute decoupling of economic growth and resource use.

\subsection{Quality of the Research}

Assessing the quality of qualitative research is challenging and the subject of extensive investigations (see Denzin, 2012; Glaser and Strauss, 1967; Patton, 2002). In this subchapter, therefore, the research process, method application, and results reported will be examined. This is done to provide insight into how an effort

\footnotetext{
${ }^{14}$ Pseudonym used exclusively in Publication 5, refers to the same case company as Navitas or Levor, while the exact relation cannot be disclosed. For details, please see Chapter 1.5.1.
} 
was made to ensure and develop the research quality through the research journey and to make clear the shortcomings of the work presented.

As Bryman (2012, pg. 389ff.) lays out, some researchers have argued for criteria such as validity and reliability to be adopted from quantitative research for application in the area of qualitative research without much adjustment at all (Mason, 2002). In contrast to this, other scholars have argued for a very different treatment of qualitative studies due to their substantially different nature compared to quantitative research. Examples of this are the criteria of trustworthiness and authenticity as proposed by Lincoln and Guba (1985). A further summary of criteria to assess quality and credibility of qualitative research are the triangulation-approaches to validity and reliability laid out by Patton (2002, pg. 555ff.).

Hereafter, those two concepts are combined to elucidate the efforts taken to ensure the quality of the research. Thus, the trustworthiness-criteria credibility, transferability, dependability, and confirmability introduced by Lincoln and Guba (1985) as represented by Bryman (2012, pg. 39off.) are used as the overall structure. Triangulation, as described by Patton (2002, pg. 556ff.), is used to enhance the assessment of credibility in particular. Here, method, sources, analyst, and theory triangulation are considered. A similar approach has been used in Kanda (2017) to discuss research quality.

\subsubsection{Credibility}

Credibility, which Bryman (2012, pg. 390) links to internal validity - referring to the link between the data gathered and the concepts and theories developed based on these - outlines the feasibility and credibility of the account of reality presented by the researcher. Further, credibility is determined by (1) whether the research was carried out according to the standards of the field, (2) adequately scrutinized according to the existing norms, and (3) whether the subjects of the study agree with the findings and conclusions drawn based on these. It is, therefore, meaningful to apply the aspects of method triangulation, sources triangulation, and analyst triangulation (Patton, 2002, pg. 556ff.) to the research when investigating the credibility of the research results.

The results reported in the appended publications are to a substantial degree based on data gathered through interviews and focus group workshops. In order to ensure appropriate respondent validation (Bryman, 2012, pg. 390), all of the publication manuscripts were provided to participants of these data gathering efforts prior to submission to check the accuracy of the representation of the results and to ensure the case companies' confidentiality. Further, in the direct collaborations with the two companies Navitas and Levor, of which data is used in all appended publications except Publication 3, continuous confidential reports were provided to company representatives and leadership, giving them the opportunity to reflect upon and correct their contents. 
As these confidential reports constituted part of the basis from which Publications 2, 4 and 5 were later developed, this step may enhance the credibility of the results. In addition, many of the focus group workshops and some of the interviews were directly followed up by meeting minutes provided to company representatives, giving the opportunity for corrections. Additionally, direct quotes constitute a substantial part of the results reported in Publications 2 and 3 and a minor one in Publication 4. This openness allows the respondents involved in the data gathering to check whether they have been misrepresented easily. Further, direct quotes support the reader of the publications in passing an informed judgment regarding the relevance of the reported data to their own situation and, even more so, whether the claims made based on the data are credible.

Method triangulation was applied to different degrees in all publication efforts to increase credibility. Although mixed methods in the sense of combining qualitative and quantitative approaches were rarely used, in any case, different qualitative methods were applied in all instances. Every writing effort was preceded by a literature study to ensure an in-depth understanding of the state of the art. Different methods of data gathering were then employed in all cases, with the support methods facilitating data gathering in interviews and focus group sessions further enhancing the quality of the data collected. Semi-quantitative approaches have been applied in the form of questionnaires and a survey, providing additional depth to the qualitative results attained and making these more tangible. This constitutes a mixed-methods approach (Given, 2008, pg. 526) particularly in Publication 3.

Sources triangulation was a vital aspect of the research conducted and central to all appended publications. Within the case companies, respondents with a broad set of backgrounds (engineering, project management, business development, service and maintenance, sales, etc.) participated in the data-gathering efforts. The roles of all respondents are presented in detail ${ }^{15}$ in Publications 2-5 in order to ensure transparency. This allows for an evaluation of whether the empirical basis is sufficiently broad to justify the conclusions drawn based on it. Further, publications 1-4 use data gathered with at least two case companies each, leading to multifaceted results foregoing unrealistic coherence in the outcomes reported.

Analyst triangulation was a key focus during the research process, and in this respect, the work presented has shortcomings. While for all focus groups, two researchers were present, a number of interviews reported in Publications 2, 4, and 5 were conducted by the author alone, due to a lack of staff. In the case of Publication 2, this could be offset by additional interviews conducted by the second author being used, joint assessment of all data gathered by the first and second author, and close coordination with a key practitioner from one of the case companies. Additionally, the backgrounds of the first and second author of Publication 2 differ, one focused on engineering and the other centered on management,

\footnotetext{
${ }^{15}$ As far as the confidentiality agreements with the case companies allow, that is.
} 
leading to broader perspectives. With Publication 3, the focus group sessions were held with all four authors present, while only the first author analyzed and transcribed the recordings.

Theory triangulation is a typical characteristic of practice-oriented research on PSSs. One might interpret the broadness of theories and concepts being applied in this concept as lacking focus, but the author sees this as a sign of comprehensiveness and awareness of the complexity of the real-world provision of productservice offerings with a lifecycle perspective. This is needed in transdisciplinary research (Sakao and Brambila-Macias, 2018). In the appended publications, theoretical backgrounds from engineering design, marketing, PSSs, PSS design and literature on a $\mathrm{CE}$, among others, are used to establish a frame of reference and to understand and investigate the servitization of manufacturing companies as well as the associated phenomena described.

\subsubsection{Transferability}

Bryman (2012, pg. 392), quoting Lincoln and Guba (1985, pg. 316), describes the dilemma of transferability in qualitative research as follows: "Whether findings hold in some other context, or even in the same context at some other time, is an empirical issue." Adjusted to the topic at hand, one could replace the word context in this quote with the word company to immediately be presented with an accurate description of the challenges of case-oriented research. Thus, where Bryman (2012, pg. 392) requires "rich accounts of a culture," here, these are rich accounts of a manufacturing company. Therefore, transferability of the results reported in the appended publications was ensured in that way: Publications 2, 4 and 5 contain detailed descriptions ${ }^{16}$ of the case companies, and their fields of business, with Publication 2 even presenting a detailed comparison of the two companies, their individual situations, and servitization progress.

The intention is to allow readers to make judgments regarding the applicability of the results presented to their individual situations. Further, the detailed reporting of the individuals involved in the data gathering allows readers to evaluate the relevance of the circumstances reported, e.g., in the form of direct quotes, to the circumstances at their own companies or the relevance to their topic of study. Publication 1 falls short in this respect, as it lacks the detail needed to conclusively judge the transferability of the results, a deficiency intended to be remedied by the level of detail sought in the follow-up Publication 2. Publication 3, aiming for broad relevance from the outset, draws its transferability from the extensive work providing the basis of the research, including literature studies in various fields, interviews, a survey and focus group sessions. This allows academic readers to judge the relevance of the proposed method to their own situations and for

\footnotetext{
${ }^{16}$ As far as permitted by the confidentiality agreements with the case companies.
} 
practitioners, the broadness of individuals involved in the empirical data gathering may indicate the relevance of the outcome to their respective work environments.

\subsubsection{Dependability}

Bryman (2012, pg. 392), drawing on Lincoln and Guba (1985), illustrates how the dependability of qualitative research could be solidified using an auditing approach. This would mean that all data acquired is submitted to peers for external review and scrutiny, a procedure for which there is hardly any evidence in practice due to its time-consuming nature (ibid.). While all data gathered has been retained, such an all-encompassing external evaluation of the research work has not been performed and would have been impossible due to the requirements of confidentiality in the collaborations with manufacturing companies.

However, a number of measures were taken to enhance the dependability and openness to scrutiny of the research reported. This was done primarily to follow the triangulation approaches described above. Further, research results were presented at international scientific conferences to receive feedback on the studies. Lastly, all publications including the empirical data reported, a detailed description of the methods applied, and the conclusions drawn have undergone peer review by at least two reviewers and have been revised at least twice on that basis. Publications 2 and 4 have undergone peer review in esteemed scientific journals by three reviewers each before being accepted for publication, while Publications 3 and 5 are under review or submitted, respectively.

\subsubsection{Confirmability}

According to Bryman (2012, pg. 393), a focus on confirmability aims to ensure that a researcher has acted in good faith and was not unduly influenced by personal values and individual preferences concerning theory. In the case of this research, this constitutes a challenge for various reasons.

Firstly, the research was, for the most part, directly financed by the case companies that were the objects of the empirical work and, exacerbating this fact, confidentiality agreements had to be signed, and all publications were to be confirmed by the project members. A sincere effort was made by the author to overcome this challenge: Although some level of commitment to the case companies is inevitable based on the extensiveness of the collaboration, a professional distance and reflexivity was the aim at all times.

Secondly, the company representatives checking the manuscripts to be submitted for publication laid their focus on ensuring the anonymity of the case companies, and it can be said with confidence that no information the case companies may consider to be unflattering was suppressed in any way. 
Thirdly, the funding received from the case companies was acknowledged in each of the publications where this applies, ensuring full transparency for the reader.

Overall, although challenging circumstances apply in this case, extensive goodfaith efforts were taken to ensure the confirmability of the research.

\subsection{Reflexivity and Problematization}

According to Reich (2017), reflexivity concerns conducting design research in much the same way as design itself is supposed to be conducted: Using the design principles, methods, and knowledge that are made available and fit the task at hand, leading to both improved research results and, ideally, an improvement of its basis. Thus, this subchapter discusses the underlying assumptions and decisions at the basis of the research conducted, their impact on its outcome, and, in hindsight, room for improvement.

\subsubsection{The Impact of Research Design and Methods}

The choice of method must have an impact on the data gathered and therefore, the depiction of reality provided by a work of qualitative research. As much as a traditional photo camera records neither sound nor movement, the methods of data gathering employed in the scope of this research work have limitations and an impact on the results presented.

An initial challenge, as laid out at the beginning of this chapter, was the lack of a clear focus and direction for the research. Departing from provider value and its impact on PSS design, the broader focus on the servitization of manufacturing companies emerged organically and over an extended period of time. This meant that the data gathering early-on in the research process lacked depth in that direction, and as research projects were finalized, there was no opportunity to return to the practitioners encountered at the time to acquire additional information.

With a focus on interviews and focus group sessions, a number of challenges demanding reflection present themselves: The interviews held at the case companies can be considered expert interviews as described by Flick (2009, pg. 165). A major challenge in this instance is finding the "right" expert to interview (Flick, 2009, pg. 168) or include in a focus group workshop, a question particularly critical as these experts are often regarded as representatives of other practitioners with similar focus when reporting the research results. This was a substantial challenge particularly with case company Levor, where initially a top management representative was tasked with identifying relevant respondents.

After several months, the task was relocated to an engineering practitioner, and an extensive meeting involving two researchers and the individual was held detailing and sharpening the data-gathering requirements. Based on this, highly engaged and relevant individuals could be identified. Again, this poses a further 
challenge, as these individuals may not be entirely representative of other practitioners with similar roles within the case company.

Time restrictions, as remarked by Flick (2009, pg. 165), posed a further problem. Some highly relevant respondents declined repeated meeting invitations; some interviews had to be cut short, and follow-up meetings could only be held in very few cases. Flick (2009, pg. 165) further mentions the problem of confidential issues being raised: Due to non-disclosure agreements being signed, this did not present any notable challenges in the case of this research, and it can confidently be said that the respondents shared in-depth knowledge and provided great detail regarding possible day-to-day challenges experienced. This was clearly driven by the motivation of the practitioners to promote change and adjustments of the processes of design and provision of PSS offerings, as they were made aware of the management's commitment to the research project.

Overall, as focus group workshops were repeatedly held discussing the acquired results, and since the research outcomes were regularly presented to and discussed with top management, the accuracy and comprehensiveness of the gathered data could be warranted.

\subsubsection{Reflecting on Underlying Assumptions and Concepts}

The key assumption of the research presented is clearly this: When products and services are combined with a lifecycle perspective, the overall environmental impact generated is lower than if a product is merely sold. Hopefully, however, this thesis is making clear that both the assumption is much more complicated than this, and that achieving it in practice is a challenging endeavor. PSSs and their environmental benefits have always been the topic of intense discussion in the field (see, e.g., Corvellec and Stål, 2017; Lindahl et al., 2014b; Mont, 2002b), and the work presented here has attempted to point out some additional critical challenges for PSSs to actually contribute to a CE.

These directly lead to the next underlying assumption: The right design of PSSs is the key to their lifecycle efficiency and effectiveness. This can be interpreted as a classic chicken-or-egg problem: Is the author convinced of this because it is scientifically proven fact evidenced in manufacturing industry practice, or because he has a background in engineering design and therefore is incapable of understanding or even identifying the actual reason? An indication that PSS design actually is the right place to look can be seen in the fact that many other researchers have focused on this topic as well when trying to identify ways of ensuring improved environmental performance throughout the lifecycle of PSS offerings (see, among many others, Manzini and Vezzoli, 2003; Tukker, 2015; Vezzoli et al., 2012). Additionally, the fact that the design largely determines the performance of an offering throughout the entire lifecycle, and all following lifecycles, cannot be called into question. Further, in this thesis, PSS design is supplemented and supported by a number of other concepts, among them servitization and value. 
Lastly, particularly when focusing on the Case Company Levor, a dual focus ideally reducing the inherent personal and historical bias has emerged. There are two researchers mainly investigating Levor: As detailed when describing the research journey, a second focus lies on lifecycle costing and associated topics and is motivated by a management background rather than an engineering one. Therefore, the thesis of Marianna Lena Kambanou will contribute much additional insight to the rather engineering-centric deliberations presented here, and one may hope that both theses together will deliver a balanced account of how manufacturing companies become providers of PSSs, and how such companies can be supported to do so effectively and efficiently.

\subsubsection{Is This Action Research?}

It depends. Because of the close collaboration with manufacturing companies throughout the research journey, the examiner of the licentiate thesis preceding this dissertation (Matschewsky, 2016) suggested that the research presented can be seen as action research during the defense.

According to the definition given in The SAGE Encyclopedia of Qualitative Research Methods (Given, 2008, pg. 4), which characterizes Action Research as overlapping cycles of investigation, implementation and, result monitoring and impact analysis, the answer is "no" in case of Navitas and "not yet" in the case of Levor. At Navitas, design processes were analyzed, and ways forward towards improving PSS-centric design processes were pointed out. The company actually made changes to its processes, and a new integrative position connecting product and service design was created. However, this occurred at the very end of the project, and for the researchers in the project, there is no way of knowing what the result was and if the changes made led to success.

At Levor, the work was much more in-depth and extensive, but at this point in time, the results are largely the same: A substantial number of detailed suggestions were made to adapt the processes of designing and providing PSSs. However, changes are being made only now and initially, it appeared that due to the project ending, the researchers would not be able to learn the actual impact of their work. Luckily, some very engaged engineers became so interested in implementing the suggestions given that a new research project commenced with a focus on investigating and enhancing the compliance of currently ongoing design projects with the recommendations based on the prior project. This can be considered implementation and result monitoring as indicated by Somekh (2006, pg. $6 \mathrm{ff}$.), meaning that the research presented in this thesis is on the verge of becoming action research just now.

However, taking a broader description such as the one given by Bryman (2012, pg. 397), the work can already be considered action research, as it resulted in the "development of a solution based on [a] diagnosis" both in the work with Navitas and Levor. Also, the author would agree that he "became a part of the field of study" (ibid.). In this context, this also means that some of the problems that can emerge 
with action research apply to the work presented here: As Bryman (ibid.) remarks, "Action research] is sometimes dismissed by academics for lacking rigor and being too partisan in approach."

A response to the challenge of lacking rigor has been given throughout this chapter, leaving the question of partisanship: The author acknowledges, that due to the extensive collaboration particularly with Levor, resulting in close relations to some practitioners, the question of partisanship cannot be dismissed out of hand. It was, of course, the goal of the project to produce knowledge of value for the case company, with the target of enhancing its performance as an actor in the market.

However, this has been continuously done by being critical, by investigating indepth and by openly communicating shortcomings and challenges where they were identified. This is true for both the confidential reports and internal information passed on during the projects and for the results reported in the appended and other publications. As it often is the challenges that are novel and interesting, leaving these out of the picture would have led to much less-valuable publications. 



\section{Chapter 4}

\section{The Appended Publications}

In this chapter, key results from the appended scientific publications are presented. The research methods and theoretical backgrounds used are reflected in the respective chapters of this thesis. To structure the presentation and to avoid repetition, each subchapter is divided as follows: (1) The author's contribution to the publication, (2) the background of the publication, and (3) key insight relevant to answering the research question(s). To ensure readability, this chapter uses the first person in explaining the contribution to the publications.

\subsection{Publication 1 - PSSs Without PSS Design}

\section{Author's Contribution}

I developed the concept for the publication based on data gathered in the early phase of the Ph.D. research on the PSS design processes of two case companies. The publication was reviewed and comments given prior to submission by the co-supervisor of my thesis. After two rounds of peer review, the publication was selected to be included in the book Sustainability Through Innovation in Product Life Cycle Design (Matschewsky, 2017) and presented at the $9^{\text {th }}$ International Symposium on Ecodesign in December 2015.

\section{Background of the Publication}

Prior research has pointed out the importance of the implementation of PSS design to ensure effective and efficient design of PSSs, and in particular with respect to achieving increased efficiency and effectiveness throughout the lifecycle (Akasaka et al., 2012; Vezzoli et al., 2015). Although a large number of methods to support PSS design were available (Vasantha et al., 2012), the way PSSs are designed in practice and how this corresponds to prior research on PSS design had not been investigated. This publication aimed to fill this gap based on the understanding of the design processes attained in the two case companies Navitas and Levor. The results call into question the extent to which design processes in manufacturing companies are adjusted to meet the needs of designing PSSs and discusses the possible impacts of this situation. Based on the two case companies studied, causes and effects of lacking design process adaptation are reported, and prescriptive ways forward are indicated. 


\section{Key Insight - Why PSS Design is not Practiced in Manufacturing Companies and Paths Forward}

Publication 1 is focused on examining the design processes and procedures of two large manufacturing companies, Navitas and Levor, located in Sweden, that offer both traditional product sales and PSSs. As such, the publication serves as the first step towards answering RQ1 as it raises many of the issues more deeply investigated in Publication 2.

\section{Identified Causes for Companies not to Carry out PSS Design}

A key reason for the lacking adjustment of design processes towards PSSs is identified in the changing incentives associated with moving towards this type of integrated offering, and how this changes what customers focus on before and during the design process. Particularly in cases of availability- and even more so with result-oriented PSSs, the customers' focus on operational efficiency is expected to be reduced, as this now mainly impacts the provider. It was identified that the case companies Navitas and Levor are partly failing to internalize the efficiency-requirements previously set by the customer in case of product sales. Therefore, both a reduction of external customer pressure and failure to balance this with increased internal requirements led to a reduced need to adapt existing design processes and implement PSS design methods. This is particularly impactful, as it also means that substantial value-capturing opportunities, related to operational efficiency, remain unexploited by PSS providers.

A second cause for the lacking adaptation of design processes to the opportunities provided by PSSs is a missing focus on the internal stakeholders standing to benefit the most from these adjustments. After drawing on the success of lean in bringing production into the design process, the publication discusses evidence that information from both remanufacturing and service is insufficiently considered at the design stage, although it is seen as highly impactful in the context of PSS design. As information concerning improvement opportunities (e.g., handling of errors occurring in the use phase) will likely not reach the right forum, the incentives for adjusting the design to the needs of internal stakeholders active in the use phase and at the end of first life of a PSS remain insufficient. Again, as described above, this means a failure to adjust from external (customer) requirements in the case of product sales to internal requirements when offering PSSs.

Thirdly, a reason for insufficient adjustment of design processes towards PSSs is seen in a missing managerial focus and the generally deficient integration of products and services throughout the lifecycle at the manufacturing company Navitas. The causes for this are seen in the persistence of a strong focus on the production and sale of products and a significant imbalance in terms of financial and organizational power between product- and service-focused divisions. As the underlying research investigated the viability of the implementation of a PSS design process, these challenges became apparent. Also, managerial support was not strong enough, partly due to over-confidence in the current processes as well as 
an incomplete understanding of the attainable benefits and the additional value to be captured by carrying out design with a focus on PSSs.

\section{Effects of not Adjusting Design Processes and Paths Forward}

The impact of a lacking design process adjustment and how it can be reconciled were explored. First, missed opportunities for value capture are discussed. In the case of PSSs, depending on the level of integration, customers increasingly focus their requirements for providers on effectiveness. Not internalizing the efficiency-focus vacated by customers in the switch from product sales to PSSs can lead to these opportunities being missed. A way forward is seen in an increased focus on provider value, carrying out provider-centric QFD (in contrast to a product-centric focus) and lifecycle costing in an effort to make the missed value capture opportunities more tangible.

Notable opportunities to design and provide more effective and efficient PSSs are also discussed to reside in the closer integration of important use- and end of first life-phase stakeholders within the PSS provider into the design process. For this, direct delegates from the respective internal departments are suggested, and a deeper understanding of the design process as such and the particularities of designing for PSSs should be created. Further, a focus on lifecycle thinking throughout the organization is discussed as a critical prerequisite to adjusting design towards more effective and efficient PSS provision.

Lastly, the importance of adjusting design processes to the needs of PSSs is underscored in relation to the goal of achieving improved environmental performance when becoming a PSS provider. Taking increased prices of resources as a backdrop, the need for higher operational efficiency is highlighted in reference to the capability of a company to successfully provide value to its customers and to capture value throughout the lifecycle.

\subsection{Publication 2 - Designing and Providing PSSs - Challenges, Opportunities, and Solutions}

\section{Author's Contribution}

The concept for the publication was initially developed by me, resulting in the drafting of an extended abstract. This abstract underwent several iterations, with additional content and insight added mainly with respect to the results by the second author, Marianna Lena Kambanou, and feedback with regards to the research design and structure provided by the third author, Tomohiko Sakao. The manuscript was written by me. The second author contributed part of the data reported, particularly with a focus on incentives, costing and data handling and subsequent opportunities and solutions; carried out writing in the results section; and worked to enhance the overall language, coherence, conciseness, and clarity of the manuscript and abstract. Overall comments with regard to structure, 
presentation, framing, and content were provided by the third author. I carried out the revisions of the manuscript, receiving comments from both co-authors.

\section{Background of the Publication}

A research gap was identified with respect to current accounts of real-world challenges of servitization, design, and provision of PSSs, as impactful publications in that area had been published some years prior (Martinez et al., 2010; Durugbo, 2013). This gap could be approached based on an extensive amount of data collected concerning the processes of two case companies by the first and second author of the publication. As a result, a set of challenges the case companies experience in their expansion to PSS design and provision was reported and supported with an extensive collection of direct quotes. Going beyond this, based on the work conducted in research projects with companies Navitas and Levor, an empirical basis was established to identify opportunities and suggest solutions to these challenges based on prescriptive methods and approaches (such as Sakao et al., 2009; Sakao and Lindahl, 2015; Desai et al., 2017). To provide actionable outcomes for practitioners, clear managerial implications are reported.

\section{Key Insight - Challenges of Designing and Providing PSSs and Ways Forward}

The central aim of Publication 2 was to identify the actual problems encountered by two manufacturing companies, Navitas and Levor, with roots in product design and product sales, in becoming providers of PSSs. In order to clarify the context of the data gathering and to facilitate the implementation of the solution opportunities identified in the manufacturing industry practice, the prescriptive methods used in the scope of the two research projects were used as the point of departure for the presentation of the results.

By applying this approach, four areas of challenges were found, and six opportunities were identified to support manufacturing companies in driving forward their servitization effectively and efficiently. These findings were further condensed to provide a comprehensive overview and practical implications for readers in manufacturing industry practice.

\section{Challenges for Manufacturing Companies in Servitization}

A persisting product-centered mindset has been found to be a key issue in both case companies and their respective management. This situation was largely based in the decades-long history of the companies in designing and selling highly advanced technological products.

A further critical challenge to effectively and efficiently designing and providing PSSs was the separation of product and service design. Based on the data gathered, a temporal, organizational and structural separation between the product- and service design processes were identified. 
Unwanted lock-in effects were found to be present as a result of the identified product-first strategy, leading to sub-optimization throughout the lifecycle of the offering. Also, a highly impactful challenge isolated was the lacking alignment with changing incentive structures. Although the transition to highly integrated PSSs ought to lead to changes in a company's incentive structures, the data collected has shown that an adjustment to these changes is largely absent in the cases investigated. This is particularly critical as the transition of service and spare part provision from being revenue sources in the case of product sales to becoming costs in the case of PSSs can easily be missed in complex organizations, as exemplified by the quotes presented in Section 4.1.3 in Publication 2.

Lastly, the observed prevalence of product-focused information and costing structures was identified as a key challenge to successfully and efficiently providing PSSs. Closely connected to the topic of changing incentives, measuring these changes appears difficult, as the structures present still adhere to traditional paradigms. Understanding costing in a PSS environment may be a critical precondition to motivate the transition to a servitized environment internally.

\section{Opportunities and Solutions to the Challenges of Servitization}

PSS design methods are seen as a possible guiding light to integrate the design of products and services successfully. At one of the case companies, a PSS design method was used as a benchmark to understand and investigate the current design processes and to identify areas and processes in need of adjustment. A further path forward to creating a comprehensive understanding of how a company is affected by servitization was found to be lifecycle costing and its application through a prescriptive method. This has proven helpful with one of the case companies, laying bare insufficient handling of data and costing approaches not fully matched to PSSs.

In addition, approaching PSS design and provision from a value perspective has been perceived as beneficial to the case companies, as it was considered important to ensure a focus on efficiency throughout all stages of the lifecycle. Further, the position of a PSS facilitator was introduced in one of the case companies, with the aim of achieving a higher level of integration between product and service design throughout the design process. Lastly, both a detailed assessment of the status quo, e.g., by carrying out actor mapping, and generally, arriving at a customer-centric, business-driven PSS design and provision, were deemed to be effective overall approaches to support overcoming servitization challenges in manufacturing industry practice. 


\subsection{Publication 3-Development and Selection of Design Methods}

\section{Author's Contribution}

The initial concept for this publication was developed by the fourth author, Tomohiko Sakao. Based on my earlier work on the industrial adoption of PSS design methods (Matschewsky et al., 2015a), I became the first author and commenced the writing in February 2018. The majority of the manuscript was written by me in the development process of the publication throughout the year 2018, and I led and organized the process throughout. The second author, Sergio A. Brambila-Macias, contributed with his extensive empirical work on user requirements on design methods for resource-efficient offerings and in writing the respective parts of the background, method, and results. He further arranged the focus group workshops with academic method developers and manufacturing industry practitioners. The third author, Abhijna Neramballi, contributed in the initial writing of method selection case. All co-authors provided feedback and comments throughout the writing process, with the fourth author particularly focusing on the aim, overall clarity and stringency of the resulting manuscript.

\section{Background of the Publication}

Design methods are recognized to be helpful in manufacturing industry practice (Reich, 2010; Montagna, 2011; Eifler and Howard, 2018) and are seen as particularly needed in cases of high uncertainty in the design process (Gidel et al., 2005). This is especially relevant when companies transition to becoming providers of integrated offerings of products and services (Dachs et al., 2014; Matschewsky et al., 2018a). Still, it appears that of the methods developed and published as a result of academic research, only very few enjoy broader use in the manufacturing industry (see, e.g., Araujo et al., 1996; Tomiyama et al., 2009; Vezzoli et al., 2015). The premise of this publication departs from this contradiction and tries to tackle the method side of the problem by essentially asking this question: How can methods be developed in a more stringent, clear and user-centric way so that they are more likely to be used in practice?

The research departed from an earlier conference publication (Matschewsky et al., 2015a), which was focused on isolating characteristics for PSS design methods to facilitate their adoption and use in the manufacturing industry. In Publication 3 , a structured method is provided, which guides both the development of a method by academics or practitioners and the selection of design methods by practitioners in search of support for a particular challenge. The proposed method was applied in the area of resource-efficient offerings, which include highly integrated PSSs, with manufacturing industry practitioners and a panel of academic experts. This resulted in the identification of method user requirements and key method characteristics aimed to support method developers in the creation or selection of methods that fulfill their identified requirements. 


\section{Key Insight - Towards Better Design Methods for Manufacturing Industry Practice}

Publication 3 covers several bases: It provides a structured method to develop or select appropriate design methods depending on the individual challenges at hand. This is illustrated separately in case the development occurs in an industrial or an academic environment. The identification of the requirements of the (prospective) users and the characteristics of the method to be designed or selected are identified in a structured fashion, and the method proposed allows for an assessment of their correlation to enable prioritization of the most important characteristics. This method was applied with practitioners and an academic panel in the area of resource-efficient offerings (comprising the various foci of the respondents on ecodesign, lifecycle assessment, PSS design and provision, etc.).

\section{A Method for the Development and Selection of Design Methods}

A method, comprised of five steps, departing from the state of the art as well as the experience of the authors in various design-centric research projects, is proposed for the development and selection of design methods. The full procedure is shown in Figure 10.

Steps 1 and 2 focus on identifying method user requirements and method characteristics, respectively. Whether the method is applied in an academic or industrial context, a status quo must be established, and the most relevant requirements and characteristics must be identified. Steps 3 to 5 are then identical, regardless of the method's application in an academic or manufacturing industry environment. Step 3 allows for the assessment of correlations between method user requirements and characteristics by applying QFD. This enables prioritization of certain characteristics with respect to highly weighed requirements. Steps 4 and 5 lay out an iterative process of method development or selection, and an assessment of compliance with the key factors identified earlier. The overall method aims to erect a stringent structure for the development and selection of design methods, while it also strives to shed light onto the process of how academically conceived design methods are developed, and thus, intends to facilitate continuous development and improvement of such methods. 


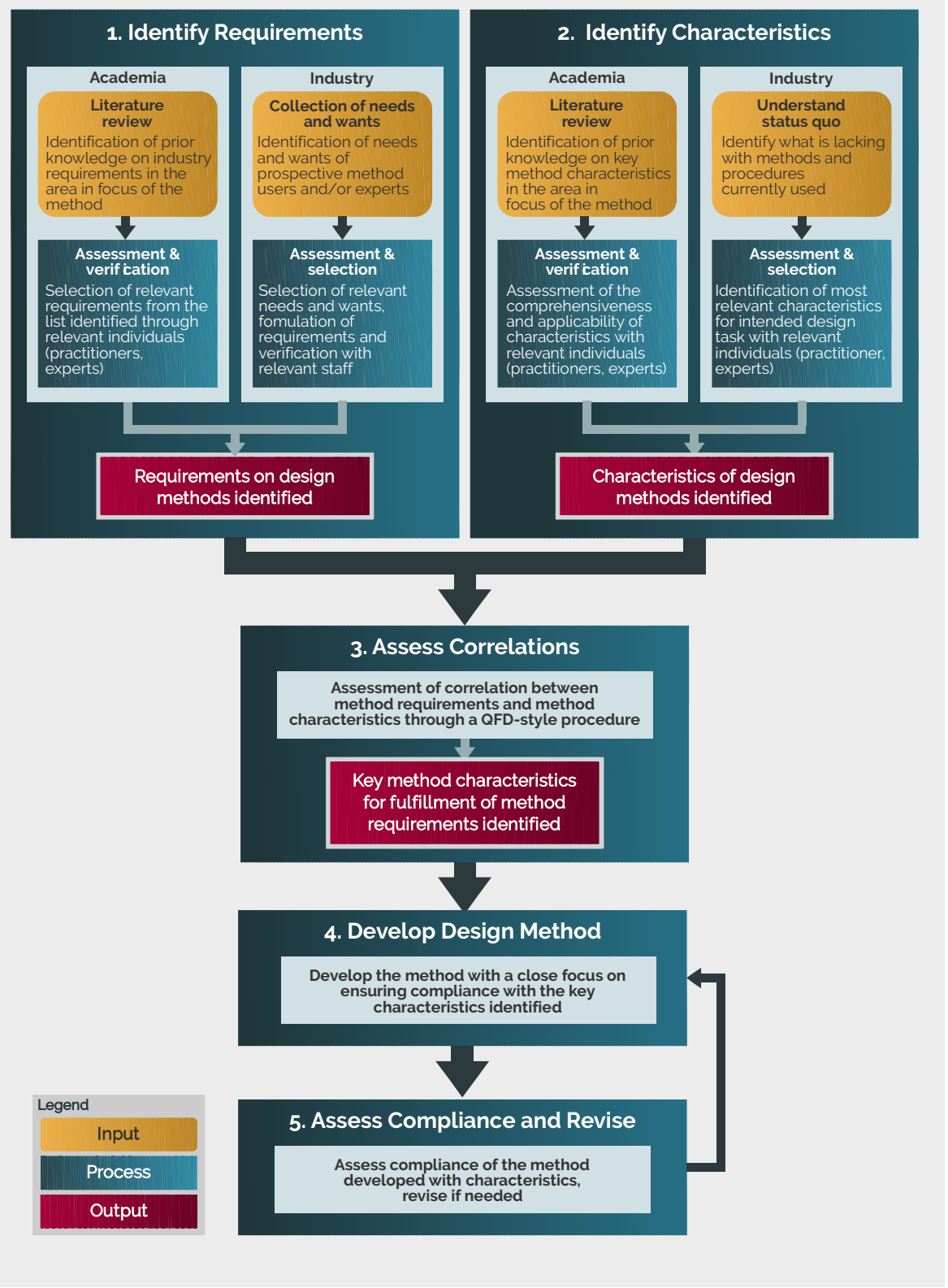

Figure 10: Method for the development of design methods (Publication 3) 
Transferable Method User Requirements and Characteristics for Resource-Efficient Offerings

The method developed was applied in the area of resource-efficient offerings to identify method user requirements and characteristics of broad relevance in the fields. Key method user requirements were identified (Step 1) based on a multistep process using literature, interviews and a web-based survey. Table 3 shows an overview of the most relevant requirements collected from a total of 24 practitioners in the field with their evaluations on a 1-5 Likert scale (larger $=$ more important).

Table 3: User requirements on methods and average rating (Brambila-Macias et al., 2017)

\begin{tabular}{lll}
\hline Category & Requirements & Average \\
\hline Outcome & Useful in early design phase & 3.80 \\
\cline { 2 - 3 } & Provide quantified results & 3.15 \\
\hline \multirow{2}{*}{ Process } & Support prioritization of improvement areas in design & 3.65 \\
\cline { 2 - 3 } & Support communication across relevant actors & 3.85 \\
\cline { 2 - 3 } & Support collaboration across relevant actors & 3.55 \\
\hline Content & Support lifecycle thinking & 4.05 \\
\hline Time and cost & Low cost of usage & 3.75 \\
\hline Users & Easy to use & 4.40 \\
\cline { 2 - 3 } & Easy to learn & 4.15 \\
\cline { 2 - 3 } & Support designers' creativity & 4.20 \\
\cline { 2 - 3 } & Provide learning opportunity & 3.20 \\
\cline { 2 - 3 } & Support management of multiple projects & 3.40 \\
\hline
\end{tabular}

The method characteristics and qualifiers providing additional detail to these were isolated and refined based on a literature review, a questionnaire and a focus group discussion in a panel of academic method developers and manufacturing industry practitioners, respectively. An abridged overview of these broadly relevant characteristics is shown in Table 4.

In a focus group session with three esteemed academic method developers in the area of resource-efficient offerings, the effort was undertaken to identify correlations between the user requirements and method characteristics to arrive at a broadly applicable set of weighted characteristics to facilitate design method development. It became apparent, however, that without a clear design task or goal as it exists in a manufacturing industry environment, arriving at a consensus with regard to these correlations is a challenge given the various backgrounds of the participants. As a result, the correlations assigned by two of the participants individually were used moving forward with the trial of Steps 4 and 5 . 
Table 4: Design method characteristics and qualifiers (Publication 3)

\begin{tabular}{|c|c|c|}
\hline Characteristic & Description & Qualifiers \\
\hline \multirow{2}{*}{$\begin{array}{l}\text { Customizability - } \\
\text { Understanding in- } \\
\text { terfacing and modu- } \\
\text { larity }\end{array}$} & \multirow{2}{*}{$\begin{array}{l}\text { - Concerned with adaptability of methods to } \\
\text { circumstances in manufacturing industry } \\
\text { practice } \\
\text { - Can be key where extensive methodologies } \\
\text { are considered impractical or where process } \\
\text { integrity is key }\end{array}$} & Modularization \\
\hline & & $\begin{array}{l}\text { Adjustability to exist- } \\
\text { ing process }\end{array}$ \\
\hline \multirow{2}{*}{$\begin{array}{l}\text { Simplicity - } \\
\text { Understanding in- } \\
\text { put and process }\end{array}$} & \multirow{2}{*}{$\begin{array}{l}\text { - Main concern lies in the extensiveness of the } \\
\text { method process and the data required for its } \\
\text { execution. }\end{array}$} & $\begin{array}{l}\text { Simplicity of data ad- } \\
\text { dressed }\end{array}$ \\
\hline & & $\begin{array}{l}\text { Simplicity of entailed } \\
\text { process }\end{array}$ \\
\hline \multirow{2}{*}{$\begin{array}{l}\text { Flexibility - } \\
\text { Understanding data, } \\
\text { knowledge and us- } \\
\text { age modes }\end{array}$} & \multirow{2}{*}{$\begin{array}{l}\text { Focused both on the conditions the method } \\
\text { is applied in and the in- and outputs of the } \\
\text { method. }\end{array}$} & Input flexibility \\
\hline & & User flexibility \\
\hline \multirow{3}{*}{$\begin{array}{l}\text { Scalability - } \\
\text { Understanding } \\
\text { scope and lifecycle }\end{array}$} & \multirow{3}{*}{$\begin{array}{l}\text { - Refers to the area in focus of the design } \\
\text { support's assessment. } \\
\text { - Particularly critical in the design of highly } \\
\text { integrated solutions based on complex sys- } \\
\text { tems of product and services with high pro- } \\
\text { vider responsibility throughout the lifecycle. }\end{array}$} & System scale \\
\hline & & \\
\hline & & Time scale \\
\hline \multirow{2}{*}{$\begin{array}{l}\text { Clarity - } \\
\text { Understanding } \\
\text { communication and } \\
\text { use }\end{array}$} & \multirow{2}{*}{$\begin{array}{l}\text { - Concentrates on the way a design support is } \\
\text { communicated to its prospective users as } \\
\text { well as its ease of use and systems in place to } \\
\text { aid its implementation and application in an } \\
\text { industrial environment. }\end{array}$} & $\begin{array}{l}\text { Form of implementa- } \\
\text { tion }\end{array}$ \\
\hline & & Communication \\
\hline \multirow{3}{*}{$\begin{array}{l}\text { Utility - } \\
\text { Understanding out- } \\
\text { come recipient and } \\
\text { process responsibil- } \\
\text { ity }\end{array}$} & \multirow{3}{*}{$\begin{array}{l}\text { - Focused on how the method caters to the } \\
\text { needs of the recipient of the outcome of the } \\
\text { design method use. } \\
\text { - Also concentrates on the ability of interested } \\
\text { parties to follow up on decisions made dur- } \\
\text { ing method use and to attain an understand- } \\
\text { ing of such processes. }\end{array}$} & Recipient \\
\hline & & \\
\hline & & $\begin{array}{l}\text { Traceability and ac- } \\
\text { countability }\end{array}$ \\
\hline
\end{tabular}

\section{Cases Showing the Usefulness of the Method and the Identified Requirements} and Characteristics

In completing the remaining steps of the method proposed, the following approach was taken: The correlations assigned by two academic focus group participants were used to evaluate three methods frequently applied in the design of resource-efficient offerings against the identified characteristics. This showcased a mode of using these weighted characteristics for the selection of a fitting method for a given industry challenge. Additionally, departing from the correlations assigned by a second participant, guidelines for the development of design methods were derived based on the individual viewpoints of the academic expert made clear by the QFD assessment of characteristics and requirements. Despite the ambiguity inherent to QFD assessments, the guidelines derived provide broadly relevant insight, particularly for academic developers of design methods for resource-efficient offerings. 


\subsection{Publication 4-Capturing and Enhancing Provider Value in PSSs}

\section{Author's Contribution}

This publication was written by me and is partially based on an earlier draft first submitted in the autumn of 2015 with contributions by both co-authors, Mattias Lindahl, and Tomohiko Sakao. Throughout the many iterations of the manuscript, both co-authors provided feedback and comments. I carried out the revisions during the review phase of the manuscript and received advice from both co-authors during this process. The concept of provider value for PSSs was initially conceived by the co-authors and first developed in Matschewsky (2012).

\section{Background of the Publication}

The research gap motivating this publication was identified in the lack of focus of prior research onto the changes in value capture for manufacturing companies expanding towards PSSs design and provision. Whereas customer value was the focus of extensive research with respect to PSSs (see Kimita et al., 2009a; Lee et al., 2015), the complexity of capturing value throughout the lifecycle in PSSs in contrast to product sales had not been investigated in-depth (cf. Pezzotta et al., 2014). Publication 4 aimed to fill that gap by proposing provider value for PSSs as a concept based on empirical exploration and providing prescriptive method support for companies eager to investigate and enhance their value capture throughout the lifecycle.

The research conducted towards filling this gap commenced in 2012 when working towards the diploma thesis. Publication 4 further encompasses two prior conference publications (Matschewsky et al., 2015b, 2016) and was appended to the licentiate thesis at an earlier draft stage (Matschewsky, 2016). Both towards the conceptualization of provider value and the testing of the proposed methods, data collected in collaboration with Case Company Arantius ${ }^{17}$ is used, supplemented by data two master's thesis students gathered at Ericsson.

\section{Key Insight - Understanding and Enhancing Provider Value in PSSs}

Publication 4 is the outcome of nearly four years of research and therefore endeavors to cover the topic of value capture of PSS providers comprehensively. To this end, the concept of provider value is introduced, methods to identify and enhance provider value in PSS are presented, and these methods are applied and discussed with manufacturing industry practitioners. Further, broadly applicable value dimensions for use as indicators in design and provision of PSSs are derived from the method application.

\footnotetext{
${ }^{17}$ Pseudonym used exclusively in Publication 4, refers to the same case company as Navitas or Levor, while the exact relation cannot be disclosed. For details, please see Chapter 1.5.1.
} 


\section{Multidimensional Value Available to PSS Providers}

The article departs from the state of the art in the area of PSSs concerning value and value assessment in a design context. Based on this, the concept of provider value in PSSs is established for the first time in a journal article. The concept was first introduced in Matschewsky et al. (2015b) and later adopted, e.g., by Bertoni et al. (2017). It is based on a departure from a focus on value in exchange at the time of the sale in product sales to a multidimensional value capture throughout the lifecycle(s) of the offering.

\section{Structured Methods to Identify and Enhance Provider Value Throughout a PSS' Lifecycle}

Based on the understanding established, Publication 4 aims to provide support for industrial practitioners to accomplish two goals: First, the current value capture in the use phase of PSS offerings should be analyzed. This is to ensure a comprehensive understanding of the status quo to direct improvement efforts in a focused fashion. In a second step, the value capture should be enhanced by taking the necessary action in the design stage and improving the offering with the goal of capturing higher value in the use phase of the subsequent iteration. These tasks are fulfilled by (1) provider value analysis and (2) provider value evaluation, respectively.

Provider value analysis enables the collection of provider-centric value dimensions in relation to physical components of the PSS and the activities of the provider during the use phase. As a point of departure, data concerning customer value can also be collected, as practitioners tend to be more familiar with the concept. Further, provider value analysis allows for companies in servitization to compare their traditional sales offerings with PSSs to acquire a deeper understanding of the differences in value capture between the two business models. As it was initially developed to structure the data gathering within a research project, this approach is briefly described in Chapter 3.3.3 as one of the approaches supporting the interviews carried out.

The value dimensions identified can then be used to prioritize development during the design phase to efficiently design towards increased value capture using the provider value evaluation method. Here, the prospective value contribution of product and service components is to be assessed with regard to the value dimensions identified from the use phase assessment. Depending on how the focus is set, the provider value evaluation method allows for a weighing of the value dimensions and provides the opportunity to highlight the uncertainty of semiquantitative assessments made early in the design process. In comparison to an earlier publication of the provider value evaluation method in Matschewsky et al. (2015b), the method in general and its individual steps were simplified in order to facilitate its implementation and use in practice. Figure 11 shows the provider value evaluation method as it was reported in the scope of Publication 4. 


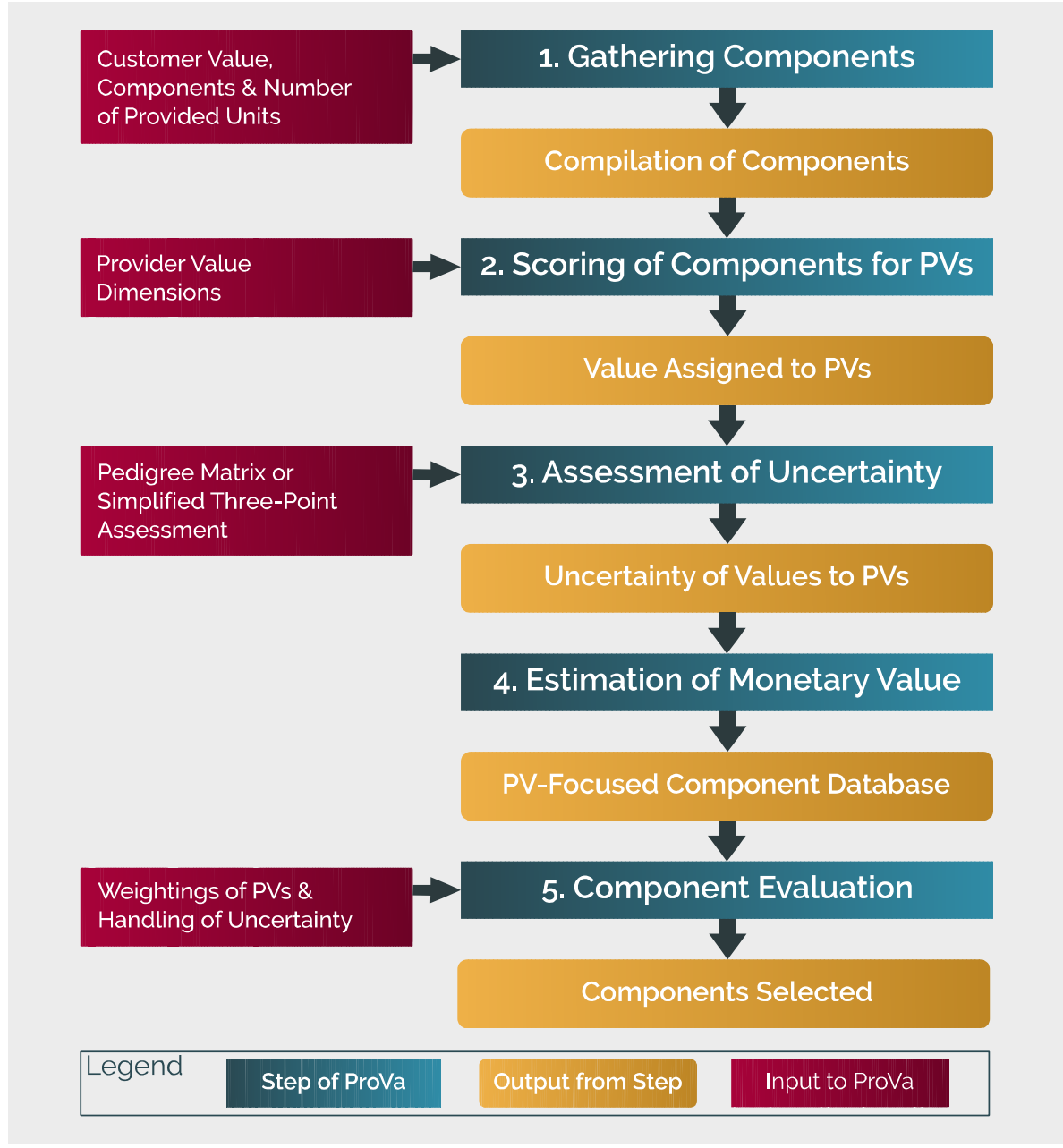

Figure 11: Process of the provider value evaluation method (Matschewsky et al., 2018b)

\section{Value Dimensions of Broad Relevance}

Based on extensive empirical work with the two case companies Arantius and Ericsson, eight clustered value dimensions of high relevance for the respective manufacturing companies were identified. They are summative descriptions of the possible sources of value described by practitioners, intended to provide an overview and to allow for the use of provider value evaluation without first performing a use phase-oriented provider value analysis. Long-term thinking refers to value-capturing opportunities regarding environmental aspects, customer trust, and continuity. Customer relations and service excellence focuses on the expected value capture from customer satisfaction based on a PSS's performance, leading to longer and more extensive connections to customers and providing the basis for further value capture. Knowledge and information refers to the expected value created by data and insight gathered digitally or by direct interaction with 
customers. Quality is seen as a cornerstone of the value proposition and the basis of a provider's value capture also when offering PSSs, where aspects such as longevity receive even greater attention. The clustered value dimension brand and size is focused on being able to satisfy customer requirements as a basis for capturing value and can be particularly crucial to take account of in smaller companies aiming to offer use- or result-oriented PSSs. Capturing monetary value is the basis for all economic activity and was, therefore, an often-mentioned and critical aspect of PSS provision. Ownership and control is further seen as an enabler of value capture throughout the use phase of an availability- or result-oriented offering. Lastly, market opportunities are to be considered in relation to the design of product and service components to ensure provider value can be captured effectively, particularly when moving to new markets. Table 5 summarizes the synthesized information.

Table 5: Clustered value dimensions identified (Matschewsky et al., 2018b)

\begin{tabular}{|c|c|c|}
\hline $\begin{array}{l}\text { Clustered } \\
\text { Dimension }\end{array}$ & Description & Supporting references \\
\hline $\begin{array}{l}\text { Long-Term } \\
\text { Thinking }\end{array}$ & $\begin{array}{l}\text { - Focus on customer trust, confidence and ex- } \\
\text { ternal stakeholders }\end{array}$ & $\begin{array}{l}\text { (Goedkoop et al., 1999; Mont, } \\
\text { 2002; Tukker, 2004, 2015; } \\
\text { Baines et al., 2007; Sundin et } \\
\text { al., 2009; Lindahl et al., 2014b) }\end{array}$ \\
\hline $\begin{array}{l}\text { Customer } \\
\text { Relations } \\
\text { and Service } \\
\text { Excellence }\end{array}$ & $\begin{array}{l}\text { - Strengthened ties to customers and improv- } \\
\text { ing perceived customer value }\end{array}$ & $\begin{array}{l}\text { (Sakao et al., 2008; Meier et } \\
\text { al., 2010) }\end{array}$ \\
\hline $\begin{array}{l}\text { Knowledge } \\
\text { and } \\
\text { Information }\end{array}$ & $\begin{array}{l}\text { - Knowledge attained can be key input for de- } \\
\text { sign processes } \\
\text { - Restricting access to knowledge can improve } \\
\text { market position } \\
\end{array}$ & $\begin{array}{l}\text { (Baines et al., 2007; Meier et } \\
\text { al., 2010; Sakao et al., 2013; } \\
\text { Opresnik and Taisch, 2015) }\end{array}$ \\
\hline Quality & $\begin{array}{l}\text { - May be even more relevant than with sales } \\
\text { because of extended responsibility }\end{array}$ & $\begin{array}{l}\text { (Aurich et al., 2006; Morelli, } \\
\text { 2006; Kimita et al., 2009b) }\end{array}$ \\
\hline $\begin{array}{l}\text { Brand and } \\
\text { Size }\end{array}$ & $\begin{array}{l}\text { - Capability of fulfilling customer require- } \\
\text { ments at any time throughout the contract } \\
\text { - Vital for main case company as market is } \\
\text { dominated by few, large players } \rightarrow \text { maintain- } \\
\text { ing capacity to meet customer needs is key } \\
\text { - For small companies: Building capacity and } \\
\text { understanding requirements of PSS }\end{array}$ & (Neely, 2009) \\
\hline $\begin{array}{l}\text { Monetary } \\
\text { Value }\end{array}$ & $\begin{array}{l}\text { - Over the long term, all other dimensions } \\
\text { must lead to monetary value } \\
\text { - Win-win-win situations between customer, } \\
\text { provider and outside stakeholders are the } \\
\text { goal }\end{array}$ & (Maussang et al., 2009) \\
\hline
\end{tabular}

\section{The Relevance of the Value Dimensions for PSS design}

The value dimensions collected with practitioners in the use phase by applying provider value analysis at Arantius were then evaluated by design phase practitioners for their relevance for future design tasks, depending on the business model used to bring the offering to market. The result of this assessment is shown 
in Table 6. This makes clear, that although most value dimensions found are seen as important in product sales scenarios, their relevance increases with a growing product-service integration and a maturing lifecycle focus of the provider.

Table 6: Evaluation of value dimensions by practitioners (Matschewsky et al., 2018b)

\begin{tabular}{|c|c|c|c|c|c|c|c|}
\hline \multirow[t]{3}{*}{$\begin{array}{l}\text { Clustered } \\
\text { Dimension }\end{array}$} & \multirow[t]{3}{*}{ Business Model } & \multicolumn{5}{|c|}{ Evaluation } & \multirow[t]{2}{*}{ Average } \\
\hline & & \multicolumn{2}{|c|}{ Not relevant } & & \multicolumn{2}{|c|}{ Highly relevant } & \\
\hline & & 1 & 2 & 3 & 4 & 5 & \\
\hline \multirow{3}{*}{$\begin{array}{l}\text { Long-Term } \\
\text { Thinking }\end{array}$} & Product sales & & 2 & 5 & 1 & 1 & 3.1 \\
\hline & Use-oriented PSSs & & & 1 & 5 & 3 & 4.2 \\
\hline & Result-oriented PSSs & & & & 1 & 8 & 4.9 \\
\hline \multirow{3}{*}{$\begin{array}{l}\text { Customer Rela- } \\
\text { tions and Ser- } \\
\text { vice Excellence }\end{array}$} & Product sales & 1 & 2 & 4 & 3 & & 2.6 \\
\hline & Use-oriented PSSs & & & & 4 & 6 & 4.6 \\
\hline & Result-oriented PSSs & & & 1 & & 9 & 4.8 \\
\hline \multirow{3}{*}{$\begin{array}{l}\text { Knowledge and } \\
\text { Information }\end{array}$} & Product sales & & 1 & 4 & 3 & 2 & 3.6 \\
\hline & Use-oriented PSSs & & & 2 & 3 & 5 & 4.3 \\
\hline & Result-oriented PSSs & & & 1 & & 9 & 4.8 \\
\hline \multirow[t]{3}{*}{ Quality } & Product sales & & 1 & 3 & 1 & 5 & 4.0 \\
\hline & Use-oriented PSSs & & & 1 & 2 & 7 & 4.6 \\
\hline & Result-oriented PSSs & & & 1 & 2 & 7 & 4.6 \\
\hline \multirow[t]{3}{*}{ Brand and Size } & Product sales & 1 & & 6 & 2 & 1 & 3.2 \\
\hline & Use-oriented PSSs & & & 1 & 6 & 4 & $4 \cdot 3$ \\
\hline & Result-oriented PSSs & & & & & 10 & 5.0 \\
\hline \multirow{3}{*}{$\begin{array}{l}\text { Monetary } \\
\text { Value }\end{array}$} & Product sales & & 1 & 2 & 2 & 4 & 4.0 \\
\hline & Use-oriented PSSs & & & 1 & 2 & 6 & 4.6 \\
\hline & Result-oriented PSSs & & & & 2 & 7 & 4.8 \\
\hline
\end{tabular}

As the identified value dimensions were based on data gathered exclusively from use phase practitioners, the respondents active in the design of PSSs remarked on some additional dimensions and topics they saw as important for the value capture of their employer. This includes productivity and flexibility with a lifecycle perspective, which was mentioned by a project manager. The issue of reliability was brought up by a service business developer, with particular relevance for the company's availability-oriented offerings and the importance of reliability for both value capture and environmental performance.

\section{Adjusting the PSS Design Process Towards Lifecycle-Focused Value Capture}

Three scenarios were discussed by practitioners to adjust the existing design process in order to capture more value throughout the lifecycle and thereby become a more efficient PSS provider. Using the provider value evaluation method to assess product and service components in the design process was seen as a viable track. Further, the provider value-focused approach presented was perceived to be helpful to assess new projects and development from a more PSS-centric point of view. A key benefit of the provider value concept and the method and approach 
proposed was seen in their communicative nature: In this context, provider value was seen as a viable means to illustrate the impact of providing PSSs instead of selling products on the design and provision processes of the company. In the words of one respondent: "That is a huge chance to educate people. Because you can explain which values are important."

\subsection{Publication 5 - Inadvertent Circularity? PSSs Towards a CE}

\section{Author's Contribution}

The concept for the publication was developed by me, and I carried out all of the writing and associated tasks. It must be remarked, however, that some of the overall insight regarding the studied company and its PSS offerings is the result of the many discussions with Marianna Lena Kambanou. The draft was reviewed prior to submission by an associate professor in the Division of Environmental Technology and Management at LiU. The publication was developed and written in response to a call for a special issue in the final phase of the research journey.

\section{Background of the Publication}

An increasing number of frameworks and methods for the implementation of PSSs and other circular business models has been reported in recent years (Lieder and Rashid, 2016; Manninen et al., 2018). However, a research gap was identified in a lacking investigation of economically-driven expansions to PSSs carried out without such support and the contributions to a CE such expansions can potentially provide irrespective of their focus. Although based on a single company, the publication hypothesizes that many manufacturing companies expand towards PSSs in such an unsupported fashion. To move towards filling this gap, this publication investigates the PSS design and provision at Kamiono ${ }^{18}$ in light of a framework supporting the assessment of PSS towards relative and absolute resource decoupling in the scope of a CE (Kjaer et al., 2019). The goal of this publication within the overall scope of the research was therefore to contribute to advancing the state of the art in PSSs towards a CE and to provide a countercheck to portions of the research work in this thesis heavily focusing on prescriptive methods.

\section{Key Insight - PSSs Transition Without Method Support: Inadvertently Circular?}

Publication 5 aims to provide focused insight regarding unsupported, economically-driven transitions to PSSs and their potential contribution to the CE. To that

\footnotetext{
${ }^{18}$ Pseudonym used exclusively in Publication 5, refers to the same case company as Navitas or Levor, while the exact relation cannot be disclosed. For details, please see Chapter 1.5.1. 
end, a brief background on the topic of PSSs and the CE is provided. Further, the assessment framework adopted from Kjaer et al. (2019), expanded with criteria for PSSs' potential CE contributions, is laid out in detail. The results of the assessment of the case company Kamiono's PSS for its possible contribution to relative resource decoupling in the scope of a CE concerning the criteria reported are presented. Further, a potential contribution of the PSS to absolute resource decoupling based on requirements reported by Kjaer et al. (2019) is discussed.

\section{Framework and Criteria to Assess the CE-Contribution of PSS}

Initially, an assessment-structure for the CE-contribution of PSS was established. Departing from Kjaer et al.'s (2019) framework, the five PSS strategies reported therein are laid out based on the theoretical background given in the original publication. These strategies are operational support, product maintenance, product sharing, take-back/end of life (EoL) management, and optimized result, and serve as a point of departure for the analysis of a PSS offering. In relation to these strategies, the authors (ibid.) identify four enablers of resource reduction through PSSs. Reflecting on these enablers, the criteria proposed for the assessment of the potential contribution of PSS to a relative resource reduction towards a CE were identified. In this instance, specific focus lay on the relevance of the criteria to use-oriented PSSs, as those are provided by Kamiono. The criteria proposed were identified under reflection of the state of the art on PSSs and a CE and are detailed in Table 7.

\section{Assessing the Case Company's PSS for its Contribution to a CE}

The results of the assessment of the company's use-oriented PSS are presented in detail in Publication 5, initially focusing on the relative resource reduction based on the established assessment criteria. In order to provide a comprehensive overview and to ensure the brevity of this chapter, the criteria, the theory at their basis and the results of investigating case company Kamiono's PSS provision are reported in Table 7. This table further includes an indication of the improvementpotential of the PSS offering in comparison to the case company's own product sales offerings, which utilize the same (physical) product components. 


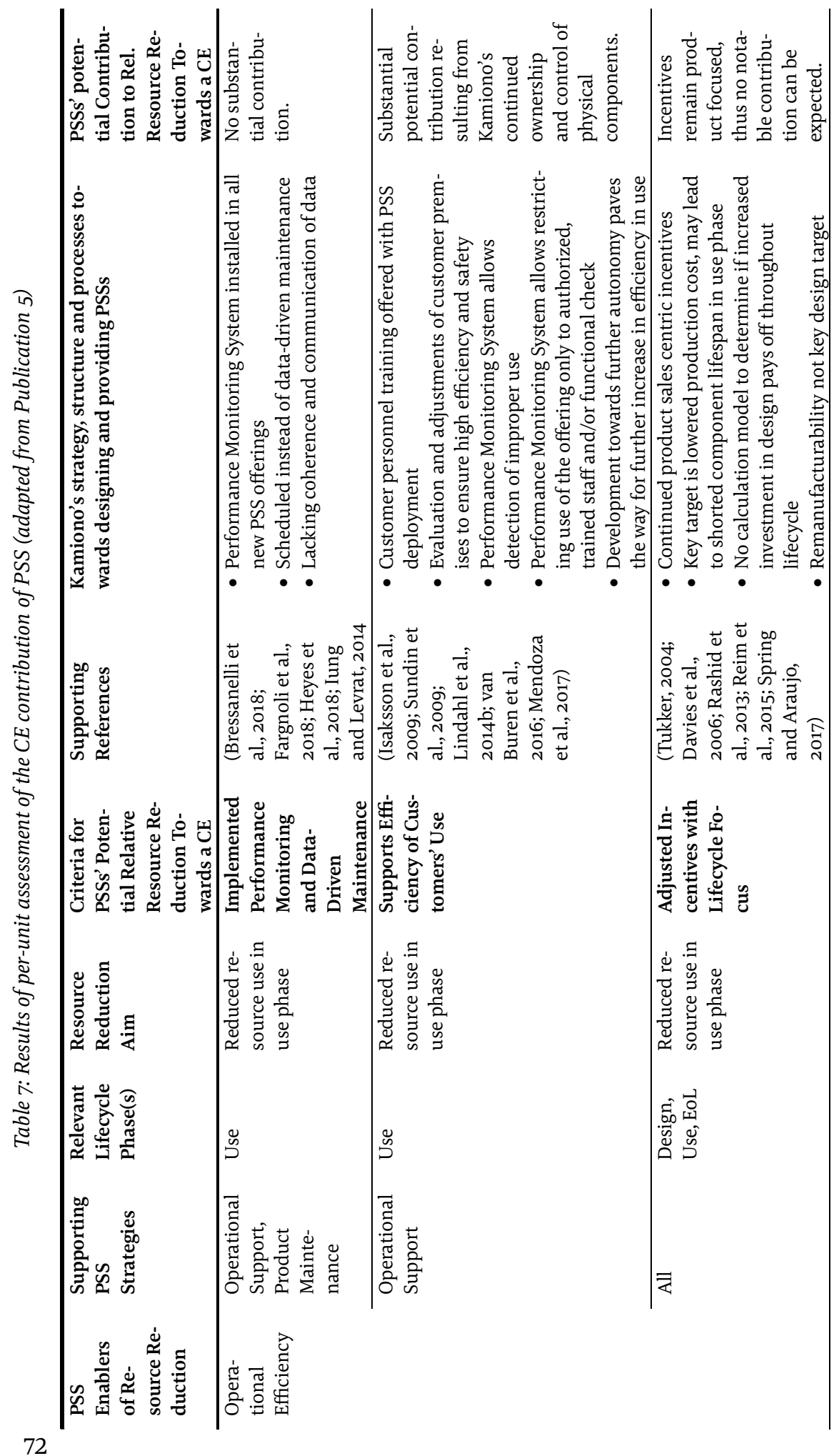




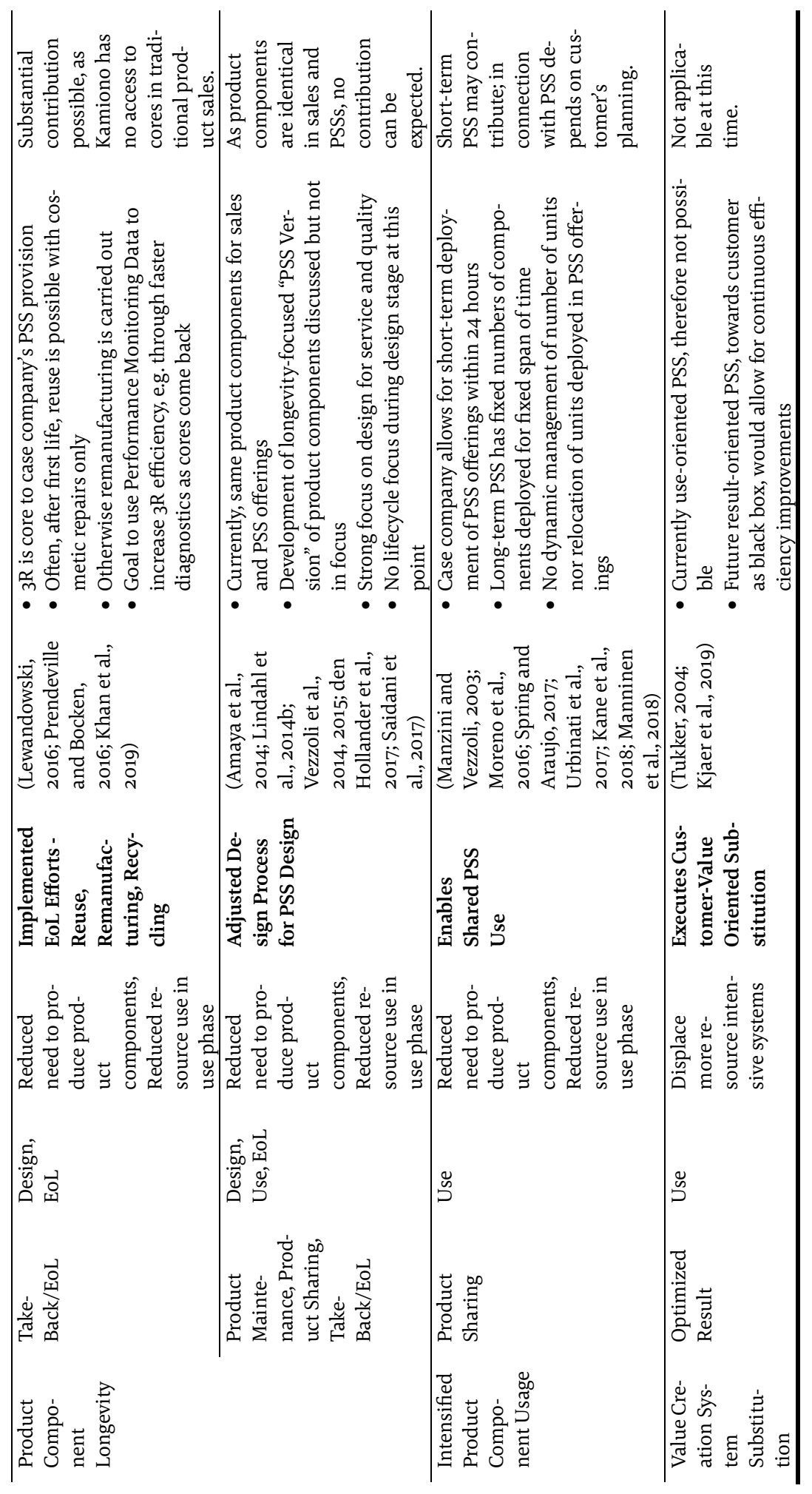


Subsequently, Publication 5 reports on the assessment of Case Company Kamiono's PSS provision with a focus on achieving absolute resource decoupling. To this end, requirements for absolute resource decoupling reported by Kjaer et al. (2019) are related to the PSS offerings of the case company. Concerning the requirement ensure net resource reduction, all enablers of resource reduction are taken into subsequent focus. In focusing on operational efficiency, the likely resource reductions achieved regarding the criterion supports efficiency of customer's use are weighed against the inefficiency of scheduled maintenance and lacking incentive structure adjustment at the case company.

In focusing on product component longevity, it is reported that Kamiono's end of life efforts increase the likelihood of reducing resource use, while gaps in design process adjustment are considered detrimental to that goal. Lastly, focusing on intensified product component usage, the case company currently does not conduct efforts except offering short-term PSSs to accommodate usage peaks of its customers, which are fit to enhance product component usage towards a net resource reduction. Moving the focus to the requirement of avoiding burden shifting between lifecycle phases in aiming for absolute decoupling, some approaches supporting this are identified at the case company.

As efforts aiming for increased product component longevity would shift a resource burden from the use- to the production phase of the lifecycle, the need for a robust calculation model is identified as a prerequisite. Further, Kamiono works towards upgrading its product components to ensure low energy use. As new product components are often more energy efficient, detrimental effects of extending product lifetimes through remanufacturing have been reported (Gutowski et al., 2011). The company's upgrading efforts may serve to mitigate this problem.

Lastly, the Case Company Kamiono's PSS offering is assessed in relation to the need to mitigate rebound effects. As Kamiono provides its PSS with a focus on the benefit of risk-sharing, reduced bound capital and ease-of-use, capital freed up with customers is a minor concern. However, as Kamiono benefits economically from providing PSSs, this is likely to lead to rebound effects based on increased lifecycle efficiency through providing PSSs and thus, may be detrimental to the target of absolute resource decoupling. 


\section{Chapter 5}

\section{Discussion - Supporting Design and Provision of PSSs}

In this chapter, the results presented in the appended publications are analyzed and discussed in the context of prior research and of one another towards providing broader and deeper insight. Although the subchapters focus on the respective four research questions, an effort is made to clarify their interrelations and mutual impacts. In all cases, the overall aim to support manufacturing companies towards effective and efficient PSS design and provision is in focus.

\subsection{PSS Design and Provision - Challenges, Effects, Intended Solutions}

Change is never easy. Implementing a new way of conducting business by way of "open heart surgery," i.e., while operating on the living corporate body and continuing business as usual at the same time, must lead to challenges. This subchapter will discuss the challenges manufacturing companies have been found to experience in adjusting their design and provision to PSSs, and the possible impact of methods to alleviate those.

Based on in-depth research into the design and provision of the two manufacturing companies Navitas and Levor reported in Publications 1 and 2, it became clear that neither case company had adjusted its processes substantially to the changes occurring as a result of their expansion towards PSSs (see e.g. Akasaka et al., 2012; Sundin et al., 2009; Wolfenstetter et al., 2015).

Resulting from an early study presented in Publication 1, initial causes for the lacking adaptation of the design processes, in particular, were identified. These largely serve to reinforce and expand the understanding existing in prior research.

When expanding to highly integrated PSSs, the use phase processes previously handled by customers in the case of product sales are now controlled by the provider. However, in the empirical work conducted for Publication 1, it became clear that this aspect had not been taken into focus by the case companies during the design phase of the offering. A central cause for the companies lacking the expected adaptation of the design and provision of PSSs has been found to reside with the insufficient internalization of customer requirements (Publication 1). 
Lindahl et al. (2014a) report on the internalization of processes previously carried out by customers through the provider as a result of their expanding role in the use phase of the offering. It was seen, though, that the internal divisions of PSS providers struggle to exert the same pressure (e.g., for lowered cost or increased resource efficiency in the use phase) that the external customer previously applied. Further, although remanufacturing is seen as central both when discussing PSSs as such (Sakao and Mizuyama, 2014) and particularly with respect to efficiency (Sundin and Bras, 2005) and effectiveness towards a CE (Lieder and Rashid, 2016), the influence of this key lifecycle stage on the design of the offering was found to be small (Publication 1).

Departing from these initial causes, an in-depth study explored and identified several deeply rooted challenges for manufacturing companies in their expansion to the design and provision of PSSs (Publication 2). It was found that these challenges emerge both based on the causes of lacking adaptation identified and based on results of that situation. Figure 12 provides an initial overview of the central challenges identified with the case companies Levor and Navitas.

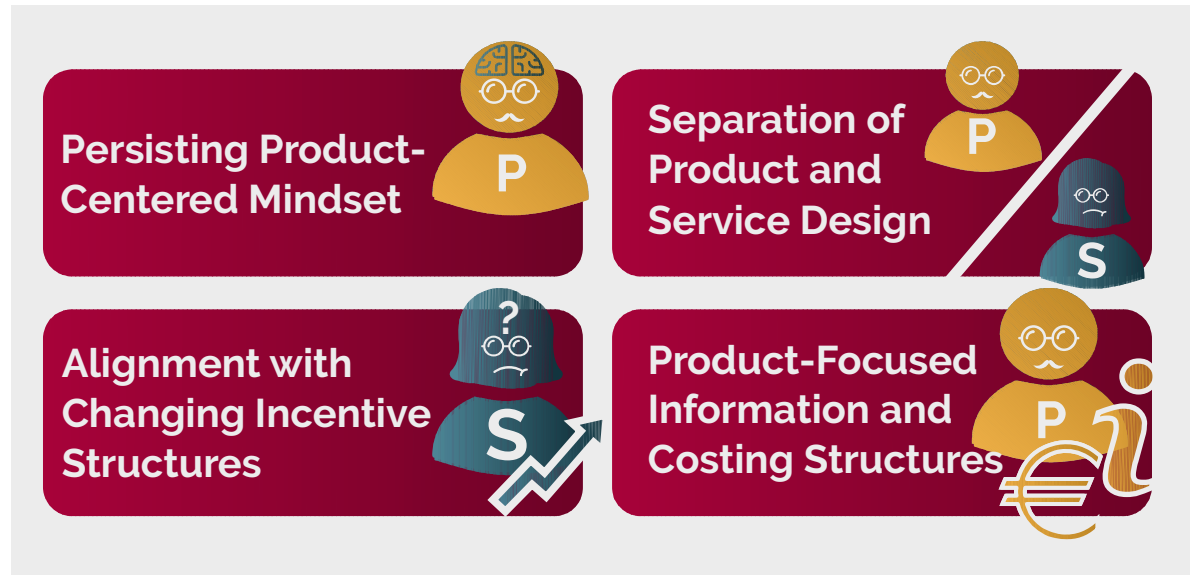

Figure 12: Challenges in servitization identified with case companies Navitas and Levor*

\subsubsection{Persisting Product-Centered Mindset}

\section{Challenge}

A key issue was identified to be the persisting product centered mindset amongst practitioners in PSS design and provision. The topic of mindset is mentioned frequently in research on servitization (Smith et al., 2014), design (Daalhuizen et al., 2014) and PSSs (Tan, 2010; Wang et al., 2011; Wolfenstetter et al., 2015), while the results presented in Publication 2 provide tangible evidence for the impact of path dependency in design on the servitization of manufacturing companies.

\section{Impact on Effectiveness and Efficiency}

This mindset challenge has an impact on both the effectiveness and efficiency of PSS design and provision and the resource efficiency and effectiveness of the 
offering as a whole, as it is connected to the entirety of the lifecycle involving company staff. Gebauer et al. (2006) see a lifecycle and PSS-centric mindset as particularly critical with sales and service staff, to the presence of which Publication 2 has raised doubts concerning Case Company Levor. Martinez et al. (2010) discuss the challenge of mindset adaptation in connection to the changed decision-making speed when moving to PSSs, which in turn may be impactful regarding effective and efficient design and provision. Focusing on efficiency and effectiveness in a $\mathrm{CE}$ context, the question of a changing mindset is considered critical in order to facilitate the transition to a circular business model (Rizos et al., 2016).

\section{Intended Solution}

No single method can be pointed out to alleviate the challenges of adapting a product-centered mindset towards a PSS focus, as methods themselves require a fitting mindset to be implemented and used successfully (Gericke et al., 2016). However, PSS design methods such as those discussed in Publication 2 (e.g., Sakao et al., 2009) can provide an overall backdrop to a comprehensive adaptation of a manufacturing company's expansion towards the design and provision of PSSs, in the wake of which the employees' mindset would be likely to shift gradually as well.

Recently, the tactics of employees in advancing servitization within manufacturing companies have been investigated, showcasing the possible impact of individual action on the organization as a whole (Lenka et al., 2018b). With respect to the challenge of a product-centric mindset in the manufacturing companies investigated, particularly the "evangelizing tactic" (ibid., pg. 4) bears relevance and excellently matches the approach to advancing servitization employed by two engineers, central project members and data gathering respondents at Levor. In the long run, such individual action may contribute to alleviating this challenge.

\subsubsection{Separation of Product and Service Design}

\section{Challenge}

The mindset-challenge is closely connected to the issue of separation of product and service design. This challenge of separate product and service-centric activities in the industry is remarked in extant literature, e.g., by Tan et al. (2010), Sakao and Shimomura (2007) and Spring and Araujo (2017). In the cases explored, this separation challenge is of a temporal, organizational and structural nature.

\section{Impact on Effectiveness and Efficiency}

The temporal separation of product and service design may have a substantial impact on the efficiency of maintenance and servicing in the use phase of the PSS. Where service is considered at a late stage of the design process, as in the case of Navitas, lacking use phase efficiency is likely (Datta and Roy, 2010). This effect

only grows when considering resource effectiveness and closing and slowing loops (Bocken et al., 2016; Fargnoli et al., 2018). Where provider activities during the use phase are of low priority at the design stage, a detrimental impact on 
resource value retention and the utilization of additional or extended lifecycles must be supposed.

Considering the organizational separation of product and service design, inefficiency at the design stage is the likely result. Multifunctional design teams are considered crucial to successful PSS design (Isaksson et al., 2009; Rossi et al., 2016), and the possibility of direct interaction between designers with different foci (e.g., products and services) may lead to superior results.

This, in turn, may be hampered by the structural separation of product and service design discovered. Given the history of manufacturing companies, the product design department is vastly larger than service design. This situation maintains the narrowness of focus on design and production and is likely to solidify the negative effects on the effectiveness and efficiency of PSS design and provision throughout the lifecycle.

\section{Intended Solution}

Getting a full understanding of the status quo of how design is currently carried out is considered a meaningful starting point. Actor mapping provides the opportunity to attain an in-depth view of the actors and the interaction among them, providing a reality check to organizational charts (Lindahl et al., 2014a). Again, a comprehensive PSS design method may provide the backdrop for a growing understanding of a need for adjustment.

\subsubsection{Alignment with Changing Incentive Structures}

\section{Challenge}

Lacking alignment with changing incentive structures is a further central issue reported. This concerns, in particular, the shift away from a value capture at the time of the sale towards continuous value capture throughout the use phase(s) of the PSS lifecycle. The importance of changing incentives and adapting to them when moving from being a maker and seller of products to becoming a provider of PSSs is discussed in prior research (Sundin and Bras, 2005; Windahl and Lakemond, 2006; Laperche and Picard, 2013).

\section{Impact on Effectiveness and Efficiency}

The main impact in terms of changing incentives when moving towards PSSs identified with both case companies Navitas and Levor is the shift of service and maintenance from being a source of revenue to becoming a cost. When this is not fully understood, inefficient PSS provision is a likely result. When it comes to effectiveness and closing, and slowing loops, a lacking understanding of the impact of additional or longer lifecycles will decrease the gains possible.

\section{Intended Solution}

A key way forward to enhance the alignment of manufacturing companies to the incentives of providing highly effective and efficient PSSs was found in attaining 
a comprehensive understanding of value capture, e.g., as described in Publication 4 through provider value analysis and provider value evaluation. Through a complete overview of the lifecycle(s) of an offering and the way a PSS provider captures value throughout it, sources of inefficiency can be identified.

Further, focusing on resource effectiveness towards a $\mathrm{CE}$ becomes viable if the value of prolonged or additional lifecycles is understood, as indicated by the quote of a business solutions manager in Publication 2 (pg. 2162): "My perspective is that first life is interesting, but really it's the second life where we can make money." If such a sentiment can become a foundation of business decisions based on fact, substantial effectiveness improvements become viable (Publication 2).

\subsubsection{Product-Focused Information and Costing Structures}

\section{Challenge}

This challenge further exacerbates the lacking alignment to changing incentive structures. Even if that was rectified, it was found that the case companies would have difficulty to measure and act upon the adjusted incentives, as both information handling and costing remains product-centric. While, e.g., the topic of "information silos" is discussed in the servitization context (see Opresnik and Taisch, 2015), Publication 2 points out related issues based on key data not being collected, lacking data analytics and continued product-focused data gathering.

\section{Impact on Effectiveness and Efficiency}

Gathering, understanding and applying data has been marked an important success factor for PSSs, particularly where effectiveness, efficiency, and a CE contribution are considered (Jabbour et al., 2017; Pagoropoulos et al., 2017; Bressanelli et al., 2018). However, faced with a prevalent product focus, an absence of understanding of the PSS lifecycle(s) and lacking incentives adjustment make meaningful data collection exceedingly difficult.

This is likely to be detrimental to use phase efficiency, as crucial efficiency drivers such as condition-based monitoring and predictive maintenance (Martinez et al., 2017; Kane et al., 2018) cannot be fully exploited. Considering resource effectiveness and closing and slowing loops, the inability to apply data-driven lessons learned in the design phase can have a particularly negative impact (Yang et al., 2009; Song and Sakao, 2017).

\section{Intended Solution}

PSS-centric lifecycle costing is discussed as a central remedy for this challenge (Sakao and Lindahl, 2015; Kambanou and Lindahl, 2016). The possible impact of such an extensive effort is shown by a quote from an R\&D Advisor reported in Publication 2 (pg. 2159): "We don't have a very good model for saying: Perhaps it is worth making a part a little bit more robust and a more expensive design because from a lifecycle cost it will be more beneficial. [...] For product cost we have a very clear model and it is very easy to make a decision from that [...]. You need to show the money to 
make the change, you can't say it feels like it is better to do it this way." Thus, a lifecycle cost-centric approach may be impactful with a focus on efficiency, but even considering effectiveness when taking into account subsequent lifecycles may benefit from this.

\subsubsection{Summary}

When discussing the challenges identified at case companies Navitas and Levor in light of prior research, considerable repercussions concerning the effectiveness and efficiency of the design and provision of PSSs from a business perspective and with regard to resource efficiency and effectiveness towards a CE emerge. As discussed and partly implemented with the case companies Navitas and Levor, prescriptive methods are pointed out as ways forward. Departing from this, the following subchapter discusses the current impact of such prescriptive approaches at large and aims to provide assistance to ensure methods become better suited to support effective and efficient PSS design and provision.

\subsection{Methods - Solution or Challenge?}

Methods are presented as a means to solve both the challenges of expanding towards PSS design and provision and the associated processes of change both in prior research (Aurich et al., 2010; Vasantha et al., 2012; Vezzoli et al., 2015) and in all appended publications, as they can reduce uncertainty (Gidel et al., 2005; Erkoyuncu et al., 2011), formalize decision-making (Luo and Wood, 2017) and provide learning opportunities (Lindahl, 2005). However, it is the methods themselves that are also seen as severely challenged (Publication 3).

Researchers point out that few of the methods produced in academia are used outside of direct collaborations with industry practitioners (Araujo et al., 1996; Geis et al., 2008) and that they are either too focused (Tukker, 2015) or too broad (Vasantha et al., 2012) to be practical to use.

A fundamental bias of the research conducted was on the applicability and relevance of methods, particularly for the design and provision of PSSs. However, the challenges identified for methods in PSSs and engineering design were reflected upon when evaluating and discussing methods in the course of the research journey. This also applies to the intended solutions discussed in relation to the challenges of expanding towards the design and provision of PSSs in Chapter 5.1.

The methods discussed as intended solutions in connection to the challenges isolated are fit to provide support to the manufacturing companies investigated in Publication 2. However, there is a critical caveat: These methods draw their applicability and impact within the case company from being applied with the support of researchers in a collaboration, or with consultants. This alleviates some of the current shortfalls of methods, e.g., with regard to potential users lacking awareness of their benefits (Araujo et al., 1996), their suboptimal presentation 
(Tromp and Hekkert, 2016) and their structural rigidity (López-Mesa and Thompson, 2006). However, improving the utility of methods in practice to support solving the challenges of PSS design and provision is a crucial aspect of enhancing efficiency and effectiveness.

Based on this motivation, an in-depth investigation into the causes of lacking method adoption and use was conducted, leading to the conception of a structured method of broad scope for the development of design methods, departing from, e.g., Lindahl (2005). This method was reported in Publication 3. This circular argument, a method to develop and select methods, might be puzzling, but this approach corresponds directly to a clearly voiced need in the field of engineering design research: Reich (2017) calls for an increase in reflexiveness. In that sense, design research should be conducted much in the same sense as design is - or should be - carried out. The development of a method to design and select design methods is, therefore, a direct response to the apparent deficiency in this area.

The method proposed was applied in the course of the research to identify both requirements of practitioners on design methods for PSSs, and to isolate essential characteristics of such methods as guiding lights for the development of methods with the prospect of enjoying high impact in practice (Publication 3). Beyond the results of this effort reported directly regarding Publication 3, particularly one of the cases reported therein is worthwhile to discuss. Here, an academic expert ${ }^{19}$ applied Step 3 of the method to conduct a QFD-style evaluation of the correlations of requirements of design method users in practice (in turn weighed by 25 practitioners through a survey) with design method characteristics.

The result of this is shown in Table 8 of Publication 3. A reflexive discussion of this case is particularly relevant with regard to the lessons learned based on it, which are dependent on the context of the individual carrying out the assessment: When analyzing the results of the case, the background of the expert in the development and deployment of design methods with an academic background in manufacturing industry environments becomes clear. This is exemplified by the most highly ranked method characteristics being focused on adjustability and modularity of a method to be designed or selected - an expectable tendency considering the broad set of circumstances academically conceived methods should function in. Based on the brief discussion of the case, some lessons learned have been derived for academic developers of design methods with a similar background as the expert - something which also applies to the author of this thesis.

Overall, the method-centric lessons learned as well as the proposed approach and the outcome of its application (Publication 3) were seen as a step forward towards

\footnotetext{
${ }^{19}$ The expert has extensive experience in ecodesign and PSS design research and practice, and is a founding partner of an ecodesign consultancy with globally active clients.
} 
informed, goal-oriented method selection and development, particularly considering the absorptive capacity of a company (see Tromp and Hekkert, 2016; Wallace, 2011). The proposed approach also points out ways to overcome challenges of how academically conceived design methods are structured, communicated and used (Lindahl, 2005; López-Mesa, 2006). Allowing the user to identify requirements and to convert these into method characteristics enables more goaloriented method development. Although more time is spent in understanding the nature of the problem to be solved by way of a method, by avoiding iterations, overall time will likely be saved by reducing trial and error (see Lindahl, 2005).

However, one might be critical of the ambiguous nature of the process supported by the method through the inclusion of the QFD approach - a reason for some researchers to question the merit of such methods at large (Hazelrigg, 2003, 2010). However, as indicated by the success of QFD in practice, it is not optimal results that are required in situations where methods are needed. Instead, the best of the available alternatives is sought, this being true also when investigating key characteristics to fulfill practitioners' requirements on design methods.

Given this, it must be discussed how the presented results correspond to the academic discussion on academically conceived design methods and their impact in practice. The method developed and tested with practitioners and experts allows for needed reflexivity in the field (see Reich, 2017), primarily by removing the black box surrounding the process in which academic design methods are currently conceived. This facilitates continuous improvement of design methods by all members of the research community. The transitional nature of design methods also extends, of course, to the method presented to develop and select design methods itself. It does not claim to be flawless. Rather, all members of the research community are invited to make improvements and adjustments, while they must be equally well-documented, clear and open for scrutiny.

\subsection{Provider Value in PSSs - Turning Challenges into Opportunities}

This subchapter discusses the conceptualization of provider value to support the understanding of the available benefits of becoming a highly efficient PSS provider with a lifecycle perspective. Further, it considers the operationalization of this concept by way of method support to be utilized in the design and use phases of a PSS. Lastly, the influence of the lessons learned based on the discussion of RQ2 in Chapter 5.2 on the provider value evaluation method is discussed.

The discussion presented in this subchapter further builds, in part, on the outcomes of the elaborations towards RQ1 in Chapter 5.1. With regard to challenges of manufacturing companies' expansion towards PSS design and provision, mainly the challenge of a lacking alignment with changing incentives structures is taken into focus, while the challenge of product-focused information and costing structures also bears relevance. The concept of multidimensional value capture for providers of PSSs is seen as an important stepping stone towards supporting 
manufacturing companies in becoming effective and efficient providers of PSS. It departs from their existing understanding of value and expands and highlights its role particularly in this new, lifecycle-centric context.

\subsubsection{The Provider Value Concept}

When shifting from a focus on product sales to PSSs with high levels of integration, the value capture changes from capturing monetary value in exchange at the time of the sale (Grönroos and Voima, 2013) to a continuous capture of multidimensional value throughout. Figure 13 summarizes the change in value capture when moving from product sales to PSSs provision.

\section{Value Capture for Product Sales}

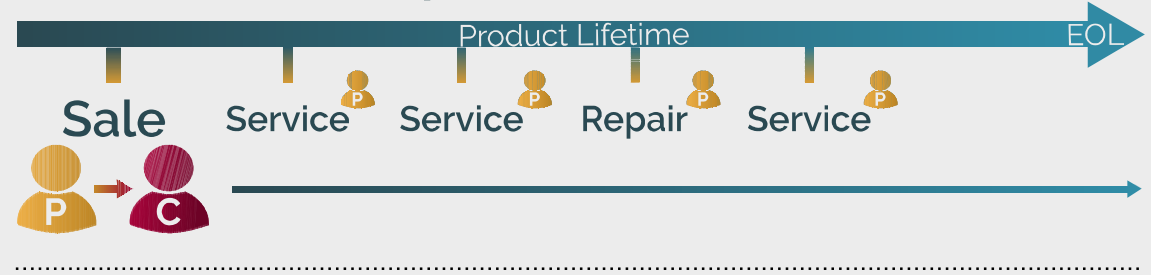

\section{Value Capture for Product-Service Systems}

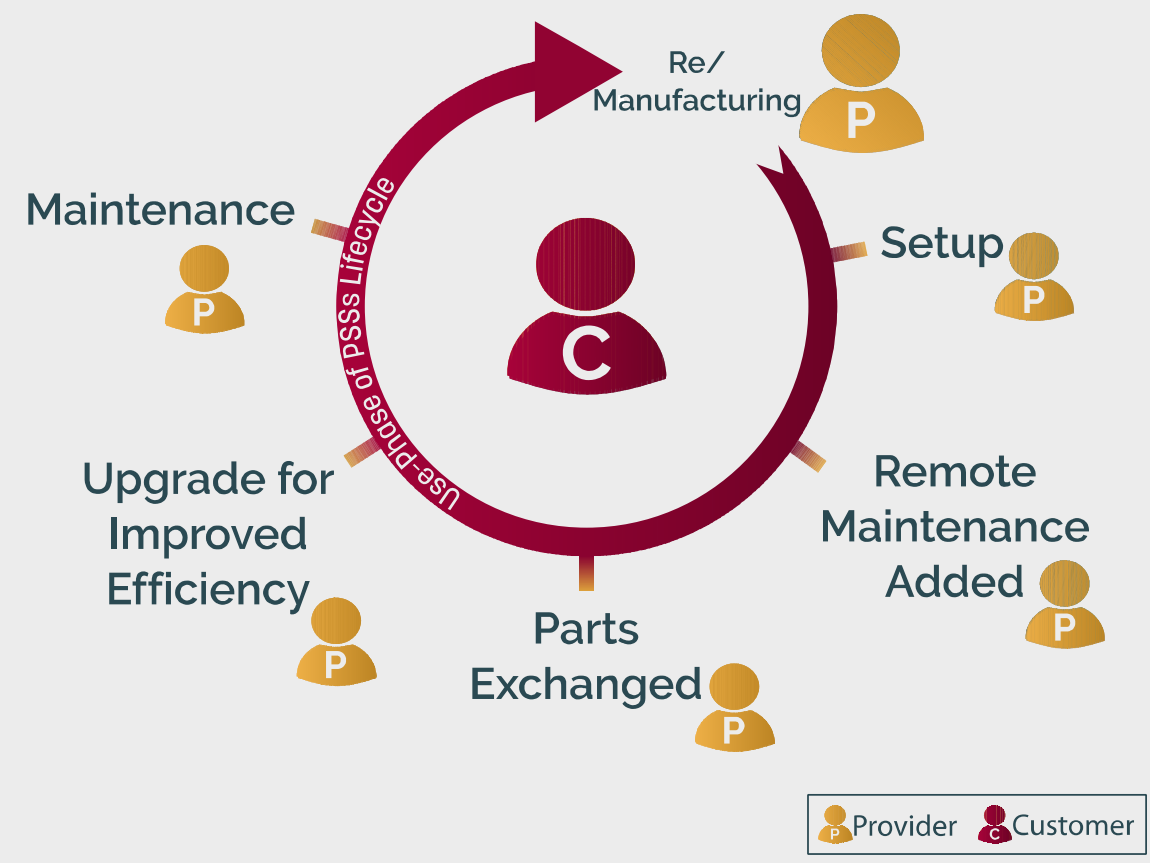

Figure 13: Value capture in product sales and PSSs (Matschewsky et al., 2018b).

In the case of product sales, the value capture in a singular moment in time warrants a focus on maximizing just this, e.g., by focusing on increasing profits by 
decreasing the costs of manufacturing. For PSS providers, however, the opportunity to capture multidimensional value throughout the lifecycle arises, especially in cases of highly integrated PSSs where the provider remains in the ownership and control of the offering (Publication 4).

From the provider's view, this can still be considered value in exchange, while the points of exchange have become many and are dispersed throughout the lifecycle. Further contrasting product sales, the value captured through providing PSSs spans beyond immediate monetary aspects. This topic is discussed in the literature as intangible value (Steiner and Harmon, 2009; A. Bertoni et al., 2015) where, e.g., knowledge is seen as a key value dimension in the context of PSSs.

However, this conceptualization was not well-exploited in the day-to-day practice of the Case Companies Arantius ${ }^{20}$ and Ericsson when investigating their PSS design and provision. Instead, a focus on out-of-gate cost, conflicting cost targets for the design and use phases and therefore an overall concentration on value in exchange in the sense of product sales remained with these PSS providers (see Publication 2 and Chapter 5.2). A central cause for this may be the duality of productand PSS-centric business models, which is often found in practice (see Kowalkowski et al., 2015; Lenka et al., 2018a).

As a result, PSS providers are likely to miss several of the opportunities for value capture attainable through a more long-term, lifecycle(s)-oriented understanding of value (Publication 4). This, in turn, would make efficient PSS provision much more difficult, as a PSS provider would continue to optimize for a product salescentric value capture, which manifests itself, e.g., in sales-centric costing approaches (see Settanni et al., 2015). With regard to effectiveness (in the sense of closing and slowing loops) missing incentives and missing understanding of the full value capturing opportunities may have a similarly adverse effect.

By providing a comprehensive understanding of the value capture based on highly integrated PSSs, a first step could be taken towards mitigating this challenge. However, merely laying out for a PSS provider that it is faced with a complex value capture that does not fit its current modes of assessment and operation is unlikely to lead to adjusted processes of design and provision, and thereby enhanced effectiveness and efficiency throughout the lifecycle. Thus, to operationalize the concept of provider value, to make it graspable and facilitate its integration into day-to-day business, a method and an approach were developed based on the needs in manufacturing industry practice.

\subsubsection{Supporting Analysis and Enhancement of Provider Value}

With the aim of providing structured support to enhancing the lifecycle-focused value capture of PSS providers, a dual approach emerged in working with Case

\footnotetext{
${ }^{20}$ Pseudonym used exclusively in Publication 4, refers to the same case company as Navitas or Levor, while the exact relation cannot be disclosed. For details, please see Chapter 1.5.1.
} 
Company Arantius (see Publication 4): A comprehensive understanding of the current value capture could only be attained in the use phase; therefore, the current PSS offering must be investigated first. This is supported by the provider value analysis approach (see Chapters 3.3.3, 4.4 and Publication 4). Then, the information gathered can be transferred and applied in the design phase towards a subsequent iteration based on provider value evaluation (see Chapter 4.4 and Publication 4).

Figure 14 provides an overview of the connection of analysis and enhancement of provider value throughout the PSS lifecycle.

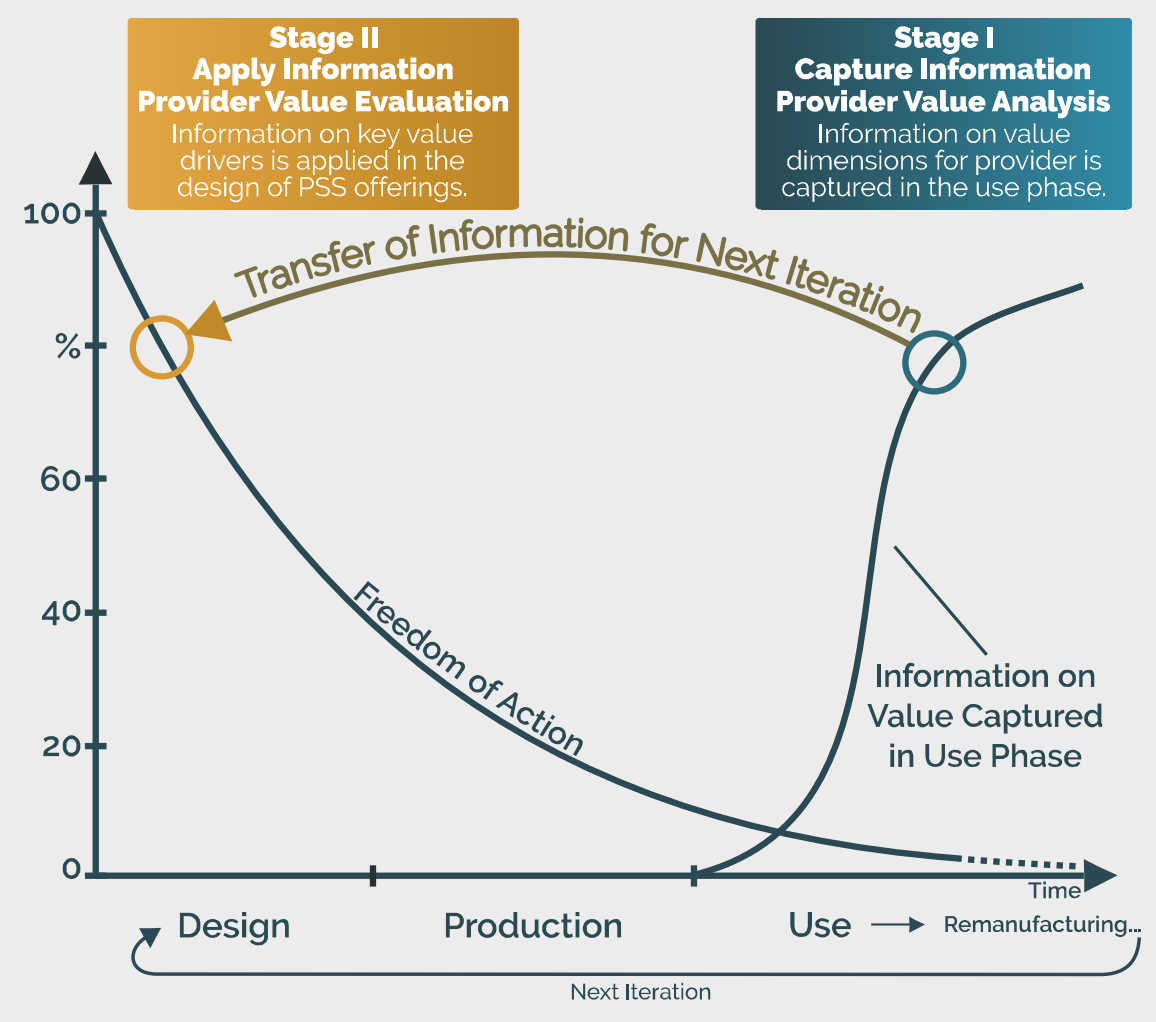

Figure 14: Analyzing and enhancing the capture of provider value (Matschewsky et al., 2018b)

\subsubsection{The Impact of Provider Value in a Manufacturing Industry Context}

The application of the provider value analysis approach with practitioners active in the use phase of Case Company Arantius' PSS provision yielded a set of provider value dimensions. These value dimensions were clustered to facilitate their application and to increase their relevance beyond the case company (see Table 5, Chapter 4.4). 
The clustered value dimensions were assessed by design stage practitioners for their relevance as indicators to be used in the design process. The results, reported in Table 6 (Chapter 4.4), underlined the relevance of the identified value dimensions to enhance the PSS provider's value capture. Further, a proportional increase of the value dimensions' relevance with the increase of product-service integration points to a particular relevance of the provider value concept for highly integrated PSSs.

The clustered value dimensions, corresponding to a number of the provider value metrics reported by Bertoni et al. (2017), constitute a step towards the identification of broadly applicable indicators. These, in turn, may allow for a provider value-focused design, provision and management of PSSs based on existing company processes and without the need to apply additional method support. Although the value dimensions identified may not be comprehensive and applicable in all cases, they provide a point of departure for companies without the resources or focus to carry out their own analysis.

The concept of provider value, as well as the presented method and approach, are considered to be helpful to more efficiently and effectively design and provide PSS offerings (Publication 4). In this, provider value may be one stepping stone to overcoming challenges of manufacturing companies' expansion to PSS design and provision remarked in Publication 2 and, e.g., in Martinez et al. (2010) and Zhang and Banerji (2017). With respect to the challenge of lacking alignment with changing incentive structures, the provider value concept in general and the provider value evaluation method, in particular, were seen as valuable by practitioners at Case Company Arantius to achieve a comprehensive understanding of the changes occurring when moving towards PSSs.

By providing indicators in the form of provider value dimensions, a transition away from a product sales-oriented understanding of cost, resolving a further challenge discussed in Chapter 5.2, is facilitated. If implemented, a consideration of both customer and provider value with a perspective on the lifecycle(s) can be a meaningful driver for comprehensively increased effectiveness and efficiency.

The results reported in Publication 4 show that the multidimensional and lifecycle-centric concept of value capture through PSSs is a viable approach to communicate and realize the advantages of making profound adjustments to existing, product-focused design and provision processes pointed out, e.g., in Bertoni et al. (2017) and Mourtzis et al. (2016).

Concerning the status quo on value assessment in prior research, the proposed approach may enhance existing methods that have a conceptual focus (Alix et al., 2009; Kimita et al., 2009b; Bertoni et al., 2011; Rondini et al., 2017). The proposed provider value analysis approach and provider value evaluation method can be seen as complementary to conceptual approaches, as they exhibit a stronger focus on detailed design evident in the component-centric nature of the design-oriented assessment. 
Through the joint presentation of the use phase and design phase-centric methods, a structured approach for improvements through subsequent iterations of design and provision is proposed. In its application within a direct academia-industry collaboration, the provider value concept has served to facilitate communication with top management, which is a critical factor in the expansion towards PSS design and provision (Windahl, 2007). This aspect was particularly crucial as many practitioners were aware of the changes in value capture when becoming a PSS provider but lacked a common way of communicating in this regard (Publication 4).

Therefore, in expanding the state of the art on the multidimensional value to be captured by PSS providers, a step is taken towards reaping the expected benefits of this type of high-efficiency, high-value offerings in manufacturing industry practice indicated in earlier literature (Meier et al., 2010; Tukker, 2015).

\subsubsection{Improvement of the Provider Value Evaluation Method}

The provider value evaluation method serves as a showcase for the possible impact of the structured approach to the development of design methods for PSSs proposed in Publication 3 and Chapter 4.3. As a result of the application of this proposed method, guidelines for method development were identified (see column 1 of Table 8 below).

Closely related to these guidelines and based on the needs of industry users, the method underwent the changes shown in Table 8.

Departing from the initial conception in Matschewsky (2012) and through its iterations shown in Matschewsky et al. (2015b) and Matschewsky et al. (2018b), the method shown in Matschewsky (2018) represents the current and most industryoriented version of the method (see Figure 15). While these iterations precede the assessment of the expert represented in Publication 3, they reinforce the relevance of the PSS design method characteristics discussed in Matschewsky et al. (2015a) and Matschewsky (2016). 


\begin{tabular}{|c|c|c|}
\hline Guideline & Initial Version & Adjusted Version \\
\hline $\begin{array}{l}\text { To ensure a method supports a } \\
\text { standardized design process and } \\
\text { can therefore be integrated } \\
\text { with the existing design pro- } \\
\text { cesses, focus on developing } \\
\text { modular and adjustable meth- } \\
\text { ods. }\end{array}$ & $\begin{array}{l}\text { The ProVa method was ini- } \\
\text { tially a structured, seven-step } \\
\text { method with a number of } \\
\text { mandatory feedback loops } \\
\text { and no flexibility but a re- } \\
\text { quirement of stepwise com- } \\
\text { pletion. }\end{array}$ & $\begin{array}{l}\text { The ProVa Core has only three } \\
\text { basic mandatory steps; the re- } \\
\text { mainder is provided as op- } \\
\text { tional modules in ProVa Plus } \\
\text { to provide additional depth } \\
\text { and insight. }\end{array}$ \\
\hline $\begin{array}{l}\text { Ensuring the design method } \\
\text { developed is useful early in the } \\
\text { design process, allows the } \\
\text { method to accept little and } \\
\text { rough data and still provide a } \\
\text { meaningful result. }\end{array}$ & $\begin{array}{l}\text { The ProVa method initially } \\
\text { required substantial data with } \\
\text { high granularity to be gath- } \\
\text { ered, both regarding value } \\
\text { and the uncertainty assess- } \\
\text { ment. }\end{array}$ & $\begin{array}{l}\text { The uncertainty assessment } \\
\text { was simplified substantially } \\
\text { and made optional, and the } \\
\text { value assessment now has a } \\
\text { stronger focus on sensitivity. }\end{array}$ \\
\hline $\begin{array}{l}\text { To make sure a method } \\
\text { supports communication across } \\
\text { relevant actors, it can be help- } \\
\text { ful to ensure it is adjustable to } \\
\text { existing processes and can be } \\
\text { used by a broad set of practi- } \\
\text { tioners with various back- } \\
\text { grounds. }\end{array}$ & $\begin{array}{l}\text { Substantial knowledge } \\
\text { required by a single } \\
\text { individual regarding } \\
\text { engineering, value and the } \\
\text { economic assessment. }\end{array}$ & $\begin{array}{l}\text { Modularity and interfaces al- } \\
\text { low for several individuals to } \\
\text { complete the assessment in- } \\
\text { dependently of one-another. }\end{array}$ \\
\hline $\begin{array}{l}\text { If an important requirement } \\
\text { on a design method is easy to } \\
\text { use, the adjustability to existing } \\
\text { processes and the simplicity of } \\
\text { the methods process should be } \\
\text { considered. }\end{array}$ & $\begin{array}{l}\text { ProVa had a structured flow } \\
\text { without the ability for adjust- } \\
\text { ment, no interfacing and no } \\
\text { flexibility in the order of } \\
\text { tasks. }\end{array}$ & $\begin{array}{l}\text { At its most basic, the method } \\
\text { has just three steps. Due to its } \\
\text { modularity, it supports inte- } \\
\text { gration into existing pro- } \\
\text { cesses and does disrupt daily } \\
\text { business through workshop } \\
\text { sessions. }\end{array}$ \\
\hline $\begin{array}{l}\text { When easy to learn is a critical } \\
\text { requirement, it appears that } \\
\text { how the method is } \\
\text { communicated is more im- } \\
\text { portant than the content of the } \\
\text { method as such. Providing a } \\
\text { handbook or video instruc- } \\
\text { tion can be helpful. }\end{array}$ & $\begin{array}{l}\text { ProVa was initially only de- } \\
\text { scribed in a thesis and scien- } \\
\text { tific publications. No further } \\
\text { support for its execution was } \\
\text { available. }\end{array}$ & $\begin{array}{l}\text { A handbook edited by prac- } \\
\text { tice-oriented consultants was } \\
\text { produced, and along with it, a } \\
\text { document to carry out the } \\
\text { method and an automated } \\
\text { spreadsheet were developed. } \\
\text { The spreadsheet is in fre- } \\
\text { quent use by students in the } \\
\text { author's course "Integrated } \\
\text { Product-Service Engineering" } \\
\text { at LiU. }\end{array}$ \\
\hline
\end{tabular}




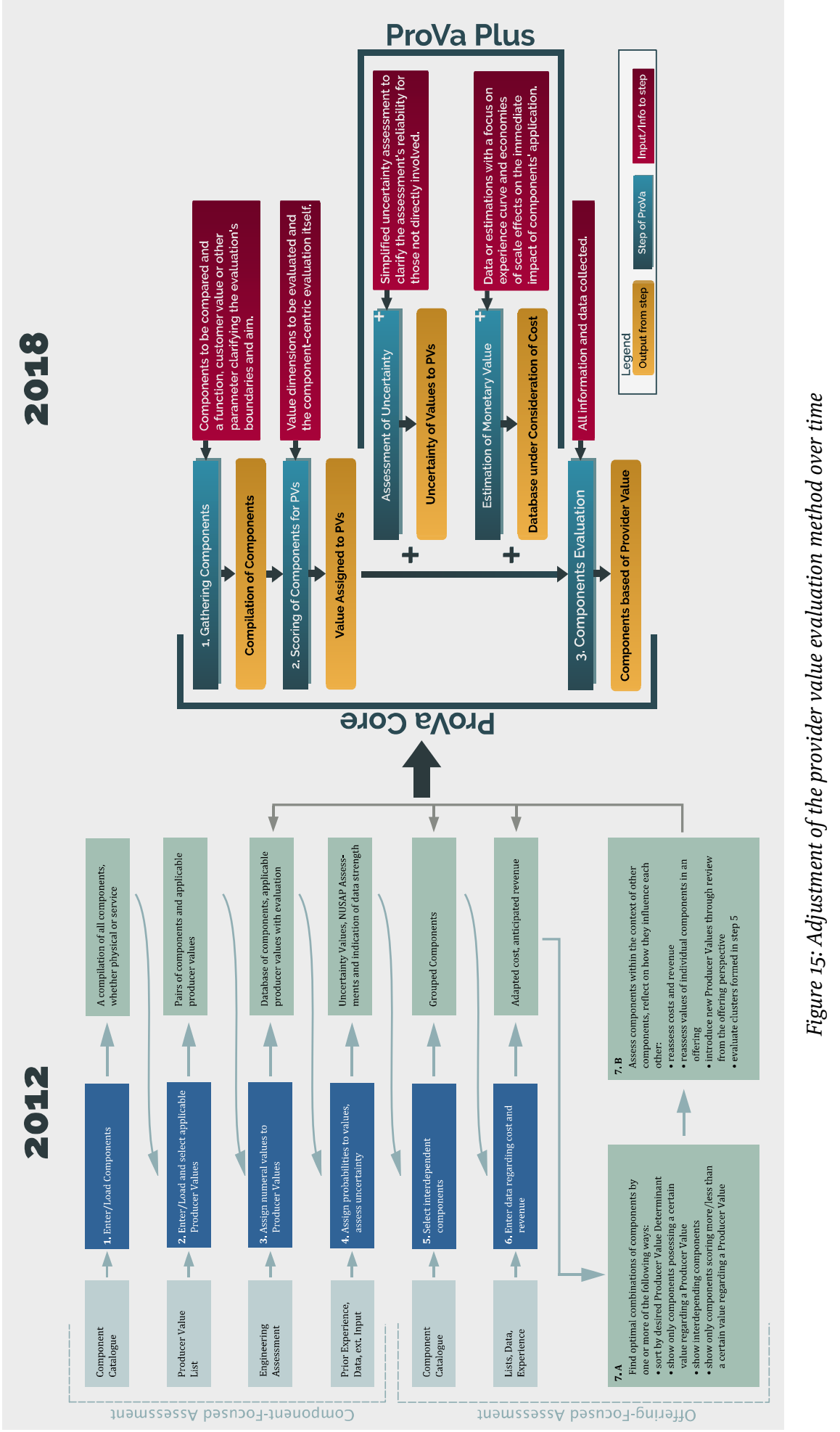




\subsection{Efficient and Effective PSSs Towards a Circular Economy}

For more than two decades now, the contribution of PSSs to a resource reduction throughout the lifecycle has been a key aspect in the focus of ongoing research (Goedkoop et al., 1999; Mont, 2002; Tukker, 2004). Despite this, investigating the actual contribution of PSSs to improved environmental performance remains challenging (Kjaer et al., 2018). With the emergence of the CE concept, an increasing emphasis is on investigating and supporting the development and implementation of PSSs with this focus (Spring and Araujo, 2017; McAloone and Pigosso, 2018; Kjaer et al., 2019). Examples reporting on the environmental performance of PSSs can be found in prior research (Lelah et al., 2011; Lindahl et al., 2014b; Kjaer et al., 2018). However, these largely treat the design and provision of the PSS as a black box, failing to provide detail about the processes determining the resource efficiency and effectiveness throughout the lifecycle.

\subsubsection{PSSs Towards a CE Without the Help of Methods}

A number of frameworks, strategies, and aids supporting the implementation of circular business models such as PSSs have been made available (EMF, 2015b; Lieder and Rashid, 2016; Heyes et al., 2018; Kalmykova et al., 2018; Manninen et al., 2018). Based on the criticism towards such academically conceived support discussed towards RQ2 in Chapter 5.2, it must be assumed that many companies expand to PSSs as a circular business model without and unaware of the existence of such support. Therefore, advancing the state of the art regarding the contributions of PSSs to a CE based on an unsupported, economically-motivated expansion may be interesting and relevant to the overall understanding regarding the real-world impact of both concepts. The company investigated in Publication 5, Kamiono ${ }^{21}$, has a background in producing and selling physical goods and has become a PSS provider largely as a result of economic motivation.

While this discussion relies on Publication 5, the lessons learned are informed by the experiences and understanding attained with manufacturing companies through five years of practice-driven research.

\subsubsection{PSSs Towards Per-Unit Efficiency and Effectiveness}

Information technology and the use of data captured through it have been reported as key facilitators of a CE in practice (Spring and Araujo, 2017; Bressanelli et al., 2018; Heyes et al., 2018). However, actual examples of its application towards improved performance regarding a CE are still scarce (Pagoropoulos et al., 2017).

The results reported point to some key aspects of the Case Company Kamiono's current application of data-driven technology, e.g. with a focus on performance

\footnotetext{
${ }^{21}$ Pseudonym used exclusively in Publication 5, refers to the same case company as Navitas or Levor, while the exact relation cannot be disclosed. For details, please see Chapter 1.5.1. 
monitoring and ensuring efficient customer use, both with a positive impact on operational efficiency, and the potential to increase its impact moving forward, e.g., through the application of data in the design process. A lacking adjustment of internal incentives, as reported responding to RQ1 in Chapter 5.1, is an aspect detrimental to the CE contributions of a PSS offering (see Lindahl, 2018). This can pose a particular challenge for companies such as Kamiono, which remains a product seller while also offering use-oriented PSSs, an issue common to many PSS providers (Kowalkowski et al., 2015; Lenka et al., 2018a).

This organizational ambivalence (Lenka et al., 2018a) can lead to a number of results, potentially affecting all aspects relevant to a CE contribution: A lacking adaptation of design processes to enhance operational efficiency and product component longevity; sales staff focusing on selling higher volume instead of the creation of more customer value, which is detrimental to operational efficiency and to reducing the need for product components; and a lacking connection and information exchange between practitioners in the different lifecycle phases (Lindahl et al., 2014b; Sundin, 2018). Since the incentive shift occurring as a result of an expanded responsibility of PSS providers for the offerings throughout the lifecycle has long been described as one of the key drivers of PSSs' potential environmental contributions (Tukker, 2004; Davies et al., 2006), the persisting room for improvement makes this aspect particularly urgent (see Chapter 5.1).

Regarding other issues in focus in the assessment reported in Publication 5, the case company has managed to capitalize on the potential of PSSs and thus, enhancing its potential contribution to relative decoupling in the scope of a CE. One such example is the matter of supporting the customer's use and thus, enhancing operational efficiency. The Case Company Kamiono has understood the potential impact of customers on its provision efficiency in the scope of the use-oriented PSS. Thus, the company offers extensive training and consulting to customers and even makes use of its performance maintenance technology to, e.g., restrict use by untrained staff, further serving to enhance operational efficiency.

\subsubsection{Enhancing PSSs' Prospects of Contributing to Absolute Decoupling}

The potential of economically-motivated expansions to PSSs to contribute to the goals of absolute resource decoupling in the scope of a CE is of paramount interest concerning the discussion going beyond the case company and with a focus on the increasingly pressing issues faced by societies. As stated in Publication 5: "There are no easy answers." This becomes particularly apparent in the emergence of conflicts between the goals of utmost efficiency with respect to a CE and the supposed need for inefficiency in practice, e.g., in order to enhance customer relations as described in Publication 5. Further, it is the comprehensiveness and complexity of the requirements to achieve absolute decoupling that makes their achievement in the scope of profit-centric activities under current economic paradigms so difficult. 
A particular challenge in this context is the continuing pursuit of larger market share and market expansion by the Case Company Kamiono. Resulting from the use-oriented PSS currently provided, this expansion goes along with the continuous deployment of more physical components in the market, even if fewer components would be sufficient to provide the accumulated customer value required. The company does pursue efficiency improvements, while a shift towards making circularity a central goal would require an even more profound change in how business is conducted than the current expansion from product sales to PSSs. What this may mean is reflected upon in the following paragraph.

Focusing on absolute decoupling, the assessment conducted in Publication 5 showed that likely only result-oriented offerings, enabling value creation system substitution and thus ensuring full flexibility in how a provider strives to create customer value, can achieve this target. Any industrial company undergoing servitization will likely depart from its history and prior knowledge. Thus, to move closer towards a CE, the initial question of any design process must be the fulfillment of customer value and how this can be achieved most efficiently.

A blank canvas would be needed as a point of departure, a feat likely nearly unachievable for an established company faced with path-dependency and inertia. ${ }^{22}$ This path dependency has effects that may even be considered desirable, depending on the point of view chosen: The continuing focus of the case company on expansion and this leading to continued and expanding production of physical components is the basis of much of the company's workforce. Although desirable at scale and in light of the challenges faced by the global community, the impact of a rapid and comprehensive change to how the case company creates customer value without sufficient provisions regarding education and continued employment could be devastating to the individual.

In light of this, circumstances outside of the reach of any individual case company must change to facilitate a comprehensive advancement towards a CE. Policy adjustments are required (van Buren et al., 2016; de Jesus and Mendonça, 2018; Reike et al., 2018), and the public incentives in place must adapt to the new trajectory (Urbinati et al., 2017; Zink and Geyer, 2017), highlighting the benefits of efficiency not only on a per-unit basis (see, e.g., European Council and European Parliament, 2009) but also encompassing all economic activity towards resource reductions

\footnotetext{
${ }^{22}$ In this context, some examples may support the argument made: The innovation drivers in the automotive sector today are technology companies, not the established automakers. How we consume media at home was revolutionized not by TV companies, but by a company founded only 21 years ago to rent DVDs via mail. The smartphone was made indispensable not by Nokia, the world market leader at the time, but by a computer company that was nearly bankrupt just ten years prior. Thus, it appears that in order to find completely new, highly efficient and revolutionary answers to the ever-same questions ("How can I get from A to B?", "How can I have shelter that is warm, dry and comfortable?", "How can I nurture my mind through acquiring knowledge and entertainment" etc.), incumbent companies are facing substantial challenges (cf. Borghei, 2018).
} 
at scale. Lastly, as indicated by Kanda and Matschewsky (2018) applying the PSS concept to large technical systems and even on a societal level may be needed to move towards absolute decoupling. 



\section{Chapter 6}

\section{Supporting the Expansion to Effective and Efficient PSS Design and Provision}

In this chapter, the research presented is synthesized and summarized to provide support to manufacturing companies expanding towards the provision of PSSs. Further, direct managerial implications are given.

The aim of this thesis is to support manufacturing companies in the expansion to effective and efficient design and provision of product-service systems. Both in detailing the research method in Chapter 3 and in discussing the research results reported in Chapter 5, an effort was made to clarify the interconnections between the different research foci as operationalized through the research questions. In this subchapter, a condensed and simplified synthesis of the results is presented, intended as a starting point for readers in manufacturing companies.

This goal is approached by way of the graphic shown in Figure 16 synthesizing the results discussed in Chapter 5. For practitioners or others interested to learn more, chapter numbers and related appended publications are referenced. The graphic is intended to be read in the order of the subchapters shown, while it is possible to read it top to bottom or to concentrate on one of the four focus points as well.

Expanding from producing and selling products to becoming a provider of effective and efficient PSSs is a challenging task. The focus lies on alleviating challenges that may be experienced by companies during their expansion to PSSs through design methods and other structured approaches. For cases where existing methods do not provide a sufficient solution, or where one fitting approach simply does not exist, ways forward to develop or identify methods in a structured way are shown. An additional particular focus is on the changes in value capture when becoming a PSS provider, for which support is offered for both analysis of the status quo and future enhancements through design. Lastly, some issues to focus on to design and provide effective and efficient PSSs are laid out, aiming to enhance the capability of a manufacturing company expanding towards becoming a provider of resource-efficient and effective PSSs.

Additionally, Table 9 (pg. 98) provides direct courses of action for manufacturing companies expanding towards the design and provision of PSSs, departing from the challenges identified. 


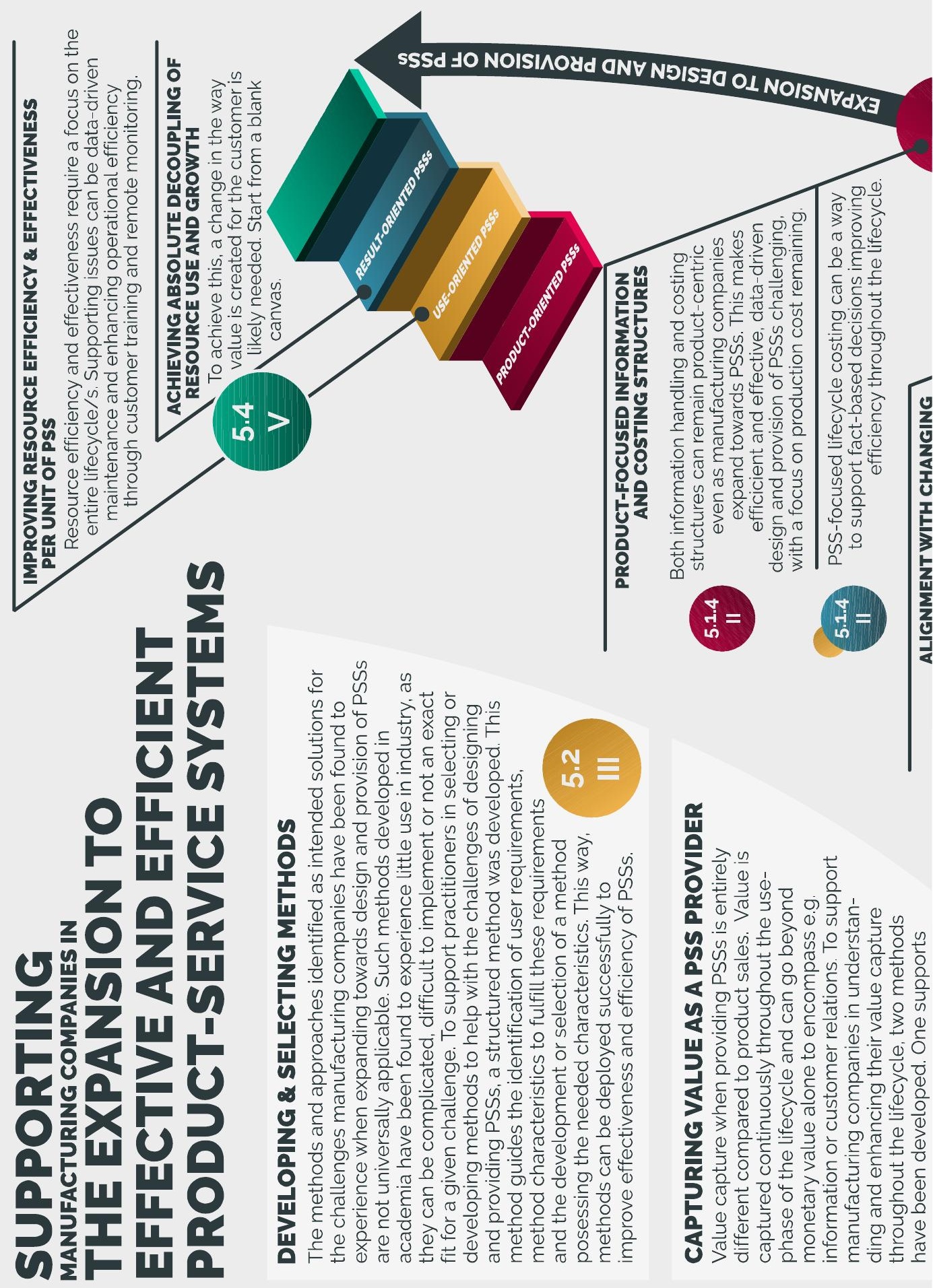




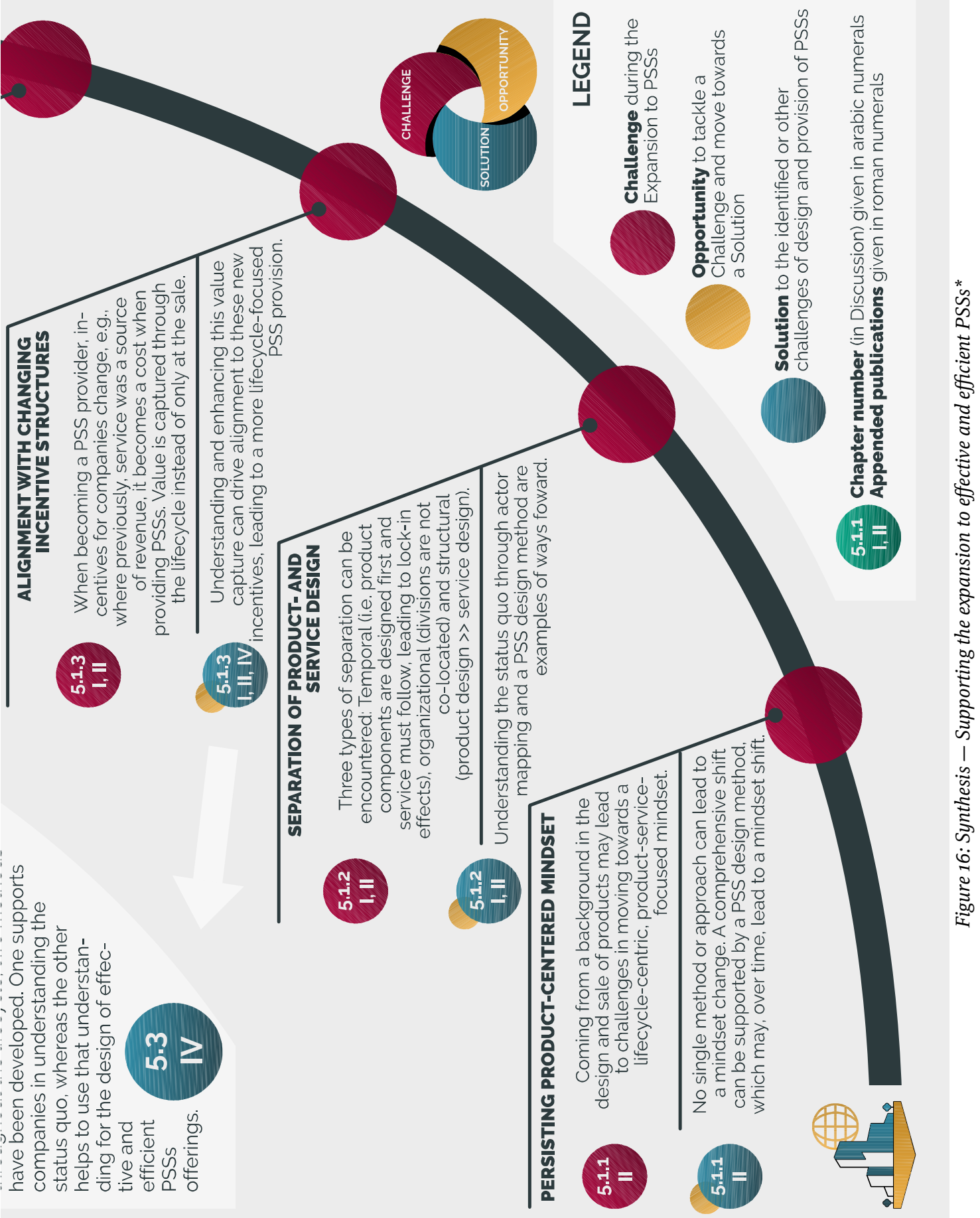




\begin{tabular}{|c|c|c|c|}
\hline $\begin{array}{l}\text { What? } \\
\text { (Course of } \\
\text { action) } \\
\end{array}$ & $\begin{array}{l}\text { When? } \\
\text { (What level of } \\
\text { PSS maturity) }\end{array}$ & How? (Approach, supporting tools) & Aspired outcome \\
\hline $\begin{array}{l}\text { Systematically } \\
\text { take account } \\
\text { of the organi- } \\
\text { zational status } \\
\text { quo to make } \\
\text { informed and } \\
\text { goal-oriented } \\
\text { decisions as to } \\
\text { what changes } \\
\text { are appropri- } \\
\text { ate }\end{array}$ & $\begin{array}{l}\text { Ideally when } \\
\text { planning to ini- } \\
\text { tially offer PSSs, } \\
\text { but at any later } \\
\text { point when in- } \\
\text { tent on chang- } \\
\text { ing approaches, } \\
\text { structures or } \\
\text { methods to be- } \\
\text { come better at } \\
\text { providing PSSs }\end{array}$ & $\begin{array}{l}\text { - Depending on company size and } \\
\text { complexity } \\
\text { - Discussions to achieve a deeper } \\
\text { understanding of actual existing } \\
\text { collaboration and lacking infor- } \\
\text { mation flows, e.g., led by PSS Fa- } \\
\text { cilitator (see below) } \\
\text { - Can be supported by a systematic } \\
\text { approach such as actor mapping } \\
\text { (see Durugbo, Tiwari, and Alcock } \\
\text { 2013) }\end{array}$ & $\begin{array}{l}\text { - Structured overview } \\
\text { of information } \\
\text { flows and processes } \\
\text { in design and provi- } \\
\text { sion of PSS as a } \\
\text { starting point for } \\
\text { adaptations }\end{array}$ \\
\hline $\begin{array}{l}\text { Designate a } \\
\text { PSS Facilitator } \\
\text { to coordinate } \\
\text { integration- } \\
\text { activities } \\
\text { within the } \\
\text { company }\end{array}$ & $\begin{array}{l}\text { Early on in prod- } \\
\text { uct-service inte- } \\
\text { gration or when } \\
\text { a lacking inte- } \\
\text { grational collab- } \\
\text { oration through } \\
\text { the lifecycle is } \\
\text { identified }\end{array}$ & $\begin{array}{l}\text { - Regular meetings including the } \\
\text { relevant departments (e.g., prod- } \\
\text { uct and service design, sales and } \\
\text { marketing, remanufacturing) } \\
\text { - Coordination of design efforts, } \\
\text { particularly in a temporal sense: } \\
\text { Focus on synchronous product- } \\
\text { service design }\end{array}$ & $\begin{array}{l}\text { - Better communica- } \\
\text { tion and under- } \\
\text { standing among } \\
\text { previously separate } \\
\text { company parts } \\
\text { - Increased efficiency } \\
\text { in design and provi- } \\
\text { sion } \\
\end{array}$ \\
\hline $\begin{array}{l}\text { Evaluate a PSS } \\
\text { design } \\
\text { method, possi- } \\
\text { bly partial im- } \\
\text { plementation } \\
\text { or process ad- } \\
\text { aptation }\end{array}$ & $\begin{array}{l}\text { At any time } \\
\text { when a lacking } \\
\text { communica- } \\
\text { tion/ under- } \\
\text { standing is } \\
\text { identified, par- } \\
\text { ticularly be- } \\
\text { tween product } \\
\text { and service de- } \\
\text { sign depart- } \\
\text { ments }\end{array}$ & $\begin{array}{l}\text { - External support (consulting, re- } \\
\text { searchers) or internal PSS facilita- } \\
\text { tor coordinates efforts } \\
\text { - Assessment of current procedures } \\
\text { is key to understand needed } \\
\text { changes and to adapt an existing } \\
\text { method or to derive a new one } \\
\text { - Integrative workshops with repre- } \\
\text { sentatives from all concerned de- } \\
\text { partments }\end{array}$ & $\begin{array}{l}\text { - Adjustments to pro- } \\
\text { cedures and ap- } \\
\text { proaches towards } \\
\text { more effective and } \\
\text { efficient PSS design } \\
\text { - Implementation of } \\
\text { method modules or } \\
\text { parts that fit the } \\
\text { current approach } \\
\text { - NOT a PSS design } \\
\text { method imple- } \\
\text { mented as is (low } \\
\text { compliance) }\end{array}$ \\
\hline $\begin{array}{l}\text { Develop a sys- } \\
\text { tematic un- } \\
\text { derstanding of } \\
\text { lifecycle cost } \\
\text { and value gen- } \\
\text { eration of PSS } \\
\text { offerings }\end{array}$ & $\begin{array}{l}\text { At a point in } \\
\text { time when such } \\
\text { an overview and } \\
\text { understanding } \\
\text { is lacking }\end{array}$ & $\begin{array}{l}\text { - Lifecycle costing of an existing of- } \\
\text { fering to have a base-line under- } \\
\text { standing from a provider } \\
\text { perspective (e.g., supported by a } \\
\text { systematic method: Sakao and } \\
\text { Lindahl, 2015) } \\
\text { - A total cost of ownership (TCO) } \\
\text { approach can be considered if a } \\
\text { stronger focus on customer cost is } \\
\text { desired (Bonetti et al., 2016) } \\
\text { - Understand key value for } \\
\text { customer as well as for own com- } \\
\text { pany with a lifecycle focus } \\
\text { - Assess and enhance value captur- } \\
\text { ing and creation in future offer- } \\
\text { ings (e.g., supported by an } \\
\text { evaluation approach: } \\
\text { Matschewsky et al., 2018) }\end{array}$ & $\begin{array}{l}\text { - Better understand- } \\
\text { ing of the actual } \\
\text { cost of activities and } \\
\text { components } \\
\text { throughout the life } \\
\text { of a PSS and the } \\
\text { value created or } \\
\text { captured } \\
\text { - An established } \\
\text { baseline for future } \\
\text { adjustments and } \\
\text { founded and quan- } \\
\text { tifiable arguments } \\
\text { for change }\end{array}$ \\
\hline
\end{tabular}




\section{Chapter 7}

\section{Conclusions and Outlook}

This chapter answers the research questions guiding the thesis work based on the results attained and discussed. Further, an outlook is given towards definite and prospective future research efforts.

\subsection{Challenges in Adjusting to the Design and Provision of PSSs}

Research Question 1 reads "How have manufacturing companies adjusted their design and provision to product-service systems?"

Judging from the viewpoint of the customers, the studied companies have become competent providers of PSSs with high levels of product-service integration throughout the lifecycle. Thus, an effective PSS provision and customer value creation can be assumed. A number of challenges, however, have been identified in terms of effectiveness and efficiency of the design and provision when investigating internal processes in manufacturing companies Navitas and Levor expanding towards PSSs. The design processes used, the mindset, the cost estimation techniques, the data handling, the incentive structures and the value perspectives present have not been substantially adjusted when departing from an exclusive product sales focus. As PSS providers take over most responsibility for the offering during the use phase, this leads to shortcomings concerning the effectiveness and efficiency of PSS design and provision throughout the lifecycle(s). Ways forward from this in the form of methods and approaches have been reported and discussed and are partly the subject of the following research questions.

\subsection{Developing and Applying Methods for PSS Design and Provision}

Research Question 2 reads "How can methods facilitating the effective and efficient design and provision of product-service systems be developed and applied?"

A number of methods and approaches are pointed out as solutions to be applied to the challenges of PSS design and provision identified in answering RQ1. However, academically conceived methods themselves have been found to suffer from shortcomings, complicating their effective use in manufacturing companies. The practical utility of these methods may be improved based on the structured method proposed, which relies on a clear process rather than keeping method development in a black box. This allows for continuous improvement of such methods by peers and facilitates their adaptation to the individual circumstances in manufacturing industry practice. In order to enhance the applicability and use of 
methods supporting PSS design and provision, method user requirements and method characteristics are reported, which were identified using the process proposed. By facilitating requirements-centric development and selection of methods, these are more likely to fulfill their task of supporting effective and efficient design and provision of PSSs rather than, at times, being an end in themselves and predominantly focused on academic publishing.

\subsection{Supporting Value Capture Throughout the Lifecycle}

Research Question 3 reads "How can the value capture through product-service systems be supported throughout the lifecycle?"

The value capture of PSS providers differs notably from that of companies exclusively engaged in the production and sale of products: The value captured through PSS provision is dispersed throughout the lifecycle(s), and often, value is captured in forms other than immediate monetary value, such as information or customer relations. Achieving a full understanding of this value capture is considered a useful stepping stone towards becoming a provider of highly effective and efficient PSSs. Manufacturing companies undergoing the expansion to PSS design and provision have been found to experience challenges in grasping this profound change in how value can be captured. As a result, neither their processes nor organizations are considerably adjusted. To support companies towards this, methods to explore how value is currently created and captured in the use phase and how to enhance future value capture based on that information in the design phase have been developed and applied in the case companies Arantius ${ }^{23}$ and Ericsson. From this, value dimensions intended to be broadly applicable have been identified, with the aim of facilitating the effective and efficient design and provision of PSSs with a lifecycle focus.

\subsection{PSSs Towards a CE Without Methods - Contributions and Shortcomings}

Research Question 4 reads "In what ways can economically-driven, unsupported expansions to product-service systems contribute to a circular economy?"

Based on an in-depth study of the manufacturing company Kamiono's ${ }^{23}$ expansion towards the design and provision of PSSs without the support of prescriptive, CE-centric methods, the contribution towards a CE based on resource efficiency and effectiveness throughout the lifecycle(s) was investigated. The investigation utilized an existing framework for the assessment of PSSs for their potential contribution towards resource decoupling in the scope of a CE. This framework was

\footnotetext{
${ }^{23}$ Pseudonym used exclusively in Publication 5, refers to the same case company as Navitas or Levor, while the exact relation cannot be disclosed. For details, please see Chapter 1.5.1.
} 
further operationalized through newly-identified assessment criteria. When considering relative resource reduction in the scope of a $\mathrm{CE}$, the study indicates that the case company's use-oriented PSS entails the potential of an improvement over a product sold to create the same customer value. However, a number of enhancement opportunities have been identified to expand the CE contribution throughout the lifecycle. With respect to an absolute decoupling of economic growth and resource consumption, it was found that use-oriented PSSs will likely be insufficient. A move towards providing result-oriented offerings with alternative, highly effective and efficient modes of customer value creation, is therefore considered vital to substantially enhance the capacity of PSSs to contribute to a CE.

\subsection{Future Research and Outlook}

Departing from the conclusions drawn on the research questions, a number of research trajectories and opportunities to expand the basis of the work emerge.

One opportunity for future research concerns broadening the understanding of manufacturing companies' expansion to designing and providing PSSs and the challenges they encounter. The results presented rely on insight gained from indepth studies of two companies, providing ample opportunity to expand the investigation. Based on this, the challenges found may be sharpened and further developed, leading to higher precision in proposing methods and approaches to move towards solving these challenges.

Connected to this, the proposed method for the structured, requirements-driven development of methods allows for extensive further research. Applying the method in manufacturing companies of different nature may point to opportunities for improvement and verify the proposed approach. A handbook will be developed, as was done in the case of the provider value evaluation method, to enable manufacturing industry practitioners to use this method without academic support.

Continuing along this prescriptive track, research in improving the effectiveness and efficiency of PSS design and provision is already under way at Levor. After four years of investigation and predominantly descriptive work, suggestions made regarding the application of methods in design, data gathering, data handling, and lifecycle focus are being used to benchmark an ongoing development project. This is likely to lead to meaningful insight and further refinement and expansion of the support available for companies seeking to expand to effective and efficient PSS design and provision.

The concept of provider value and the methods presented to operationalize it provide further opportunity for continued investigation. Based on the reflection of respondents, this shall mostly focus on method usage for learning and to provide practitioners with a comprehensive but tangible understanding of what a 
manufacturing company stands to gain from becoming a PSS provider, and designing and providing PSSs with a comprehensive lifecycle focus.

Lastly, much remains to be done with respect to understanding and supporting effective and efficient PSSs towards a CE. The proposed criteria and underlying framework should be applied to more cases of use- and result-oriented PSSs in order to investigate their comprehensiveness and robustness. Further, returning to a prescriptive lens, the lessons learned feed into the work with Levor and, likely, other future projects, broadening their impact.

The challenge of fulfilling the promises of PSSs for improved environmental performance made two decades ago still remains to be solved. This especially concerns the aspired contribution to an absolute decoupling of economic growth and resource use. By now, time is of the essence. "We are called to be the architects of the future, not its victims." - R. Buckminster Fuller. 


\section{References}

Abukhader, S.M., 2008. Eco-efficiency in the era of electronic commerce - should "Eco-Effectiveness" approach be adopted? J. Clean. Prod. 16, 801-808.

Adrodegari, F., Saccani, N., Kowalkowski, C., Vilo, J., 2017. PSS business model conceptualization and application. Prod. Plan. Control 28, 1251-1263.

Akao, Y., 2004. Quality Function Deployment: Integrating Customer Requirements Into Product Design. Productivity Press, New York.

Akasaka, F., Nemoto, Y., Kimita, K., Shimomura, Y., 2012. Development of a knowledge-based design support system for Product-Service Systems. Comput. Ind. 63, 309-318.

Alix, T., Ducq, Y., Vallespir, B., 2009. Product service value analysis: two complementary points of view, in: Proceedings of the 1st CIRP Industrial Product-Service Systems (IPS2) Conference. Cranfield University.

Alonso-Rasgado, T., Thompson, G., Elfström, B.-O., 2004. The design of functional (total care) products. J. Eng. Des. 15, 515-540.

Amaya, J., Lelah, A., Zwolinski, P., 2014. Design for intensified use in productservice systems using life-cycle analysis. J. Eng. Des. 25, 280-302.

Annarelli, A., Battistella, C., Nonino, F., 2016. Product service system: A conceptual framework from a systematic review. J. Clean. Prod. 139, 1011-1032.

Araujo, C.S., Benedetto-Neto, H., Campello, A.C., Segre, F.M., Wright, I.C., 1996. The utilization of product development methods: A survey of UK industry. J. Eng. Des. 7, 265-277.

Aurich, J.C., Fuchs, C., Wagenknecht, C., 2006. Life cycle oriented design of technical Product-Service Systems. J. Clean. Prod. 14, 1480-1494.

Aurich, J.C., Mannweiler, C., Schweitzer, E., 2010. How to design and offer services successfully. CIRP J. Manuf. Sci. Technol. 2, 136-143.

Baines, T.S., Bigdeli, A.Z., Bustinza, O.F., Guang Shi, V., Baldwin, J., Ridgway, K., 2017. Servitization: Revisiting the State-of-the-art and Research Priorities. Int. J. Oper. Prod. Manag. 37, 256-278.

Baines, T.S., Lightfoot, H., Peppard, J., Johnson, M., Tiwari, A., Shehab, E., Swink, M., 2009a. Towards an operations strategy for product-centric servitization. Int. J. Oper. Prod. Manag. 29, 494-519.

Baines, T.S., Lightfoot, H.W., Evans, S., Neely, A., Greenough, R., Peppard, J., Roy, R., Shehab, E., Braganza, A., Tiwari, A., Alcock, J.R., Angus, J.P., Bastl, M., Cousens, A., Irving, P., Johnson, M., Kingston, J., Lockett, H., Martinez, V., Michele, P., Tranfield, D., Walton, I.M., Wilson, H., 2007. State-of-the-art in 
product-service systems. Proc. Inst. Mech. Eng. Part B J. Eng. Manuf. 221, 1543-1552.

Baines, T.S., Lightfoot, H.W., Kay, J.M., 200gb. Servitized manufacture: practical challenges of delivering integrated products and services. Proc. Inst. Mech. Eng. Part B J. Eng. Manuf. 223, 1207-1215.

Barquet, A.P.B., de Oliveira, M.G., Amigo, C.R., Cunha, V.P., Rozenfeld, H., 2013. Employing the business model concept to support the adoption of productservice systems (PSS). Ind. Mark. Manag. 42, 693-704.

Bertoni, A., 2013. Value Driven Design a methodology for value-oriented decision making in preliminary design. Luleå University of Technology.

Bertoni, A., Bertoni, M., Isaksson, O., 2013. Value visualization in Product Service Systems preliminary design. J. Clean. Prod. 53, 103-117.

Bertoni, A., Bertoni, M., Panarotto, M., Johansson, C., Larsson, T., 2015. Expanding Value Driven Design to Meet Lean Product Service Development. Procedia CIRP 30, 197-202.

Bertoni, A., Bertoni, M., Panarotto, M., Johansson, C., Larsson, T.C., 2016. Valuedriven product service systems development: Methods and industrial applications. CIRP J. Manuf. Sci. Technol. 15, 42-55.

Bertoni, M., Bertoni, A., Isaksson, O., 2016. Evoke: A value-driven concept selection method for early system design. J. Syst. Sci. Syst. Eng. 1-32.

Bertoni, M., Eres, H., Isaksson, O., 2011. Criteria for assessing the value of Product Service System design alternatives: an aerospace investigation, in: Functional Thinking for Value Creation. Springer Berlin Heidelberg, pp. 141-146.

Bertoni, M., Hallstedt, S., Isaksson, O., 2015. A model-based approach for sustainability and value assessment in the aerospace value chain. Adv. Mech. Eng. 7, 1-19.

Bertoni, M., Rondini, A., Pezzotta, G., 2017. A Systematic Review of Value Metrics for PSS Design. Procedia CIRP 64, 289-294.

Beuren, F.H., Sousa-Zomer, T.T., Cauchick-Miguel, P.A., Beuren, F.H., Sousa-Zomer, T.T., Cauchick-Miguel, P.A., 2017. Proposal of a framework for productservice systems characterization. Production 27.

Binswanger, M., 2001. Technological progress and sustainable development: what about the rebound effect? Ecol. Econ. 36, 119-132.

Birkhofer, H., Kloberdanz, H., Sauer, T., Berber, B., 2002. Why design methods don't work and how to get them to work. Proc. Eng. Des. Integr. Prod. Dev. 3rd Int. Semin. 
Blessing, L.T.M., Chakrabarti, A., 2009. DRM, a design research methodology. Springer London, London.

Bocken, N.M.P., de Pauw, I., Bakker, C., van der Grinten, B., 2016. Product design and business model strategies for a circular economy. J. Ind. Prod. Eng. 33, 308-320.

Bocken, N.M.P., Olivetti, E.A., Cullen, J.M., Potting, J., Lifset, R., 2017. Taking the Circularity to the Next Level: A Special Issue on the Circular Economy. J. Ind. Ecol. 21, 476-482.

Bocken, N.M.P., Short, S.W., Rana, P., Evans, S., 2014. A literature and practice review to develop sustainable business model archetypes. J. Clean. Prod. 65, $42-56$.

Bonetti, S., Perona, M., Saccani, N., 2016. Total Cost of Ownership for ProductService System: Application of a Prototypal Model to Aluminum Melting Furnaces. Procedia CIRP 47, 60-65.

Boons, F., Montalvo, C., Quist, J., Wagner, M., 2013. Sustainable innovation, business models and economic performance: An overview. J. Clean. Prod. $45,1-8$.

Borghei, B.B., 2018. Incumbent Actors in Sectoral Transformations Towards Sustainability: A sociotechnical study of the European heavy commercial vehicles sector. Linköping University, Linköping, Sweden.

Brambila-Macias, S.A., Nilsson, S., Widgren, M., Lindahl, M., Sakao, T., 2017. Support for Designing Resource Efficient and Effective Solutions: Current Use and Requirements by Swedish Industry - Report from "Product and Service Design Support for REES" Project of Mistra REES program. Linköping. http://urn.kb.se/resolve?urn=urn:nbn:se:liu:diva-154181.

Brambila-Macias, S.A., Sakao, T., Kowalkowski, C., 2018. Bridging the gap between engineering design and marketing: insights for research and practice in product/service system design. Des. Sci. 4, e7.

Brax, S., 2005. A manufacturer becoming service provider - challenges and a paradox. Manag. Serv. Qual. An Int. J. 15, 142-155.

Bressanelli, G., Adrodegari, F., Perona, M., Saccani, N., 2018. The role of digital technologies to overcome Circular Economy challenges in PSS Business Models: an exploratory case study. Procedia CIRP 73, 216-221.

Bryman, A., 2012. Social Research Methods, 4th ed. SAGE Publications, Oxford.

Buchert, T., Halstenberg, F.A., Bonvoisin, J., Lindow, K., Stark, R., 2017. Targetdriven selection and scheduling of methods for sustainable product development. J. Clean. Prod. 161, 403-421.

Calabrese, A., Castaldi, C., Forte, G., Levialdi, N.G., 2018. Sustainability-oriented service innovation: An emerging research field. J. Clean. Prod. 193, 533-548. 
Cavalieri, S., Pezzotta, G., 2012. Product-Service Systems Engineering: State of the art and research challenges. Comput. Ind. 63, 278-288.

Ceschin, F., 2013. Critical factors for implementing and diffusing sustainable product-Service systems: insights from innovation studies and companies' experiences. J. Clean. Prod. 45, 74-88.

Ceschin, F., Gaziulusoy, I., 2016. Evolution of design for sustainability: From product design to design for system innovations and transitions. Des. Stud. $47,118-163$.

Chen, C.W., 2018. Guidance on the conceptual design of sustainable productservice systems. Sustainability 10, 2452.

Collopy, P.D., Hollingsworth, P.M., 2012. Value-Driven Design. J. Aircr. 48, 749-759.

Corvellec, H., Stål, H.I., 2017. Evidencing the waste effect of Product-Service Systems (PSSs). J. Clean. Prod. 145, 14-24.

Daalhuizen, J., Person, O., Gattol, V., 2014. A personal matter? An investigation of students' design process experiences when using a heuristic or a systematic method. Des. Stud. 35, 133-159.

Dachs, B., Biege, S., Borowiecki, M., Lay, G., Jäger, A., Schartinger, D., 2014. Servitisation of European manufacturing: evidence from a large scale database. Serv. Ind. J. 34, 5-23.

Datta, P.P., Roy, R., 2010. Cost modelling techniques for availability type service support contracts: A literature review and empirical study. CIRP J. Manuf. Sci. Technol. 3, 142-157.

Davies, A., Brady, T., Hobday, M., 2006. Charting a path toward integrated solutions. MIT Sloan Manag. Rev. 43, 39-48.

de Jesus, A., Mendonça, S., 2018. Lost in Transition? Drivers and Barriers in the Eco-innovation Road to the Circular Economy. Ecol. Econ. 145, 75-89.

den Hollander, M.C., Bakker, C.A., Hultink, E.J., 2017. Product Design in a Circular Economy: Development of a Typology of Key Concepts and Terms. J. Ind. Ecol. 21, 517-525.

Denzin, N.K., 2012. Triangulation 2.o. J. Mix. Methods Res. 6, 80-88.

Desai, A., Lindahl, M., Widgren, M., 2017. Actors and System Maps - A Methodology for Developing Product/Service Systems, in: Matsumoto, M., Masui, K., Fukushige, S., Kondo, S. (Eds.), Sustainability through Innovation in Product Life Cycle Design. Springer Japan, pp. 217-232.

Durugbo, C., 2013. Competitive product-service systems: lessons from a multicase study. Int. J. Prod. Res. 51, 5671-5682. 
Durugbo, C., Tiwari, A., Alcock, J.R., 2013. Modelling information flow for organisations: A review of approaches and future challenges. Int. J. Inf. Manage. 33, 597-610.

Eckert, C., 2013. That which is not form: The practical challenges in using functional concepts in design. Artif. Intell. Eng. Des. Anal. Manuf. 27, 217231.

Eifler, T., Howard, T.J., 2018. The importance of robust design methodology: case study of the infamous GM ignition switch recall. Res. Eng. Des. 29, 39-53.

EMF, 2015a. Towards a Circular Economy: Business rationale for an accelerated transition. Ellen MacArthur Foundation.

EMF, 2015b. Growth Within: a circular economy vision for a competitive Europe. Ellen MacArthur Foundation.

Erkoyuncu, J., Roy, R., Datta, P., 2011. Service uncertainty and cost for product service systems. Complex Eng. Serv. Syst. 52, 1223-1238.

European Council, European Parliament, 2009. Directive 2009/125/EC establishing a framework for the setting of ecodesign requirements for energy-related products.

Fargnoli, M., Costantino, F., Di Gravio, G., Tronci, M., 2018. Product service-systems implementation: A customized framework to enhance sustainability and customer satisfaction. J. Clean. Prod. 188, 387-401.

Fernandes, J., Henriques, E., Silva, A., Moss, M.A., 2014. A method for imprecision management in complex product development. Res. Eng. Des. 25, 309-324.

Flick, U., 2009. An Introduction to Qualitative Research. SAGE Publications, London, UK.

Font Vivanco, D., Kemp, R., Van Der Voet, E., 2015. The relativity of eco-innovation: environmental rebound effects from past transport innovations in Europe. J. Clean. Prod. 101, 71-85.

Gebauer, H., Friedli, T., Fleisch, E., 2006. Success factors for achieving high service revenues in manufacturing companies. Benchmarking An Int. J. 13, 374-386.

Geis, C., Bierhals, R., Schuster, I., Badke-Schaub, P., Birkhofer, H., 2008. Methods in practice - A study on requirements for development and transfer of design methods, in: International Design Conference - DESIGN 2008. pp. 369-376.

Geis, C., Birkhofer, H., 20og. Checklists as Tools for Reflective Practice for Designers. DS 58-9 Proc. ICED 09, 17th Int. Conf. Eng. Des. Vol. 9, Hum. Behav. Des. Palo Alto, CA, USA, 24.-27.08.2009.

Geissdoerfer, M., Savaget, P., Bocken, N.M.P., Hultink, E.J., 2017. The Circular Economy - A new sustainability paradigm? J. Clean. Prod. 143, 757-768. 
Gericke, K., Kramer, J., Roschuni, C., 2016. An Exploratory Study of the Discovery and Selection of Design Methods in Practice. J. Mech. Des. 138, 101109.

Gidel, T., Gautier, R., Duchamp, R., 2005. Decision-making framework methodology: an original approach to project risk management in new product design. J. Eng. Des. 16, 1-23.

Given, L.M., 2008. The Sage encyclopedia of qualitative research methods. Sage Publications.

Glaser, B.G., Strauss, A.L., 1967. The discovery of grounded theory : strategies for qualitative research. Aldine Pub. Co, New York.

Goedkoop, M.J., Van Halen, C.J.G., Te Riele, H.R.M., Rommens, P.J.M., 1999. Product Service systems, Ecological and Economic Basics. Research report 1999/36 submitted to Ministerje van Volkshuisvesting. Ruimtelijke Ordening en Milieubeheer., The Netherlands.

Grönroos, C., 2008. Service logic revisited: who creates value? And who cocreates? Eur. Bus. Rev. 20, 298-314.

Grönroos, C., Ravald, A., 2011. Service as business logic: implications for value creation and marketing. J. Serv. Manag. 22, 5-22.

Grönroos, C., Voima, P., 2013. Critical service logic: making sense of value creation and co-creation. J. Acad. Mark. Sci. 41, 133-150.

Grubic, T., Jennions, I., 2018. Do outcome-based contracts exist? The investigation of power-by-the-hour and similar result-oriented cases. Int. J. Prod. Econ. 206, 209-219.

Gutowski, T.G., Sahni, S., Boustani, A., Graves, S.C., 2011. Remanufacturing and Energy Savings. Environ. Sci. Technol. 45, 4540-4547.

Halme, M., Anttonen, M., Hrauda, G., Kortman, J., 2006. Sustainability evaluation of European household services. J. Clean. Prod. 14, 1529-1540.

Haupt, M., Vadenbo, C., Hellweg, S., 2017. Do We Have the Right Performance Indicators for the Circular Economy?: Insight into the Swiss Waste Management System. J. Ind. Ecol. 21, 615-627.

Hazelrigg, G.A., 2010. The Pugh controlled convergence method: model-based evaluation and implications for design theory. Res. Eng. Des. 21, 143-144.

Hazelrigg, G.A., 2003. Validation of engineering design alternative selection methods. Eng. Optim. 35, 103-120.

Herzog, M., Meuris, D., Bender, B., Sadek, T., 2014. The Nature of Risk Management in the Early Phase of IPS2 Design. Procedia CIRP 16, 223-228.

Heyes, G., Sharmina, M., Mendoza, J.M.F., Gallego-Schmid, A., Azapagic, A., 2018. Developing and implementing circular economy business models in service-oriented technology companies. J. Clean. Prod. 177, 621-632. 
Intlekofer, K., Bras, B., Ferguson, M., 2010. Energy Implications of Product Leasing. Environ. Sci. Technol. 44, 4409-4415.

Isaksson, O., Bertoni, M., Hallstedt, S., Lavesson, N., 2015. Model Based Decision Support for Value and Sustainability in Product Development. 2oth Int. Conf. Eng. Des. (ICED),Milan.

Isaksson, O., Larsson, T.C., Rönnbäck, A.O., 2009. Development of product-service systems: challenges and opportunities for the manufacturing firm. J. Eng. Des. 20, 329-348.

Jabbour, C.J.C., Jabbour, A.B.L. de S., Sarkis, J., Filho, M.G., 2017. Unlocking the circular economy through new business models based on large-scale data: An integrative framework and research agenda. Technol. Forecast. Soc. Change.

Jänsch, J., Birkhofer, H., 2007. Imparting Design Methods With the Strategies of Experts, in: ICEDo7: 16th International Conference of Engineering Design.

Kalmykova, Y., Sadagopan, M., Rosado, L., 2018. Circular economy - From review of theories and practices to development of implementation tools. Resour. Conserv. Recycl. 135, 190-201.

Kambanou, M.L., Lindahl, M., 2016. A Literature Review of Life Cycle Costing in the Product-Service System Context. Procedia CIRP 47, 186-191.

Kanda, W., 2017. Stimulating the diffusion of environmental technologies through export. Linköping University, Linköping, Sweden.

Kanda, W., Matschewsky, J., 2018. An exploratory expansion of the concept of product-service systems beyond products and services. Procedia CIRP 73, 185-190.

Kane, G.M., Bakker, C.A., Balkenende, A.R., 2018. Towards design strategies for circular medical products. Resour. Conserv. Recycl. 135, 38-47.

Khan, M.A., Kalverkamp, M., Wuest, T., 2019. Cascade Utilization During the Endof-Life of Product Service Systems: Synergies and Challenges, in: Cascade Use in Technologies 2018. Springer Berlin Heidelberg, Berlin, Heidelberg, pp. $1-7$.

Kim, K.-J., Lim, C.-H., Heo, J.-Y., Lee, D.-H., Hong, Y.-S., Park, K., 2016. An evaluation scheme for product-service system models: development of evaluation criteria and case studies. Serv. Bus. 10, 507-530.

Kimita, K., Shimomura, Y., Arai, T., 2009a. A customer value model for sustainable service design. CIRP J. Manuf. Sci. Technol. 1, 254-261.

Kimita, K., Shimomura, Y., Arai, T., 2009b. Evaluation of customer satisfaction for PSS design. J. Manuf. Technol. Manag. 20, 654-673. 
Kirchherr, J., Reike, D., Hekkert, M., 2017. Conceptualizing the circular economy: An analysis of 114 definitions. Resour. Conserv. Recycl. 127, 221-232.

Kjaer, L.L., Pigosso, D.C.A., McAloone, T.C., Birkved, M., 2018. Guidelines for evaluating the environmental performance of Product/Service-Systems through life cycle assessment. J. Clean. Prod. 190, 666-678.

Kjaer, L.L., Pigosso, D.C.A., Niero, M., Bech, N.M., McAloone, T.C., 2019. Product/Service-Systems for a Circular Economy: The Route to Decoupling Economic Growth from Resource Consumption? J. Ind. Ecol. 23, 22-35.

Kowalkowski, C., Gebauer, H., Kamp, B., Parry, G., 2017. Servitization and deservitization: Overview, concepts, and definitions. Ind. Mark. Manag. 6o, 4-10.

Kowalkowski, C., Windahl, C., Kindström, D., Gebauer, H., 2015. What service transition? Rethinking established assumptions about manufacturers' service-led growth strategies. Ind. Mark. Manag. 45, 59-69.

Krueger, R.A., Casey, M.A., 2014. Focus Groups: A Practical Guide for Applied Research, 5th ed. Sage Publications, Thousand Oaks.

Kuijken, B., Gemser, G., Wijnberg, N.M., 2017. Effective product-service systems: A value-based framework. Ind. Mark. Manag. 60, 33-41.

Kurak, C.D.F., Barquet, A.P.B., Rozenfeld, H., Carlos, S., Paulo, S., 2013. Challenges for PSS Implementation: Identification and Classification, in: ProductService Integration for Sustainable Solutions. Springer Berlin Heidelberg, pp. $275-285$.

Lahti, T., Wincent, J., Parida, V., 2018. A definition and theoretical review of the circular economy, value creation, and sustainable business models: Where are we now and where should research move in the future? Sustain. 10, 2799.

Laperche, B., Picard, F., 2013. Environmental constraints, Product-Service Systems development and impacts on innovation management: Learning from manufacturing firms in the French context. J. Clean. Prod. 53, 118-128.

Lee, S., Geum, Y., Lee, S., Park, Y., 2015. Evaluating new concepts of PSS based on the customer value: Application of ANP and niche theory. Expert Syst. Appl. 42, 4556-4566.

Lelah, A., Mathieux, F., Brissaud, D., 2011. Contributions to eco-design of machineto-machine product service systems: the example of waste glass collection. J. Clean. Prod. 19, 1033-1044.

Lenka, S., Parida, V., Sjödin, D.R., Wincent, J., 2018a. Towards a multi-level servitization framework: Conceptualizing ambivalence in manufacturing firms. Int. J. Oper. Prod. Manag. 38, 810-827. 
Lenka, S., Parida, V., Sjödin, D.R., Wincent, J., 2018b. Exploring the microfoundations of servitization: How individual actions overcome organizational resistance. J. Bus. Res. 88, 328-336.

Lewandowski, M., 2016. Designing the business models for circular economytowards the conceptual framework. Sustainability 8.

Lieder, M., Rashid, A., 2016. Towards circular economy implementation: A comprehensive review in context of manufacturing industry. J. Clean. Prod. $115,36-51$.

Lim, C.-H., Kim, K.-J., Hong, Y.-S., Park, K., 2012. PSS Board: a structured tool for product-service system process visualization. J. Clean. Prod. 37, 42-53.

Lincoln, Y.S., Guba, E.G., 1985. Naturalistic inquiry. Sage Publications.

Lindahl, M., 2018. Key Issues When Designing Solutions for a Circular Economy, in: Designing for the Circular Economy. Routledge.

Lindahl, M., 2005. Engineering Designers' Requirements on Design for Environment Methods and Tools. Royal Institute of Technology.

Lindahl, M., Ölundh, G., 2001. The Meaning of Functional Sales, in: 8th CIRP International Seminar on Life Cycle Engineering-Life Cycle Engineering: Challenges and Opportunities. pp. 211-220.

Lindahl, M., Sakao, T., Carlsson, E., 2014a. Actors and System Maps for Integrated Product Service Offerings - Practical Experience from Two Companies. Procedia CIRP 16, 320-325.

Lindahl, M., Sundin, E., Rönnbäck, A., Ölundh, G., Östlin, J., 2006. Integrated product and service engineering-the IPSE project, in: Perspectives on Radical Changes to Sustainable Consumption and Production (SCP). Copehagen, pp. 315-324.

Lindahl, M., Sundin, E., Sakao, T., 2014b. Environmental and economic benefits of Integrated Product Service Offerings quantified with real business cases. J. Clean. Prod. 64, 288-296.

Linder, M., Williander, M., 2017. Circular Business Model Innovation: Inherent Uncertainties. Bus. Strateg. Environ. 26, 182-196.

Lofthouse, V., 2006. Ecodesign tools for designers: defining the requirements. J. Clean. Prod. 14, 1386-1395.

López-Mesa, B., 2006. Design Methods and their sound use in Practice, in: Design Methods for Practice. pp. 87-94.

López-Mesa, B., Thompson, G., 2006. On the significance of cognitive style and the selection of appropriate design methods. J. Eng. Des. 17, 371-386.

Luo, J., Wood, K.L., 2017. The growing complexity in invention process. Res. Eng. Des. 28, 421-435. 
Manninen, K., Koskela, S., Antikainen, R., Bocken, N., Dahlbo, H., Aminoff, A., 2018. Do circular economy business models capture intended environmental value propositions? J. Clean. Prod. 171, 413-422.

Manzini, E., Vezzoli, C., 2003. A strategic design approach to develop sustainable product service systems: examples taken from the 'environmentally friendly innovation' Italian prize. J. Clean. Prod. 11, 851-857.

Manzini, E., Vezzoli, C., 2002. Product-Service Systems and Sustainability: Opportunities for Sustainable Solutions. UNEP.

Martinez, V., Bastl, M., Kingston, J., Evans, S., 2010. Challenges in transforming manufacturing organisations into product-service providers. J. Manuf. Technol. Manag. 21, 449-469.

Martinez, V., Neely, A., Velu, C., Leinster-Evans, S., Bisessar, D., 2017. Exploring the journey to services. Int. J. Prod. Econ. 192, 66-80.

Mason, J., 2002. Qualitative Researching. SAGE Publications, London.

Matschewsky, J., 2018. Värdet i att samtidigt utveckla produkter och tjänster. Production 2030.

Matschewsky, J., 2017. PSS without PSS Design - Possible Causes, Effects and Solutions, in: Sustainability through Innovation in Product Life Cycle Design. Springer Japan, pp. 233-248.

Matschewsky, J., 2016. What's in it for the Provider?: A Lifecycle-Focused Approach towards Designing for Value in Product-Service Systems. Linköping University.

Matschewsky, J., 2012. Evaluation and optimization of Product/Service Systems within the development process. Hochschule für Technik und Wirtschaft Dresden.

Matschewsky, J., Kambanou, M.L., Sakao, T., 2018a. Designing and providing integrated product-service systems - challenges, opportunities and solutions resulting from prescriptive approaches in two industrial companies. Int. J. Prod. Res. 56, 2150-2168.

Matschewsky, J., Lindahl, M., Sakao, T., 2018b. Capturing and enhancing provider value in product-service systems throughout the lifecycle: A systematic approach. CIRP J. Manuf. Sci. Technol. In Press.

Matschewsky, J., Lindahl, M., Sakao, T., 2015a. Facilitating Industrial Adoption of Design Methods for Product-Service Systems, in: ICED15: 2oth International Conference on Engineering Design. Milan, pp. 301-310.

Matschewsky, J., Sakao, T., Khanagha, S., Elfving, S.W., 2016. What's in it for the Provider? The Case of a Telecom Vendor's Value Capturing from the Transition to Product-Service Systems. Procedia CIRP 47, 6-11. 
Matschewsky, J., Sakao, T., Lindahl, M., 2015b. ProVa - Provider Value Evaluation for Integrated Product Service Offerings. Procedia CIRP 30, 305-310.

Maussang, N., Zwolinski, P., Brissaud, D., 2009. Product-service system design methodology: from the PSS architecture design to the products specifications. J. Eng. Des. 20, 349-366.

McAloone, T.C., Pigosso, D.C.A., 2018. Designing Product Service Systems for a Circular Economy, in: Charter, M. (Ed.), Designing for the Circular Economy. Routledge, pp. 102-112.

McDonough, W., Braungart, M., 2002. Cradle to Cradle: Remaking the Way We Make Things. North Point Press, New York.

Meier, H., Roy, R., Seliger, G., 2010. Industrial Product-Service Systems-IPS2. CIRP Ann. - Manuf. Technol. 59, 607-627.

Mendoza, J.M.F., Sharmina, M., Gallego-Schmid, A., Heyes, G., Azapagic, A., 2017. Integrating Backcasting and Eco-Design for the Circular Economy: The BECE Framework. J. Ind. Ecol. 21, 526-544.

Michelini, G., Moraes, R.N., Cunha, R.N., Costa, J.M.H., Ometto, A.R., 2017. From Linear to Circular Economy: PSS Conducting the Transition. Procedia CIRP $64,2-6$.

Miles, L.D., 1971. Techniques of value analysis and engineering. McGraw-Hill.

Miles, M., Huberman, A., Saldaña, J., 2013. Qualitative data analysis: A methods sourcebook. SAGE Publications.

Miller, M., Mattes, K., 2014. Demonstration of a multi-criteria based decision support framework for selecting PSS to increase resource efficiency (No. S11/2014), Working Paper Sustainability and Innovation.

Mont, O., 2002. Clarifying the concept of product-service system. J. Clean. Prod. 10, 237-245.

Montagna, F., 2011. Decision-aiding tools in innovative product development contexts. Res. Eng. Des. 22, 63-86.

Morelli, N., 2006. Developing new product service systems (PSS): methodologies and operational tools. J. Clean. Prod. 14, 1495-1501.

Morelli, N., 2002. Designing Product/Service Systems: A Methodological Exploration. Des. Issues 18, 3-17.

Moreno, M., De los Rios, C., Rowe, Z., Charnley, F., 2016. A conceptual framework for circular design. Sustainability 8, 937.

Mourtzis, D., Doukas, M., Fotia, S., 2016. Classification and Mapping of PSS Evaluation Approaches. IFAC-PapersOnLine 49, 1555-1560. 
Müller, P., Kebir, N., Stark, R., Blessing, L., 2009. PSS layer method - application to microenergy systems, in: Sakao, T., Lindahl, M. (Eds.), Introduction to Product/Service-System Design. Springer London, pp. 3-30.

Murray, A., Skene, K., Haynes, K., 2017. The Circular Economy: An Interdisciplinary Exploration of the Concept and Application in a Global Context. J. Bus. Ethics 140, 369-380.

Neely, A., 2009. Exploring the financial consequences of the servitization of manufacturing. Oper. Manag. Res. 1, 103-118.

Nußholz, J.L.K., 2017. Circular business models: Defining a concept and framing an emerging research field. Sustainability 9, 1810.

O’Hare, J.A., 2010. Eco-Innovation Tools for the Early Stages: An Industry-Based Investigation of Tool Customisation and Introduction. University of Bath.

OECD, 2015. OECD Green Growth Studies: Material Resources, Productivity and the Environment. OECD Publishing.

Onwuegbuzie, A.J., Frels, R., 2016. Seven steps to a comprehensive literature review : A multimodal cultural approach. SAGE Publications.

Opresnik, D., Taisch, M., 2015. The value of Big Data in servitization. Int. J. Prod. Econ. 165, 174-184.

Pagoropoulos, A., Pigosso, D.C.A., McAloone, T.C., 2017. The Emergent Role of Digital Technologies in the Circular Economy: A Review. Procedia CIRP 64, $19-24$.

Panarotto, M., 2015. A Model-Based Methodology for Value Assessment in Conceptual Design. Blekinge Tekniska Högskola.

Parida, V., Burström, T., Visnjic, I., Wincent, J., 2019. Orchestrating industrial ecosystem in circular economy: A two-stage transformation model for large manufacturing companies. J. Bus. Res.

Parida, V., Wincent, J., 2019. Why and how to compete through sustainability: a review and outline of trends influencing firm and network-level transformation. Int. Entrep. Manag. J.

Paterson, M., Higgs, J., 2005. Using Hermeneutics as a Qualitative Research Approach in Professional Practice. Qual. Rep. 10, 339-357.

Patton, M.Q., 2002. Qualitative Research \& Evaluation Methods. SAGE Publications.

Payne, A.F., Storbacka, K., Frow, P., 2007. Managing the co-creation of value. J. Acad. Mark. Sci. 36, 83-96.

Pezzotta, G., Pinto, R., Pirola, F., Ouertani, M.-Z., 2014. Balancing Product-service Provider's Performance and Customer's Value: The SErvice Engineering Methodology (SEEM). Procedia CIRP 16, 50-55. 
Pieroni, M.P.P., McAloone, T.C., Pigosso, D.C.A., 2019. Business model innovation for circular economy and sustainability: A review of approaches. J. Clean. Prod. 215, 198-216.

Prendeville, S., Bocken, N., 2016. Design for Remanufacturing and Circular Business Models, in: Sustainability Through Innovation in Product Life Cycle Design Part of the Series EcoProduction. Springer, Singapore, pp. 269283.

Rashid, A., Asif, F.M.A., Krajnik, P., Nicolescu, C.M., 2013. Resource Conservative Manufacturing: an essential change in business and technology paradigm for sustainable manufacturing. J. Clean. Prod. 57, 166-177.

Reich, Y., 2017. The principle of reflexive practice. Des. Sci. 3, 1-27.

Reich, Y., 2010. My method is better! Res. Eng. Des. 21, 137-142.

Reike, D., Vermeulen, W.J.V., Witjes, S., 2018. The circular economy: New or Refurbished as CE 3.0? - Exploring Controversies in the Conceptualization of the Circular Economy through a Focus on History and Resource Value Retention Options. Resour. Conserv. Recycl. 135, 246-264.

Reim, W., Parida, V., Örtqvist, D., 2015. Product-Service Systems (PSS) business models and tactics - a systematic literature review. J. Clean. Prod. 97, 61-75.

Reim, W., Sjödin, D., Parida, V., 2018. Mitigating adverse customer behaviour for product-service system provision: An agency theory perspective. Ind. Mark. Manag. 74, 150-161.

Ritchie, J., Lewis, J., 2003. Qualitative research practice : a guide for social science students and researchers. Sage Publications.

Ritzén, S., Ölundh Sandström, G., 2017. Barriers to the Circular Economy Integration of Perspectives and Domains. Procedia CIRP 64, 7-12.

Rizos, V., Behrens, A., van der Gaast, W., Hofman, E., Ioannou, A., Kafyeke, T., Flamos, A., Rinaldi, R., Papadelis, S., Hirschnitz-Garbers, M., Topi, C., 2016. Implementation of circular economy business models by small and medium-sized enterprises (SMEs): Barriers and enablers. Sustainability 8 , 1212.

Rondini, A., Bertoni, M., Pezzotta, G., 2017. An IPA Based Method for PSS Design Concept Assessment, in: Procedia CIRP. Elsevier, pp. 277-282.

Rondini, A., Matschewsky, J., Pezzotta, G., Bertoni, M., 2018. A simplified approach towards customer and provider value in PSS for small and medium-sized enterprises, in: Procedia CIRP. Elsevier, pp. 61-66.

Rondini, A., Pezzotta, G., Pirola, F., Rossi, M., Pina, P., 2016. How to Design and Evaluate Early PSS Concepts: The Product Service Concept Tree. Procedia CIRP 50, 366-371. 
Rossi, M., Germani, M., Zamagni, A., 2016. Review of ecodesign methods and tools. Barriers and strategies for an effective implementation in industrial companies. J. Clean. Prod. 129, 361-373.

Saidani, M., Yannou, B., Leroy, Y., Cluzel, F., 2017. How to Assess Product Performance in the Circular Economy? Proposed Requirements for the Design of a Circularity Measurement Framework. Recycling 2, 6.

Sakao, T., 2011. What is PSS design? - Explained with two industrial cases. Procedia - Soc. Behav. Sci. 25, 403-407.

Sakao, T., Birkhofer, H., Panshef, V., Dörsam, E., 2009. An effective and efficient method to design services: empirical study for services by an investmentmachine manufacturer. Int. J. Internet Manuf. Serv. 2, 95-110.

Sakao, T., Brambila-Macias, S.A., 2018. Do we share an understanding of transdisciplinarity in environmental sustainability research? J. Clean. Prod. 170, 1399-1403.

Sakao, T., Lindahl, M., 2015. A method to improve integrated product service offerings based on life cycle costing. CIRP Ann. - Manuf. Technol. 64, 33-36.

Sakao, T., Lindahl, M., 2012. A value based evaluation method for Product/Service System using design information. CIRP Ann. - Manuf. Technol. 61, 51-54.

Sakao, T., Mizuyama, H., 2014. Understanding of a product/service system design: a holistic approach to support design for remanufacturing. J. Remanufacturing 4, 1-24.

Sakao, T., Napolitano, N., Tronci, M., Sundin, E., Lindahl, M., 2008. How are product-service combined offers provided in Germany and Italy? Analysis with company sizes and countries. J. Syst. Sci. Syst. Eng. 17, 367-381.

Sakao, T., Öhrwall Rönnbäck, A., Ölundh Sandström, G., 2013. Uncovering benefits and risks of integrated product service offerings - Using a case of technology encapsulation. J. Syst. Sci. Syst. Eng. 22, 421-439.

Sakao, T., Shimomura, Y., 2007. Service Engineering: a novel engineering discipline for producers to increase value combining service and product. J. Clean. Prod. 15, 590-604.

Sakao, T., Song, W., Matschewsky, J., 2017. Creating service modules for customising product/service systems by extending DSM. CIRP Ann. Manuf. Technol. 66, 21-24.

Settanni, E., Thenent, N.E., Newnes, L.B., Parry, G., Goh, Y.M., 2015. To Cost an Elephant: An Exploratory Survey on Cost Estimating Practice in the Light of Product-Service-Systems. J. Cost Anal. Parametr. 8, 1-22.

Smith, L., Maull, R., C.L. Ng, I., 2014. Servitization and operations management: a service dominant-logic approach. Int. J. Oper. Prod. Manag. 34, 242-269. 
Somekh, B., 2006. Action Research: a methodology for change and development. Open University Press, Buckingham.

Song, W., Ming, X., Han, Y., Xu, Z., Wu, Z., 2014. An integrative framework for innovation management of product-service system. Int. J. Prod. Res. 53, 2252-2268.

Song, W., Sakao, T., 2017. A customization-oriented framework for design of sustainable product/service system. J. Clean. Prod. 140, 1672-1685.

Spring, M., Araujo, L., 2017. Product biographies in servitization and the circular economy. Ind. Mark. Manag. 6o, 126-137.

Stark, R., Buchert, T., Neugebauer, S., Bonvoisin, J., Finkbeiner, M., 2017. Benefits and obstacles of sustainable product development methods: A case study in the field of urban mobility. Des. Sci. 3, e17.

Steiner, F., Harmon, R., 2009. The impact of intangible value on the design and marketing of new products and services: An exploratory approach, in: PICMET 'o9 - 2009 Portland International Conference on Management of Engineering \& Technology. IEEE, pp. 2066-2079.

Sundin, E., 2018. Circular Economy and design for remanufacturing, in: Charter, M. (Ed.), Designing for the Circular Economy. Routledge.

Sundin, E., Bras, B., 2005. Making functional sales environmentally and economically beneficial through product remanufacturing. J. Clean. Prod. 13, 913-925.

Sundin, E., Lindahl, M., Ijomah, W., 2009. Product design for product/service systems. J. Manuf. Technol. Manag. 20, 723-753.

Tan, A.R., 2010. Service-oriented product development strategies. PhD thesis. DTU Management.

Tan, A.R., Matzen, D., McAloone, T.C., Evans, S., 2010. Strategies for designing and developing services for manufacturing firms. CIRP J. Manuf. Sci. Technol. 3, 90-97.

Tomiyama, T., Gu, P., Jin, Y., Lutters, D., Kind, C., Kimura, F., 2009. Design methodologies: Industrial and educational applications. CIRP Ann. Manuf. Technol. 58, 543-565.

Tromp, N., Hekkert, P., 2016. Assessing methods for effect-driven design: Evaluation of a social design method. Des. Stud. 43, 24-47.

Tukker, A., 2015. Product services for a resource-efficient and circular economy A review. J. Clean. Prod. 97, 76-91.

Tukker, A., 2004. Eight types of product-service system: eight ways to sustainability? Experiences from SusProNet. Bus. Strateg. Environ. 13, 246260. 
Ulaga, W., Chacour, S., 2001. Measuring Customer-Perceived Value in Business Markets: A Prerequisite for Marketing Strategy Development and Implementation. Ind. Mark. Manag. 30, 525-540.

Ulaga, W., Reinartz, W.J., 2011. Hybrid Offerings: How Manufacturing Firms Combine Goods and Services Successfully. J. Mark. 75, 5-23.

Ullman, D.G., 2002. Toward the ideal mechanical engineering design support system. Res. Eng. Des. - Theory, Appl. Concurr. Eng. 13, 55-64.

Urbinati, A., Chiaroni, D., Chiesa, V., 2017. Towards a new taxonomy of circular economy business models. J. Clean. Prod. 168, 487-498.

Urmetzer, F., Neely, A., Martinez, V., 2018. Engineering Services: Unpacking Value Exchange, in: Value Creation through Engineering Excellence. Springer International Publishing, Cham, pp. 75-96.

Valtakoski, A., 2017. Explaining servitization failure and deservitization: A knowledge-based perspective. Ind. Mark. Manag. 6o, 138-150.

van Buren, N., Demmers, M., van der Heijden, R., Witlox, F., van Buren, N., Demmers, M., van der Heijden, R., Witlox, F., 2016. Towards a Circular Economy: The Role of Dutch Logistics Industries and Governments. Sustainability 8, 647 .

van Halen, C., Vezzoli, C., Wimmer, R., 2005. Methodology for Product Service System Innovation: How to Develop Clean, Clever and Competitive Strategies in Companies. Uitgeverij Van Gorcum.

Vandermerwe, S., Rada, J., 1988. Servitization of business: Adding value by adding services. Eur. Manag. J. 6, 314-324.

Vargo, S.L., Lusch, R.F., 2004. Evolving to a New Dominant Logic for Marketing. J. Mark. 68, 1-17.

Vargo, S.L., Maglio, P.P., Akaka, M.A., 2008. On value and value co-creation: A service systems and service logic perspective. Eur. Manag. J. 26, 145-152.

Vasantha, G., Roy, R., Corney, J., 2014. Challenges and Opportunities in Transforming Laser System Industry to Deliver Integrated Product and Service Offers, in: Collaborative Systems for Smart Networked Environments. Springer Berlin Heidelberg, pp. 127-134.

Vasantha, G.V.A., Roy, R., Corney, J.R., 2015. Advances in Designing ProductService Systems. J. Indian Inst. Sci. 95, 429-447.

Vasantha, G.V.A., Roy, R., Lelah, A., Brissaud, D., 2012. A review of product-service systems design methodologies. J. Eng. Des. 23, 635-659.

Vezzoli, C., Ceschin, F., Diehl, J.C., Kohtala, C., 2015. New Design Challenges to Widely Implement ‘Sustainable Product-Service Systems.' J. Clean. Prod. 97, $1-12$. 
Vezzoli, C., Ceschin, F., Diehl, J.C., Kohtala, C., 2012. Why have "Sustainable Product-Service Systems" not been widely implemented? Meeting new design challenges to achieve societal sustainability. J. Clean. Prod. 35, 288290.

Vezzoli, C., Kohtala, C., Srinivasan, A., Xin, L., Fusakul, M., Sateesh, D., Diehl, J.C., 2014. Product-Service System Design for Sustainability. Greenleaf Publishing, Sheffield, UK.

Wallace, K., 2011. Transferring Design Methods into Practice, in: Birkhofer, H. (Ed.), The Future of Design Methodology. Springer London, London, pp. 239-248.

Wang, P.P., Ming, X.G., Li, D., Kong, F.B., Wang, L., Wu, Z.Y., 2011. Status review and research strategies on product-service systems. Int. J. Prod. Res. 49, 68636883.

Williams, A., 2007. Product service systems in the automobile industry: contribution to system innovation? J. Clean. Prod. 15, 1093-1103.

Windahl, C., 2007. Integrated Solutions in the Capital Goods Sector: Exploring innovation, service and network perspectives. Linköping University Electronic Press.

Windahl, C., Lakemond, N., 2006. Developing integrated solutions: The importance of relationships within the network. Ind. Mark. Manag. 35, 806818.

Witjes, S., Lozano, R., 2016. Towards a more Circular Economy: Proposing a framework linking sustainable public procurement and sustainable business models. Resour. Conserv. Recycl. 112, 37-44.

Wolf, B., 2011. Design Methods - What Reaches Industrial Practice?, in: International Conference on Research into Design Engineering. pp. 978981.

Wolfenstetter, T., Bohm, M., Krcmar, H., Brundl, S., 2015. Why product service systems development is special, in: 2015 International Conference on Industrial Engineering and Systems Management (IESM). IEEE, pp. 12211228.

Woodruff, R.B., 1997. Customer value: The next source for competitive advantage. J. Acad. Mark. Sci. 25, 139-153.

Xing, K., Wang, H.-F., Qian, W., 2013. A sustainability-oriented multi-dimensional value assessment model for product-service development. Int. J. Prod. Res. 51, 5908-5933.

Yang, J.Y.J., 2009. A Balanced Performance Measurement Scorecard Approach for Product Service Systems, in: 2009 International Conference on Business Intelligence and Financial Engineering. IEEE, pp. 548-551. 
Yang, M., Evans, S., 2019. Product-service system business model archetypes and sustainability. J. Clean. Prod. 220, 1156-1166.

Yang, M., Evans, S., Vladimirova, D., Rana, P., 2016. Value uncaptured perspective for sustainable business model innovation. J. Clean. Prod.

Yang, X., Moore, P., Chong, S.K., 2009. Intelligent products: From lifecycle data acquisition to enabling product-related services. Comput. Ind. 6o, 184-194.

Yin, R.K., 2013. Case Study Research: Design and Methods. SAGE Publications.

Yoon, B., Kim, S., Rhee, J., 2012. An evaluation method for designing a new product-service system. Expert Syst. Appl. 39, 3100-3108.

Zeithaml, V.A., 1988. Consumer Perceptions of Price, Quality, and Value: A MeansEnd Model and Synthesis of Evidence. J. Mark. 52, 2.

Zhang, W., Banerji, S., 2017. Challenges of servitization: A systematic literature review. Ind. Mark. Manag. 65, 217-227.

Zink, T., Geyer, R., 2017. Circular Economy Rebound. J. Ind. Ecol. 21, 593-602.

\section{*Vector illustrations used under the Creative Commons License}

In figures marked with an asterisk*, vector illustrations created by members of the Noun Project, www.thenounproject.com, were used as the basis of the author's work. As part of the license, the original creators receive credit, and they deserve great appreciation for openly sharing the product of their creativity. Thank you all!

Bicycle by Felix Brönnimann

Skyscraper building by Ditya Zulkarnain

Globe shape by amy morgan

EU stars by Kelsey Chisamore

Brain by Path Lord

Mustache by Cindyfla

Mouth by André Luiz Gollo

Glasses by Lastspark

Information symbol by Lloyd Humphreys

Euro symbol by Tomáš Otrubčák

Woman's hair shape by Icon Island

Upward-pointing arrow by Wilson Joseph
(Cover)

(Cover, Figures 3, 16)

(Cover, Figures 3, 16)

(Cover)

(Figure 12)

(Figure 12)

(Figure 12)

(Figure 12)

(Figure 12)

(Figure 12)

(Figure 12)

(Figure 12) 


\section{Publications}

The publications associated with this thesis have been removed for copyright reasons. For more details about these see:

http://urn.kb.se/resolve?urn=urn:nbn:se:liu:diva-156261 


\section{INSTITUTE OF TECHNOLOGY}

Linköping Studies in Science and Technology, Dissertation No. 1978, 2019

Department of Management and Engineering

Linköping University

SE-581 83 Linköping, Sweden

www.liu.se
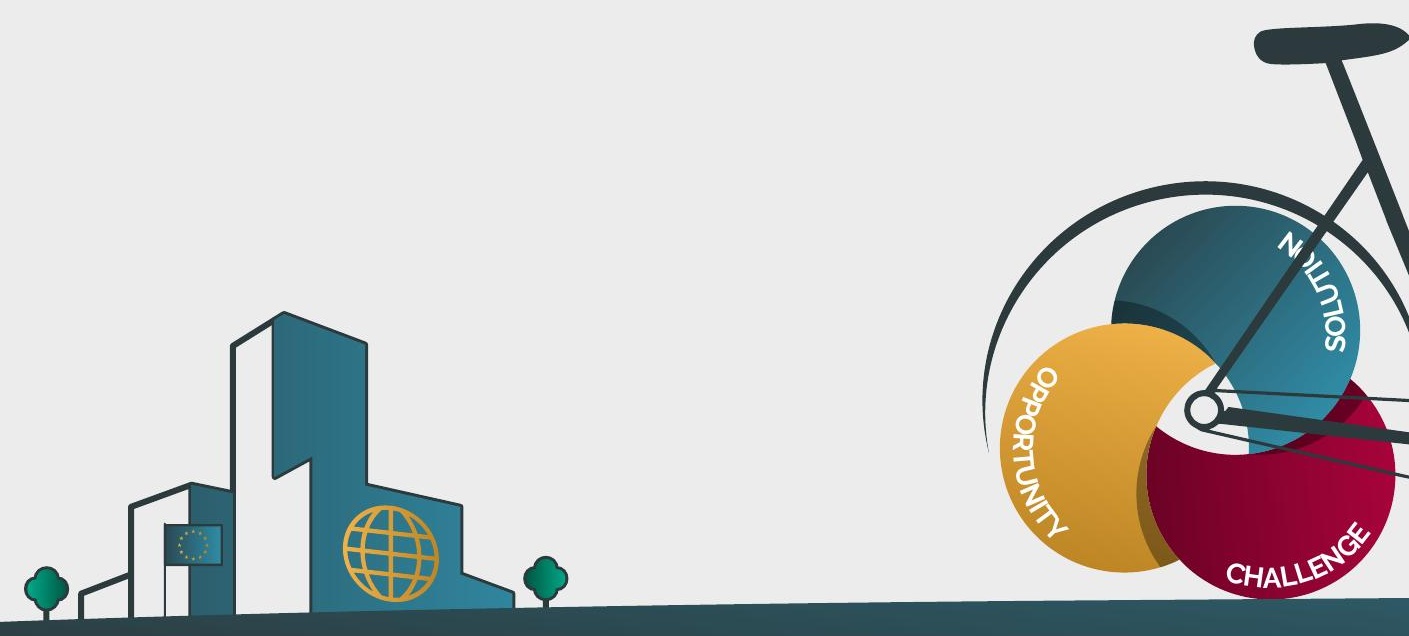